\title{
The Collection 6 MODIS aerosol products over land and ocean
}

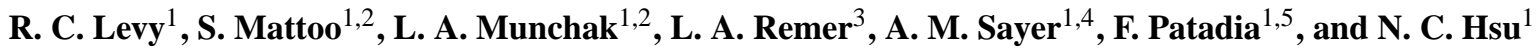 \\ ${ }^{1}$ Climate and Radiation Laboratory, NASA Goddard Space Flight Center, Greenbelt, MD 20771, USA \\ ${ }^{2}$ Science Systems and Applications, Inc, Lanham, MD 20709, USA \\ ${ }^{3}$ JCET, University of Maryland - Baltimore County, Baltimore, MD 21228, USA \\ ${ }^{4}$ Goddard Earth Sciences Technology And Research (GESTAR), Universities Space Research Association (USRA), \\ Columbia, MD, USA \\ ${ }^{5}$ Goddard Earth Sciences Technology And Research (GESTAR), Morgan State University (MSU), Baltimore, MD, USA \\ Correspondence to: R. C. Levy (robert.c.levy@nasa.gov)
}

Received: 21 November 2012 - Published in Atmos. Meas. Tech. Discuss.: 4 January 2013

Revised: 8 August 2013 - Accepted: 24 September 2013 - Published: 6 November 2013

\begin{abstract}
The twin Moderate resolution Imaging Spectroradiometer (MODIS) sensors have been flying on Terra since 2000 and Aqua since 2002, creating an extensive data set of global Earth observations. Here, we introduce the Collection 6 (C6) algorithm to retrieve aerosol optical depth (AOD) and aerosol size parameters from MODIS-observed spectral reflectance. While not a major overhaul from the previous Collection 5 (C5) version, there are enough changes that there are significant impacts to the products and their interpretation. The C6 aerosol data set will be created from three separate retrieval algorithms that operate over different surface types. These are the two "Dark Target" (DT) algorithms for retrieving (1) over ocean (dark in visible and longer wavelengths) and (2) over vegetated/dark-soiled land (dark in the visible), plus the "Deep Blue" (DB) algorithm developed originally for retrieving (3) over desert/arid land (bright in the visible). Here, we focus on DT-ocean and DTland (\#1 and \#2). We have updated assumptions for central wavelengths, Rayleigh optical depths and gas $\left(\mathrm{H}_{2} \mathrm{O}, \mathrm{O}_{3}\right.$, $\mathrm{CO}_{2}$, etc.) absorption corrections, while relaxing the solar zenith angle limit (up to $\leq 84^{\circ}$ ) to increase poleward coverage. For DT-land, we have updated the cloud mask to allow heavy smoke retrievals, fine-tuned the assignments for aerosol type as function of season/location, corrected bugs in the Quality Assurance (QA) logic, and added diagnostic parameters such topographic altitude. For DT-ocean, improvements include a revised cloud mask for thin-cirrus detection, inclusion of wind speed dependence on the surface reflectance, updates to logic of QA Confidence flag (QAC) assignment, and additions of important diagnostic information.
\end{abstract}

At the same time, we quantified how "upstream" changes to instrument calibration, land/sea masking and cloud masking will also impact the statistics of global AOD, and affect Terra and Aqua differently. For Aqua, all changes will result in reduced global AOD (by 0.02) over ocean and increased AOD (by 0.02) over land, along with changes in spatial coverage. We compared preliminary data to surface-based sun photometer data, and show that C6 should improve upon C5. C6 will include a merged DT/DB product over semi-arid land surfaces for reduced-gap coverage and better visualization, and new information about clouds in the aerosol field. Responding to the needs of the air quality community, in addition to the standard $10 \mathrm{~km}$ product, $\mathrm{C} 6$ will include a global (DT-land and DT-ocean) aerosol product at $3 \mathrm{~km}$ resolution.

\section{Introduction}

Aerosols, the small, suspended liquid and solid particles in the atmosphere, are important components of Earth's climate system. Among their many roles, they force the global energy budget (IPCC, 2007), perturb the hydrological cycle (Koren and Feingold, 2011), and in large concentrations are detrimental to human health (Pope et al., 2002).

Characterizing aerosol global distribution and changes over time are necessary for understanding present and possible future climate conditions (e.g., IPCC, 2007). Towards these goals, NASA has deployed a suite of satellites known as the Earth Observation System (EOS) to monitor a number of important climate properties, including aerosols. Two of 
these EOS-era satellite sensors are the twin MODerate resolution Imaging Spectroradiometers (MODIS, Salomonson, 1989), which have been flying in polar orbit on Terra $\left(M_{\mathrm{T}}\right)$ since 2000 and Aqua $\left(M_{\mathrm{A}}\right)$ since 2002 (Remer et al., 2008). MODIS has a wide spectral range $(0.41 \mu \mathrm{m}$ to $14.5 \mu \mathrm{m}$ in 36 channels or bands), broad swath $(2330 \mathrm{~km})$ and relatively fine spatial resolution ( $1 \mathrm{~km}$ or less depending on band).

MODIS' combination of swath, spectral bands and spatial resolution lead to many algorithms for retrieving aerosol information from MODIS observations. While some algorithms are mainly atmospheric correction algorithms for the retrieval of ocean or land properties, others are for the explicit purpose of retrieving aerosol properties. Here, we focus on the methodology and products from a specific family of algorithms, designed for retrieving aerosol properties over dark (in visible wavelengths) surfaces over land (Kaufman et al., 1997a) and ocean (Tanré et al., 1997). This so-called dark target (DT) retrieval is performed operationally (within 1-2 days) of satellite overpass, which is in fact two separate algorithms (DT-ocean and DT-land). Specific retrieved products include aerosol optical depth (AOD) at $0.55 \mu \mathrm{m}$ over land and ocean, and fine model fraction (FMF) of AOD at $0.55 \mu \mathrm{m}$ over ocean. The standard retrieval resolution is $10 \mathrm{~km}$ (at nadir).

In addition to providing useful information to the climate community, the instrument's $2330 \mathrm{~km}$ swath enables nearly global coverage every day, which makes the operational DT aerosol product attractive for near-real-time monitoring of aerosol (Al Saadi et al., 2005; Koren and Kaufman, 2004). The spatial resolution and repeatability lends to ample statistics for deriving gridded global products (e.g. King et al., 2003; Levy et al., 2009a; Shi et al., 2011) for a variety of other applications (Stier et al., 2005; Yu et al., 2006; Kaufman et al., 2005).

Because the operational MODIS aerosol product is so important to so many applications, its continued usefulness requires a continuing effort to upgrade (better products) while maintaining its integrity (keeps working) and usability (user relearning not required). The last "major" update of the darktarget aerosol product was implemented in early 2006, marking the start of so-called Collection 5 (C5; Levy et al., 2007a, b; Remer et al., 2008). At that point, the DT-land algorithm was significantly overhauled. Through validation efforts (e.g., Remer et al., 2008; Levy et al., 2010), assimilation studies (e.g., Hyer et al., 2011; Zhang and Reid et al., 2010), and other work since 2006 (e.g., Bréon et al., 2011), the C5 aerosol algorithm and products have been evaluated in detail. From these and other evaluations, we learned about the conditions in which the retrieval and products performed well, but also conditions in which the product fell short of expectations. Using this information, we prepared for a Collection 6 (C6).

For C6, instead of a "major" upgrade to the algorithm and products, only "maintenance and modest improvement" was proposed. "Maintenance" included streamlining the science codes, updating the processing environment along with new computer machinery, and improving the user experience when accessing and analyzing the data. "Modest improvement" meant such improvements that would increase the global accuracy and coverage of the product, but without major change to the science of the algorithm. However, there are major changes to how data "confidence" or Quality Assurance (QA) is assigned (Hubanks, 2012). Obsolete parameters have been deleted from the product files, whereas new diagnostic parameters have been added. The result is more information available to recreate the conditions of the retrieval and for the user to determine what may have gone awry.

The C6 algorithm will be applied to all archived and future data that will be collected from both MODIS instruments. C6 will represent a continuous, consistent data record spanning more than a decade for each satellite. In addition, from our experience when transitioning from Collection 4 (C4) to $\mathrm{C} 5$, the effort necessitated an evaluation of how changes in upstream activity (calibration, cloud masking, etc.) would impact the aerosol products. Even if the aerosol algorithms were to remain unchanged from C5 to C6, the global aerosol product would be different because the inputs are different. Finally, in response to the air quality community's need for high resolution aerosol retrieval (e.g., C. Li et al., 2005), the C6 product will not only include the standard $10 \mathrm{~km}$ aerosol retrieval product (Remer et al., 2005) but also global products at $3 \mathrm{~km}$ (Remer et al., 2013; Munchak et al., 2013).

This paper therefore is intended to introduce the community to the C6 dark-target aerosol algorithm and products. We first summarize the basic concepts of the DT retrieval algorithm. Then we document the changes from C5 to C6, describing why we made these changes, as well as their expected impacts to regional and global aerosol statistics. Note that C6 not only represents an update to the aerosol algorithm but also an update to all MODIS algorithms, including the calibration and cloud masking algorithms that produce the inputs to the aerosol algorithm. Also note that when we report changes, they are not necessarily in chronological order or order of largest impact.

In general, the $\mathrm{C} 5 \rightarrow \mathrm{C} 6$ changes can be separated into four categories: (a) changes to the algorithm that were necessitated by changes in upstream products (e.g. calibration, cloud mask or land/sea flags), (b) modifications to the retrieval that would produce different values for the samenamed parameters as in C5 (if there were no changes to upstream products), (c) additions and deletions to the list of available parameters, and (d) completely new products that will be available in separate data files. This paper addresses all four categories of modification. Some of the changes are seemingly small details, but they must be documented. In the interest of the more casual reader, these details can be found in the Appendices. In combination with this paper in the refereed literature, we plan to update the online Algorithm Theoretical Basis Document (ATBD), last updated in 2009 (for C5). We recognize that there will be considerable 
duplication, although the ATBD leaves more room for describing the history and theory of the algorithm, as well as a more convenient avenue for updating information as needed.

In Sect. 2, we describe the MODIS Dark Target (DT)algorithm, its history through $\mathrm{C} 5$, and and why it needed improvement. In Sect. 3, we begin with upstream changes to the algorithm, including calibration, geolocation and ancillary data upgrades. In Sect. 4, we describe changes to the DT algorithm and products for C6, divided into: changes to the upstream products (Sect. 4.2), changes in radiative transfer and look-up tables (Sect. 4.3), changes specifically for DTland (Sect. 4.4) and DT-ocean (Sect. 4.5), changes to combined land and ocean (Sect. 4.6), new DT products (Sect. 4.7) and the Deep Blue (DB)-DT merge products (Sect. 4.8). Section 5 is devoted to the new L3 aggregation protocol. Section 6 revisits L1B changes, specifically related to Terra, and how we expect the two sensors to better track each other. Section 7 introduces a new, parallel aerosol product at higher $(3 \mathrm{~km})$ resolution. In Sect. 8, we discuss how we intend to use the MODIS product to help transition to future satellite data products.

\section{MODIS aerosol retrieval}

\subsection{MODIS jargon and basic retrieval concepts}

MODIS observes a swath approximately $2330 \mathrm{~km}$ wide, and makes between 14 and 15 orbits per day. For ease of processing and data storage, MODIS data are organized into 5 min swath segments called granules (288 per day), which are composed of 1354 by 2030 pixels at nominal $1 \mathrm{~km}$ resolution (near nadir). The fundamental MODIS file is called Level 0 (L0) and refers to raw counts from the sensor's detectors; when organized into scans, they are known as Level 1A (L1A). Level 1B (L1B) are calibrated data, providing geolocated radiances or reflectances, and these L1B data are the inputs to the MODIS geophysical retrieval algorithms, including aerosol. The resulting geophysical products (in $5 \mathrm{~min}$ granules) are designated as Level 2 (L2). Level 3 (L3) refers to daily and monthly statistics of the geophysical products, organized on to a $1^{\circ} \times 1^{\circ}$ latitude/longitude grid (King et al., 2003). Note that these products are processed in a linear fashion (L0 $\rightarrow \mathrm{L} 1 \mathrm{~A} \rightarrow \mathrm{L} 1 \mathrm{~B} \rightarrow \mathrm{L} 2 \rightarrow \mathrm{L} 3)$, and that some L2 products are used as inputs for other "downstream" L2 products. This is true for aerosol retrieval, which is a L2 product that requires the existence of other $\mathrm{L} 2$ products as well as L1B. All MODIS data products (from L1 onward) are provided in Hierarchal Data Format Files (HDF), and are labeled MODXX for Terra and MYDXX for Aqua. Each HDF file provides metadata and scientific data sets (SDSs). SDSs may be multi-dimensional (e.g., across-track $\times$ alongtrack $\times$ bands).

The L2 aerosol product files are known as MOD04 (Terra) and MYD04 (Aqua), or MxD04 (in general). The
MxD04 retrieval requires input L1B files, L2 files, and ancillary data provided by NOAA/NCEP. L1B files include the nominal $1 \mathrm{~km}, 0.5 \mathrm{~km}$, and $0.25 \mathrm{~km}$ reflectance products (MxD021KM, MxD02HKM and MxD02QKM; http://mcst. gsfc.nasa.gov/content/11b-documents), and the $1 \mathrm{~km}$ geolocation product (MxD03; Wolfe et al., 2002). The required L2 products are the "cloud-mask" (MxD35_L2; Ackerman et al., 2010) and "atmospheric profile" (MxD07_L2). Ancillary data are at $1^{\circ} \times 1^{\circ}$ resolution, and include the closest 6hourly, meteorological analysis from the Global Data Assimilation Model (GDAS; http://www.emc.ncep.noaa.gov/gmb/ gdas/). The aerosol retrieval fails if any one of these input files is missing.

MODIS pixel size increases towards swath edges, (http: //eoweb.dlr.de:8080/short_guide/D-MODIS.html), such that nominal pixel size is $1.0 \times 1.0 \mathrm{~km}$ at nadir, but $4.8 \times 2.0 \mathrm{~km}$ at edge. Thus, the 1354 pixel-wide granule, in fact, represents a $2330 \mathrm{~km}$-wide swath. Since MxD04 is not gridded, the product spatial resolution also increases toward swath edges. Standard MxD04 files (MxD04_L2) have a nominal spatial resolution of $10 \times 10 \mathrm{~km}$ at nadir, but increase to $48 \times 20 \mathrm{~km}$ near the swath edge. L3 products (Hubanks et al., 2008), however, are aggregated to a constant $1^{\circ} \times 1^{\circ}$ grid, and are denoted as MxD08_D3 (daily), MxD08_E3 (8-day) and MxD08_M3 (monthly). Note that aerosol products are bundled with other atmospheric products (clouds and water vapor) in these L3 files (King et al., 2003).

The MODIS aerosol retrieval algorithms are maintained and updated by the MODIS aerosol science team. The operational MODIS retrieval data are produced and archived by the MODIS Adaptive Processing System (MODAPS; http://modaps.nascom.nasa.gov/services/), and are available online (http://ladsweb.gsfc.nasa.gov). MODIS calibration is supported by the MODIS Characterization Support Team (MCST; http://mcst.gsfc.nasa.gov). The quality and accuracy of downstream retrieved products (including aerosol) is dependent on the accuracy of the calibration of the algorithm's input radiances, which the MCST reports accuracy of \pm 2 $3 \%$ for typical situations (Xiong et al., 2005, 2007).

\subsection{Basic concepts of the MODIS aerosol retrieval algorithms}

The MODIS aerosol algorithms have been in development for over $20 \mathrm{yr}$, well before the launch of Terra. These algorithms were designed to capitalize on the wide spectral range of the MODIS instrument. The primary assumption is that in a clear-sky (non-cloudy) scene, the solar radiation backscattered from aerosols have different spectral signatures than either the Earth's surface or atmospheric molecules. By using multiple bands in the visible (VIS), near-IR (NIR), and shortwave-IR (SWIR) wavelength regions, one can perform a retrieval to back out the aerosol signature, and infer the physical properties of the aerosols within the scene. Of course, the devil is in the details, and since the Earth's surface, molecular 
atmosphere and aerosols do not have entirely independent spectral signatures, the MODIS retrieval must make observational and physically based assumptions.

To that end, the operational MODIS aerosol retrieval algorithms are actually three separate algorithms; each requires separate assumptions about the Earth's surface and the expected aerosol types above these surfaces. Prior to launch, algorithm concepts were developed for vegetated land surfaces (Kaufman et al., 1997a) and remote ocean regions (Tanré et al., 1997). Collectively, we denote these algorithms as the dark-target (DT) algorithms because they operate best on regions that are "dark" visually. The third algorithm, developed well after launch, is known as the Deep-Blue (DB) algorithm (Hsu et al., 2004, 2006), and was originally designed for application over bright-desert regions. Although these surfaces appear "bright" visually, they are actually fairly dark in the near-UV (Deep Blue band near $0.41 \mu \mathrm{m}$ ), improving the signal for aerosol retrieval relative to longer, visible wavelengths. The DB algorithm is handled by a different science team, and except for a final merge to make a "best-of" product (discussed in Sect. 4.8), this paper focuses on the C6 DT aerosol product.

Prior to launch, the physical and numerical assumptions that form the basis of the DT algorithms, as well as the protoalgorithms themselves, were tested using mathematical techniques and by using proxy data obtained from aircraft instruments and field experiments (Tanré et al., 1996; Kaufman et al., 1997b; Chu et al., 1998; Remer and Kaufman, 1998; Remer et al., 1998; Tanré et al., 1999). Although the details of the DT algorithms have evolved over time, the basic concepts remain unchanged. There are complete descriptions of the C5 DT algorithms in the literature (e.g., Levy et al., 2007a, b; Remer et al., 2005, 2008) and within the online C5 Algorithm Theoretical Basis Documents (ATBD, Levy et al., 2009b).

Tanré et al. (1996) suggested that to increase signal-tonoise, one should perform the MODIS aerosol retrieval at a lower resolution (e.g., $10 \mathrm{~km}$ at nadir) than the inputted spectral reflectance data (e.g., $500 \mathrm{~m}$ ). Pixels that are non-optimal for aerosol retrieval, for whatever reason, can be screened out yet leave enough "good" pixels to make a successful retrieval. Therefore, the pixel data are organized into $N$ by $N$ boxes (e.g., 20 by 20), and the geo-location information (e.g., MxD03 or MxD35) are used to determine nominal surface type (water, land or other) of the scene, and which fork of the retrieval to follow. If all $(100 \%)$ pixels are considered "water", then the over-ocean algorithm is performed. If any pixel (at least 1) is considered "land", then the land retrieval is attempted. If a scene has no land pixels, but has at least one "other" pixel (e.g., coastal or lake shore), then no retrieval is attempted at all. Regardless of which fork is chosen, it is not likely that all pixels are suitable for aerosol retrieval. For example, there is a test to determine if a "land" pixel is in fact contaminated by water (e.g., small stream, ephemeral water body). Likewise, there is a test ( $\mathrm{Li}$ et al., 2003) to filter out shallow water pixels contaminated by underwater sediment. Other tests filter out ice/snow pixels (R. R. Li et al., 2005), bright land scenes, glint over water, etc. Finally, Martins et al. (2002) describe how to filter out cloudy pixels. Once all truly unsuitable pixels are removed, the procedure discards the brightest $25 \%$ and darkest $25 \%$ of remaining pixels over ocean, and the brightest $50 \%$ and darkest $20 \%$ over land. Because the reflectance has been screened for clouds and nonoptimal surfaces, and the remaining pixels have been further filtered, residual contamination is minimized over most situations. Furthermore, the retrieval performs corrections for absorption by atmospheric gases (water vapor, ozone, etc.). The pixels that remain, after all de-selection and gas corrections are applied, are understood to represent the conditions that it may be possible to retrieve aerosol properties (e.g., Remer et al., 2012). These pixels are averaged, yielding a final set of mean spectral reflectance that is understood to be representative of conditions that DT aerosol retrieval can succeed, e.g., clear skies, no gases, and low surface variability. The algorithm takes this set of "observed" top-of-atmosphere (TOA) spectral reflectance, and tries to match to values within look up tables (LUTs).

The LUTs, themselves, represent atmospheric optical properties (TOA reflectance, atmospheric transmission, etc.) for a set of likely aerosol conditions. We assume that a particular aerosol type $X$ is characterized by a size distribution (dV/d $R$, with $V$ and $R$ volume and radius), and index of refraction that varies spectrally. Using a Mie code (for assumed spherical particles) or analogous (for non-spherical particles), one can compute the spectral scattering and extinction coefficients that represent a single particle of type $X$. Increasing the columnar loading of particle $X$ is the same as creating an integral of extinction coefficient - the AOD, and AOD varies spectrally. In other words, we can index aerosol type $X$ by AOD at $0.55 \mu \mathrm{m}$ (to include values such as 0.0 , $0.5,1.0,2.0$, etc.), and thus have determined AOD at any other wavelength. In addition, atmospheric properties vary by sun/satellite geometry, so at discrete values of solar and observation angles, there are determined properties of TOA reflectance, atmospheric transmission and backscattering ratio for a particular indexed AOD of aerosol type $X$. Note that for $\mathrm{AOD}=0.0$, this is the molecular-only (Rayleigh) case, so that for AOD $>0.0$, the LUT represents the coupling of aerosols plus molecular scattering.

There are differences between the details of creating LUTs over ocean versus over land. Over ocean, the LUT represents the optical properties of ocean (glint, foam, waterleaving radiance) coupled with the atmosphere (molecular plus aerosol). Over land, the LUT is calculated over a black surface, so that the TOA is the atmosphere only. Over ocean, there are nine such aerosol type $X$ 's, where each type is a single mode of log-normal size distribution. There are four "fine" modes (having effective radius $\left.r_{\mathrm{e}}<0.25 \mu \mathrm{m}\right)$ and five "coarse" modes $\left(r_{\mathrm{e}}>1.0 \mu \mathrm{m}\right)$. Over land, there are five aerosol types, each comprised of two 
or more log-normal modes. These may be "fine-dominated", or "coarse-dominated" depending on which mode dominates the size distribution. For simplicity, we will use the term fine model, to represent both the fine modes over ocean and the fine-dominated models over land. Likewise, the coarse model refers to the coarse modes over ocean as well as the coarse-dominated models over land. Details of the RT codes and LUT assumptions are described more fully in literature (e.g. Levy et al., 2007a; Remer et al., 2005).

When we say inversion to the LUT, we assume that the ambient aerosol scene consists of a mixture of fine and coarse models, such that each contributes to the spectral TOA reflectance. Since everything is indexed to AOD at $0.55 \mu \mathrm{m}$, the total AOD is the weighted combination of AOD from each model, weighted by the fine model fraction ( $\eta$ or FMF). Although both DT algorithms perform inversions to find matches to the LUT, the required assumptions are different.

Over the ocean, except for where there is strong glint, sediments or other surface contamination, surface reflection becomes negligible as the wavelength increases. This means that a reflecting aerosol layer provides good contrast over the ocean, and that at least two pieces of aerosol information (loading, size) can be retrieved (Tanré et al., 1996). Spectral reflectance $\left(\rho_{\lambda}\right)$ observations in six wavelengths $(0.55,0.65$, $0.86,1.24,1.63$, and $2.11 \mu \mathrm{m})$ are compared with LUT reflectance that represents various combinations of fine model (selected from 4 modes) and coarse model (selected from 5 modes). Thus, the retrieved products over ocean are the total aerosol optical depth (AOD or $\tau$ ) at $0.55 \mu \mathrm{m}$, the fine mode fraction of AOD at $0.55 \mu \mathrm{m}$ (FMF or $\eta$ ) and which fine/coarse combination provided the best solution, along with the least squares spectral fitting error $(\varepsilon)$.

On the other hand, over land, the surface is much more variable, and is dark enough only under some conditions. Therefore, many more assumptions need to be made about the surface and aerosol type, in order to accurately determine only one piece of information (aerosol loading). Kaufman et al. (1997b) discovered that in many vegetated regions, there is a consistent relationship between surface reflectance at $0.47,0.65$ and $2.11 \mu \mathrm{m}$ (the "VISto2.1" relationship). Therefore, observation/LUT comparison is done in only these three wavelength bands. Since the LUT is calculated without surface contributions, the algorithm is constrained by the surface spectral relationships. Since the land algorithm tries to deal with larger surface uncertainty with only three spectral bands, both fine and coarse model aerosol types must be prescribed as a function of season and location. The retrieved products over land include total AOD $(0.55 \mu \mathrm{m})$, fraction of fine-model aerosol type (also known as FMF), constrained surface reflectance, and fitting error.

Thus both DT algorithms retrieve total AOD at $0.55 \mu \mathrm{m}$ $(\tau)$ and FMF ( $\eta$ : mode over ocean, model over land) with a the spectral fitting error $(\varepsilon)$. Each algorithm reports additional derived and diagnostic parameters. Derived parameters can be calculated from information contained within the
LUT and/or other retrieved products. For example, knowing the resulting total AOD and FMF, and which aerosol types were selected (or assumed), one can go back to the lookup table, and recover additional information about the retrieved aerosol. This includes AOD in other wavelengths, which can be used to calculate Ångström Exponent (AE). The retrieval solution also determines effective radius, asymmetry parameter, and other properties of the size distribution or radiation field. Diagnostic parameters include information used to perform the retrieval, as well as information about the retrieval itself. Solar zenith angle is an example of information going into the retrieval; the number of pixels used, is an example of information about the retrieval.

Finally, there is the run-time Quality Assurance (QA) (Hubanks, 2012). At selected stages during the retrieval process, the algorithm will evaluate whether a task was or could have been adequately performed. If, for some reason, a task was not performed correctly, conditions for retrieval are marginal, or something is not "behaving" as expected, the quality of the retrieved product should be degraded. Among other tests, the QA logic will examine how many pixels were thrown out during cloud masking, how well the retrieval solution fits the observations, and whether or not the solution is characteristic of realistic physical conditions. Each test triggers its own QA flag. If, during the retrieval, some aspect is less than ideal, the overall accuracy of the retrieval is expected to degrade. Ideal performance is given the highest $\mathrm{QA}$ "Confidence" value $(\mathrm{QAC}=3)$, with good, marginal and no confidence retrievals given QAC values of 2,1 and 0 , respectively. The results of the many individual QA tests, plus the final determination of QAC are all coded into a five-byte SDS. Different bits represent the results of individual tests. For C5, the QA logic and bit values were discussed in the ATBD (Levy et al., 2009b).

\subsection{Evaluation of the C5 MODIS aerosol products}

Immediately following Terra launch the first aerosol products were evaluated in a variety of ways that included qualitative examinations and quantitative comparisons of data collected from collocated sun photometer (SP) data including those from Aerosol Robotic NETwork (AERONET) stations (Holben et al., 1998; Ichoku et al., 2002; Chu et al., 2002; Remer et al., 2002). Evaluation led to modifications of the algorithm to avoid problematic situations and also to add capability, expand retrieval coverage, and provide new products. Each major change to the algorithm is labeled a "Collection", although minor changes had made under the same Collection number. The early Collections were frequently revised. The first set of validated products appeared in Collection 2 (C2), although these were quickly replaced by $\mathrm{C} 3$ within the first two years of Terra launch. C4 was the first stable, widely used and well-documented set of MODIS aerosol products (Remer et al., 2005). However, the $\mathrm{C} 4$ aerosol product over land produced unacceptable levels of bias (Levy et al., 2005). 
A second-generation land algorithm was developed and implemented as C5 (Levy et al., 2007a, b) and other changes were implemented at the same time. The MODIS Deep Blue algorithm (Hsu et al., 2006) was added to the Collection 5 processing after the processing had already begun and was thus labeled Collection 5.1 (C51). Since the dark-target algorithms are identical for C5 and C51, we refer to them both as "C5". Details of the C5 DT algorithms are presented in the literature (Remer et al., 2005, 2008 over ocean; Levy et al., 2007a and b over land) as well as within the online ATBD (Levy et al., 2009b).

Identical C5 DT aerosol retrieval algorithms have been applied to the entire time series of both MODIS' data (2000/2002 through 2011). This has allowed time for an exhaustive evaluation process, including numerous papers on global, regional and local MODIS product "validation". Global validation has been performed by comparing MODIS-retrieved AOD and size parameters to similar parameters observed from AERONET, both over land (Levy et al., 2010) and over ocean (Remer et al., 2008). In addition to these global studies, MODIS has also been compared to additional ground based (e.g., Levy et al., 2005), airborne (e.g., Redemann et al., 2009) and shipborne SPs (e.g., Kleidman et al., 2012).

The major goal of the validation studies was to define an expected error (EE) envelope, containing at least $67 \%$ (approximately one standard deviation) of the matchups on a scatter plot. From pre-launch sensitivity studies, the overall EE for AOD should be a combination of absolute error (dominating at low AOD) and relative error (dominating at high AOD). For C005, the EE for total AOD (at $0.55 \mu \mathrm{m}$ ) was defined to be $\pm(0.03+5 \%)$ over ocean (Remer et al., 2008) where $\mathrm{QAC} \geq 1$, and $\pm(0.05+15 \%)$ over land (Levy et al., 2010) where $\mathrm{QAC}=3$. While the $\mathrm{EE}$ was defined for the set of all MODIS/sun photometer combinations, actual comparability depended on conditions of the observation scene (location, season, etc.) as well as the estimated QAC of the retrieval (e.g. Breón et al., 2011). The MODIS/AERONET agreements were about the same for Terra and Aqua, with similar percentages falling within EE. The $\mathrm{C} 5$ algorithm was the first to allow retrievals of small negative AOD, down to -0.05 . While not physical, randomly retrieving a negative AOD is a statistically realistic portrayal of small positive AOD, and clearly helped in reducing the statistical bias as compared to sun photometer.

In addition to AOD, EE definition was attempted for retrieved aerosol size parameters over ocean and land. Although Kleidman et al. (2005) pointed out that FMF was not uniquely defined, MODIS retrieved FMF compared with AERONET-retrieved sky-radiance FMF within approximately \pm 0.20 . Anderson et al. (2005) worked with Ångström exponent (AE) because it is less ambiguous. Levy et al. (2010) found that the MODIS-retrieved FMF over land had too little skill to derive meaningful EE envelope. Breón et al. (2011) defined EE for fine-mode AOD over ocean, but did not do so over land.

While a useful EE could be defined for AOD over both land and ocean, these and other validation studies clearly showed that $\mathrm{C} 5$ aerosol products were not equally accurate and stable every place and every time. MODIS/AERONET "comparability" (regression slope, intercept, correlation and number within EE envelope) varied as a function of location and season, conditions of retrieval (scattering geometry, cloud fraction), and also due to subjective algorithm tests during retrieval. In some cases, these evaluations indicated that assumed confidence (QAC levels) was assigned based on the wrong criteria.

There are large tracts of Earth (over both land and ocean) with few AERONET sites to compare with. Data assimilation (e.g. Hyer et al., 2010; Zhang et al., 2008) is a tool that can be used to characterize the MODIS product away from AERONET sites. Data are compared not only with AERONET, but also with each other (neighboring pixels), with pre-run model estimates, and with statistical measures for estimating confidence. These studies concluded that over $30-50 \%$ of the globe, the C5 MODIS data were performing acceptably (within EE) and could be inserted directly into a weather or transport model. Another $30 \%$ of the data could be used if appropriate "bias correction" was applied. However, $20 \%$ of the data were unusable and had to be discarded. For example, Shi et al. (2011) concluded that MODIS data over the southern oceans was unusable for data assimilation, because of cloud contamination and unrealistic high values.

\subsection{Terra versus Aqua}

The global validation studies (such as Levy et al., 2010; Remer et al., 2008) indicated that there was no significant difference between MODIS/AERONET comparability (slope, offset, correlation, fraction within EE) for the two MODIS instruments $\left(M_{\mathrm{T}}\right.$ and $\left.M_{\mathrm{A}}\right)$. There were slight differences, however, that in hindsight can be explained. Remer et al. (2008) noted that regression slope for $M_{\mathrm{T}}(0.967)$ was higher than for $M_{\mathrm{A}}(0.900)$. At the same time, the monthly global mean AOD for $M_{\mathrm{T}}$ was consistently higher than $M_{\mathrm{A}}$ by about 0.015 . Monthly regional means were also 0.015 higher. Finally, a curious thing had happened when going from C4 to C5 (Remer et al., 2008). $M_{\mathrm{T}}$ 's time series of monthly mean over-ocean AOD jumped by 0.015 , while $M_{\mathrm{A}}$ 's remained constant. In other words, something changed between $\mathrm{C} 4$ and $\mathrm{C} 5$ that created the offset.

Over land, Remer et al. (2008) found no such offset between $M_{\mathrm{T}}$ and $M_{\mathrm{A}}$; also no significant difference between overall MODIS/AERONET comparability. Yet a time series plot (their Fig. 5) shows an apparent downward tendency for $M_{\mathrm{T}}$, which is not visible for $M_{\mathrm{A}}$. Levy et al. (2010) suggests (in their Fig. 15) that $M_{\mathrm{T}}$ /AERONET comparability also changes over time, such that $M_{\mathrm{T}}>$ AERONET prior to 2004 and $M_{\mathrm{T}}<\mathrm{AERONET}$ afterwards. This kind of 
divergent behavior was not limited to the aerosol product. Wang et al. (2012) showed that Normalized Difference Vegetation Index (NDVI) was also diverging.

What was causing the Terra/Aqua offset in AOD over ocean, and the drifting AOD over land? The ocean color retrieval team had long been using vicarious calibration techniques (e.g. Franz et al., 2007) to reduce drifts in their tiny ocean color signal. This issue was especially problematic in the deep blue MODIS wavelengths (e.g. $0.41 \mu \mathrm{m}$ ), but was not considered to be major problem for the longer wavelengths used for aerosol and NDVI retrieval. Yet Wang et al. (2012) demonstrated that even small drifting of the blue $(0.47 \mu \mathrm{m})$ could be responsible for the NDVI product divergence, in that this channel was used for estimating aerosol effects. Furthermore own sensitivity tests (unpublished) demonstrated that a 1-2\% drift in blue channel (less than the stated accuracy maintained by MCST) was sufficient to produce a trend or multi-sensor divergence in the MODIS aerosol products.

Due to calibration updates, there was a significant jump in the aerosol product when going from $\mathrm{C} 4$ to $\mathrm{C} 5$. MCST is updating the calibration as we go from $\mathrm{C} 5$ to $\mathrm{C} 6$. This is not a trend paper, or a calibration paper, but as we discuss the C5 $\rightarrow$ C6 aerosol retrieval and products, we must account for updates to the upstream products that are used as input to the aerosol retrieval.

\section{Experimental setup}

There are clearly problems with the MODIS C5 product. Yet, there is overall agreement with AERONET data, and the product has been shown to be usable within an assimilation framework. There are many, many users of the MODIS aerosol product, and they have come to expect relative consistency in product output and format. Therefore, the aim of "maintenance and modest refinement" was to improve the MODIS-DT aerosol product without a complete overhaul. This means that the basic theory, science and logic of the DT algorithms would remain similar to C5. However, there were coding bugs to fix, assumptions to reconsider, and diagnostic information to add. Also, based on our experience when going from $\mathrm{C} 4 \rightarrow \mathrm{C} 5$, and the extensive use of MODIS AOD data for determining aerosol climatology and trends (e.g., Remer et al., 2008; Zhang and Reid, 2010; Mishchenko et al., 2007; Karneili et al., 2009; de Meij et al., 2012; Kishcha et al., 2007; Koukouli et al., 2010, etc.), impacts due to upstream calibration and must also be quantified. Even if the aerosol algorithms were to remain unchanged from C5 to C6, the global aerosol product would be different because the inputs are different. C6 not only represents an update to the aerosol algorithm but also an update to all MODIS algorithms, including the calibration (MxD02) and cloud masking algorithms (MxD35) that produce the inputs to the aerosol algorithm. Since the final C6 algorithm will be applied to all archived and future data that will be collected from both MODIS instruments, we need a test bed of data that samples enough of the globe, across enough of the time series.

In addition to calibration updates, MCST was also updating the geolocation information. As described in Sect. 2.2, the MODIS aerosol retrieval requires geolocation information as to whether "ocean" or "land" fork should be followed. Yet, as Carroll et al. (2011) explains, there are sometimes significant and rapid changes in land/water cover, especially in the Arctic. Also, there are coastal and lakeshore regions with complicated, fractal-like structure. For C6, the MCST is relying on a $250 \mathrm{~m}$-resolution water mask (Carroll et al., 2009), which provides significant changes to land/sea discrimination (http://landweb.nascom.nasa.gov/ QA_WWW/forPage/LWM_diff.html), especially for lakes and river basins. This will lead to differences in water/land flagging for selecting which DT-retrieval fork.

As discussed in the introduction, there are four categories of $\mathrm{C} 5 \rightarrow$ C6 changes. Two of these changes will lead to revised values of AOD and aerosol size. These are (a) changes to upstream products (e.g. calibration, cloud mask or land/sea flags) and (b) modifications to the retrieval that would produce different values for the same-named parameters as in C5 (if there were no changes to upstream products). These are not necessarily independent changes, because sometimes a retrieval modification was made to account for changed upstream product. Therefore, when we report changes and their impacts, they are not necessarily in chronological order or order of largest impact. In some cases, we may report on a change that was later abandoned.

To incrementally test the impacts of any changes, we set up an "operational-like" processing environment on our nonMODAPS machines. We also tasked the MODAPS group to set up a testing environment on their machines, in order to repeatedly process different versions of the algorithm on multiple granules, days or months of MODIS aerosol products. Depending on the test performed, MODIS data were chosen from different periods of the combined Terra/Aqua mission. Some tests only required small amounts of data on Terra or Aqua separately, while others required full months of data from both satellites. Large statistical evaluation required processing of multiple months of data across multiple years, which included both January and July from 2003, 2008 and 2010, as well as April and October 2008. These months were picked because they sample the time period of the Terra/Aqua trend divergence, as well as a complete year. We might be able to determine whether to expect the Terra/Aqua divergence (discussed in Sect. 2.4) to remain when the entire time series is reprocessed for $\mathrm{C} 6$.

To assess the impacts of different algorithm upgrades, our metrics included basic statistics (global mean AOD, number of valid retrievals), histograms, and dual collocation with AERONET or other SP data. However, while the statistical tests are quantitative, the easiest way to assess individual 
changes is to make pictures, specifically maps of gridded, monthly mean AOD. These are in form of difference maps (e.g., "new - baseline"). From these tests, we can determine whether the change had a significant global impact, where it had significant impact, and whether or not it pushed MODIS data closer to or farther from SP values.

\section{Changes that affect the DT aerosol product (MxD04_L2)}

In this section, we describe the major changes to the DT (land and ocean) aerosol algorithms and products, as we move from C5 to C6. Section 4.1 shows the "overall" changes for the four months in 2008, and breaks them down incrementally for one month (July 2008). Section 4.2 illustrates upstream (calibration, geolocation and cloud mask changes). Section 4.3 concerns changes that are common to both DT algorithms, including radiative transfer and gas absorption corrections. Sections 4.4 and 4.5 are concerned with changes to the specific algorithms over land and ocean, respectively, where Sect. 4.6 discusses the combined products.

\subsection{Overall change summary}

Rather than begin by listing and describing each update, we use Fig. 1 to show the overall change to the MODIS DT AOD products. Here we use Aqua as the example, and plot the four months (January, April, July and October) of 2008. Each panel represents gridded $1^{\circ} \times 1^{\circ}$ mean, where the mean is calculated by averaging all the L2 observations that occur within each grid box. This is not necessarily the way one should create a monthly mean AOD (see Sect. 6 and Levy et al., 2009a), but it is easy to compute and adequate for our purpose. For each row (month in 2008), there are four panels. The left panel is the gridded AOD for C5, the left-center is the gridded AOD for expected C6, the right-center is the difference C6-C5 for grids where both data sets have a value, and the right panel is the change in coverage (usually increased) for C6 as compared to C5. Here we plot aggregation of the QA-filtered SDS known as Optical_Depth_Land_And_Ocean. Only retrievals that meet certain $\mathrm{QAC}$ requirements (e.g. $\mathrm{QAC}=3$ over land, and $\mathrm{QAC} \geq 1$ over ocean, as recommended by Remer et al., 2008) are stitched into this SDS.

From these global maps, we note the following major changes to the aerosol product:

1. There are large differences between C5 and C6 over both land and ocean.

2. Over most global ocean, AODs are reduced. The largest negative changes $(<-0.04)$ are in the midlatitudes (e.g., $40-50^{\circ}$ latitude in both hemispheres). This includes the well-scrutinized "roaring 40s" in the Southern Hemisphere (SH). AOD tends to be increased over the tropics.
3. Over most global land, AOD is decreased. There are larger decreases $(<-0.04)$ over the more arid regions (e.g. southwestern United States, middle Asia, Sahel in Africa, southern Africa, savannas of Brazil), and general increase over the more vegetated regions (e.g. Canada and Eastern US; rainforests of South America, Africa and Asia).

4. There is new "coverage" in C6. This includes the entire latitude belt (over ocean) towards the pole of the winter season. There is also new coverage over inland water bodies of Asia.

5. The patterns are consistent from month to month, although the locations of the largest changes varies.

There are many changes in both upstream processing and aerosol retrieval that have led to these major changes. This is illustrated in Fig. 2, where we trace the change in Aqua's July 2008 AOD from C5 (panel a) to C6 (panel k), with the overall difference (C6-C5) plotted in panel f. Note that these panels are the same as the three leftward panels of the third row in Fig. 1. As we consider each major change to the upstream and processing we will refer to the appropriate panel in Fig. 2.

\subsection{Upstream changes including L1B reflectance, geolocation and cloud mask}

As described in Sect. 2.4, analysis of the C5 aerosol time series showed curious differences between AOD derived from $M_{\mathrm{T}}$ versus $M_{\mathrm{A}}$. We will discuss in more detail (in Sect. 8), but the short story is that we believe the reason for the curious differences was due to issues in instrument calibration, especially for $M_{\mathrm{T}}$. MCST is continually updating the calibration coefficients, and even for the same MODIS measurements (e.g. L1A data), the C6 L1B data will be different than C5. Although calibration changes to $M_{\mathrm{T}}$ are much larger and have larger impacts on aerosol retrieval (discussed in Sect. 8), calibration has interesting non-linear effects on Aqua's aerosol products.

In the same way we created maps of gridded $\left(1^{\circ} \times 1^{\circ}\right)$ monthly mean AOD (e.g. Figs. 1 and 2), we can create maps of monthly "mean" TOA reflectance in the seven bands. While this quantity is not physically correct (angular dependence is ignored), its calculation helps to provide intuition. Maps of reflectance (C5) and differences (C6-C5) are shown in Fig. 3, for Aqua during July 2008. Note that these are taken from the along-orbit (swath) granules so that reflectance is normalized by cosine of solar zenith angle.

Each row of Fig. 3 represents a MODIS wavelength band that is used in aerosol retrieval $(0.47,0.55,0.65,0.86,1.24$, 1.63 and $2.11 \mu \mathrm{m})$. For each row, the two left panels are calculated from the observed reflectance that is reported in the $1 \mathrm{~km} \mathrm{L1B}$ files (MYD021KM). Missing or bad data are not included. The 1st panel is that computed from the C5 files, 


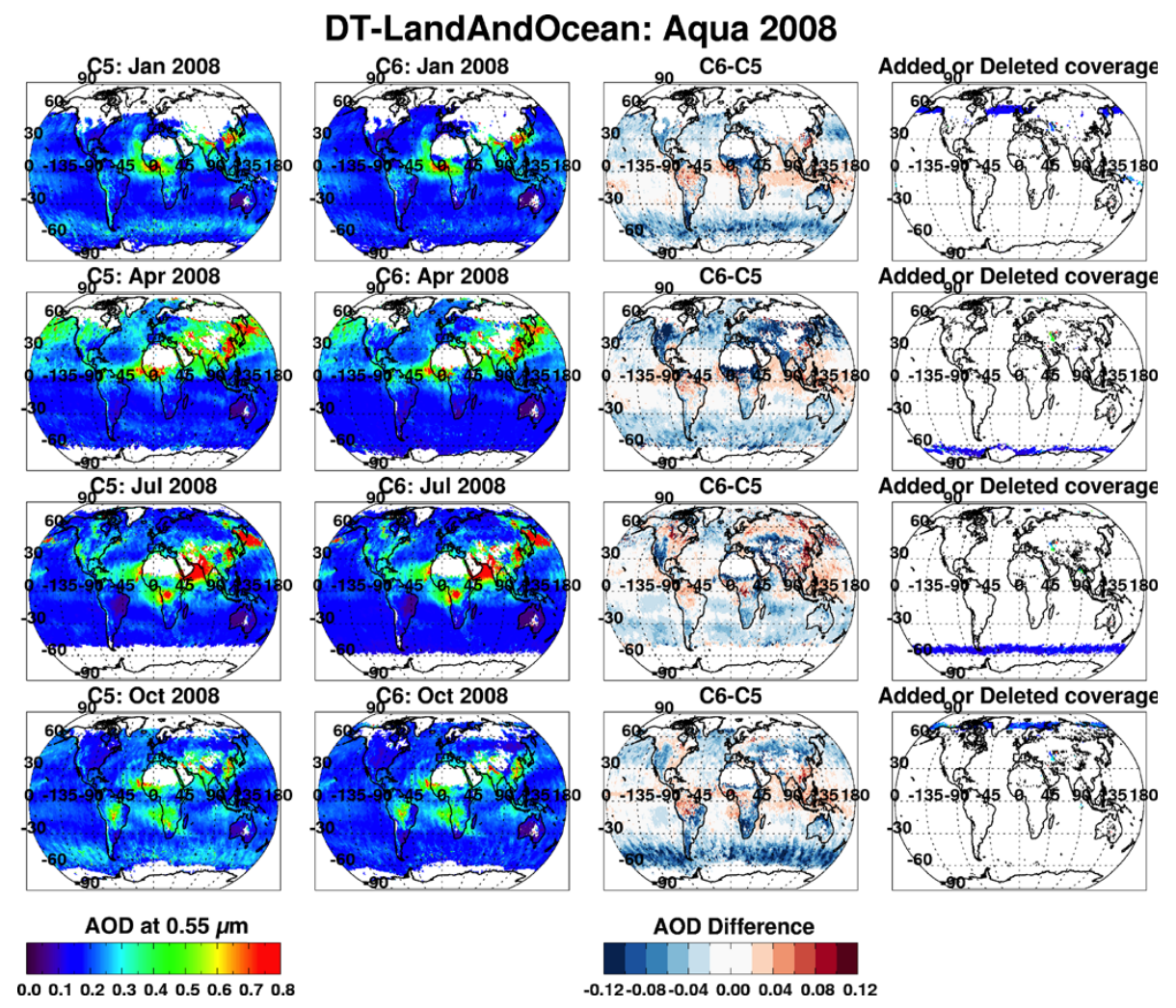

Fig. 1. Gridded, monthly averaged $1^{\circ} \times 1^{\circ}$ AOD (at $0.55 \mu \mathrm{m}$ ) over land and ocean retrieved from Aqua for four months (January, April, July and October) in 2008. For each row (month), the 1st panel is an aggregated product produced from C5, the 2nd panel is from C6 and the 3rd panel is the differences C6-C5. The 4th panel shows the additional AOD coverage (colors) versus deleted coverage (black).

whereas the 2 nd panel is the difference if computed from the C6 files. There is no screening for clouds, ice or anything else, so we see our world, spectrally. Areas of mostly clear sky (dark) and areas of persistent clouds (brighter) are apparent. Frozen Greenland is highly reflective. Water is dark, especially for longer wavelengths. In general, after calibration changes, observed TOA reflectance is reduced in $0.47,0.55$, 0.65 and $0.86 \mu \mathrm{m}$ bands (by about $0.3 \%$ ), but is the same or slightly increased in the $1.24,1.63$ and $2.11 \mu \mathrm{m}$ bands (by less than $0.1 \%$ ). These are small changes, and we would not expect them to impact aerosol retrieval.

As explained in Sect. 2.2, the aerosol retrieval algorithm aggregates and averages a subset of the L1B reflectance observations (pixels). During the retrieval process, gas absorption corrections are applied, along with cloud masking, snow masking and other pixel deselection. Pixels that are too bright for DT aerosol retrieval are removed, as well as pixels too dark (too small of a signal to expect success). While the details are somewhat different between the two DT algorithms, the result is one set set of clear-sky, non-desert, non-snow, TOA spectral reflectance in seven bands $(0.47,0.55,0.65$, $0.86,1.24,1.63$ and $2.11 \mu \mathrm{m}$ ), from which a subset may be later used for over-land ( 5 bands) or over-ocean (6 bands) retrieval. Specifically, this quantity is reported as SDSs named
"Mean_Reflectance_Land" and "Mean_Reflectance_Ocean" within the MxD04 file. The right-side panels of Fig. 3 show gridded averages from these L2 SDSs.

Again, while this quantity is not physically meaningful (angular dependence is ignored), the 3rd column of Fig. 3 illustrates the relative differences between land and ocean and over different regions. Maps in this column are derived from C5 aerosol algorithm using C5 reflectance (MYD02) and C5 geolocation/cloud mask (MYD03/MYD35) inputs, demonstrating the well-known spectral dependence of clearsky reflectance. For example, in the $0.86 \mu \mathrm{m}$ band, although the reflectance is not "atmospherically corrected", one can clearly see the regions of strong vegetation versus regions of less vegetation, and no vegetation (water). Also, in this band, one can see the patterns of heavy aerosol (such as East Asian and Indian plumes). The maps in the 4th column of Fig. 3 show the change in spectral TOA "mean" reflectance if only the MYD02 files were replaced by C6 versions (keeping the C5 MYD03 and MYD35 inputs).

Comparing the 2nd and 4th columns, it is clear that there is non-linear relationship between changed inputs (C6-C5 MYD02 files) and changed aerosol retrieval inputs (C6C5 MYD04 files). There are differences between land and ocean, and there is something strange about the $1.63 \mu \mathrm{m}$ 


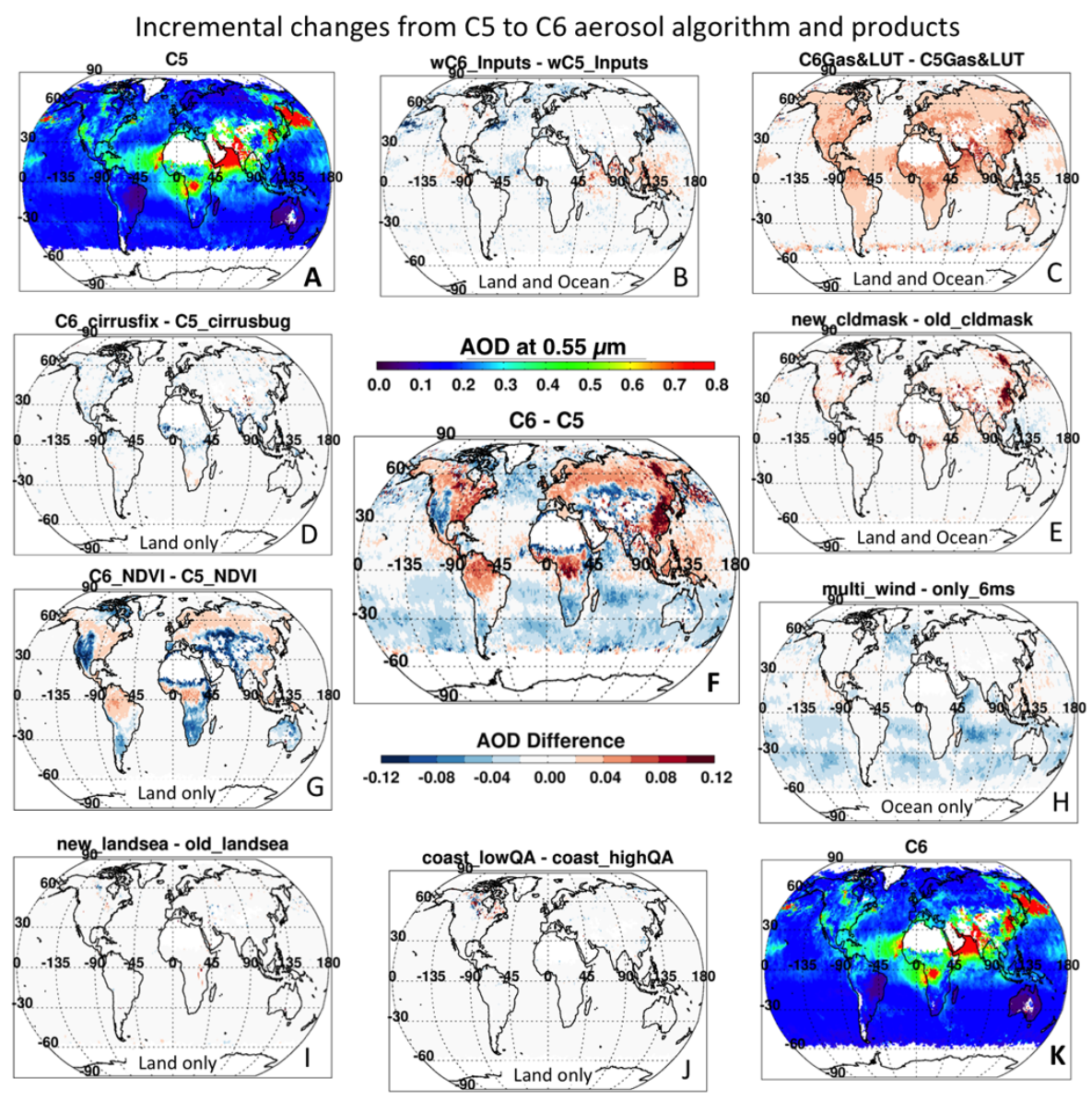

Fig. 2. Global, gridded $1^{\circ} \times 1^{\circ}$ maps of AOD and AOD differences (new - old) due to major changes to the DT aerosol retrieval algorithm. The example is from July 2008. (a) C5 AOD. (b) Differences due to using new L1B inputs. (c) Differences due to new wavelength and gas absorption coefficients. (d) Differences due to correcting a bug in the cirrus cloud masking. (e) Differences due to modified cloud masking. (g) Differences due to correcting the VIS/SWIR surface relationship to NDVIswir over land. (h) Differences due to including wind speed dependence over ocean. (i) Differences due to treatment of land sea masking. (j) Differences due to treatment of coastal quality flags. (f) Overall differences C6-C5. (k) C6 AOD. The AOD color scale is for (a and k), whereas the AOD Difference color scale is for all other panels.

band. Except for the $1.63 \mu \mathrm{m}$ band, the overall sign of the change is consistent between land and ocean, but over ocean, the relative change is much larger than might be expected by the small changes to inputs. While puzzling at first, the non-linear response over ocean was traced back to the issue of pixel decision. We discuss more thoroughly in Sect. 4.5, but essentially there are pixels that are "too dark" to retrieve successfully. The small decrease $(-0.3 \%)$ in $0.86 \mu \mathrm{m}$ band leads to $10 \%$ fewer successful retrievals over ocean, shifting the distribution of L 2 reflectance values. Over land, there is no reduction of successful retrievals, so the entire L2 reflectance is reduced by $0.3 \%$. As this happens over mostly dark regions (vegetation), where reflectance is on the order of 0.1 in the visible, this leads to a trivial decrease of 0.0003 in the visible bands.

In addition to "calibration" changes that lead to differences in the values of L1B reflectance, MCST is also applying a different protocol when dealing with missing or bad data in the L1B. As discussed on the MCST web page (http://mcst.gsfc.nasa.gov/calibration/ time-dependent-list-non-functional-or-noisy-detector),

there are anomalous, degraded, and or non-functional detectors within the MODIS image. This is especially true for Aqua and for bands \#6 (1.63 $\mu \mathrm{m})$ and \#5 (1.24 $\mu \mathrm{m})$. In C5 data, data for these bad detectors may have been averaged from adjacent detectors. While indicated by lowered Quality Assurance (QA), the aerosol (and other) algorithms tended to ignore the distinction between valid and interpolated data. For C6, MCST is not providing interpolated data, but instead leaving missing data values (e.g., -9999). The insertion of negative fill values impacts any test that calculates standard deviation of reflectance, such as cloud masking (e.g., Martins et al., 2002). The issue of MCST protocol for 
L1B Reflectance: Jul 2008 Aqua

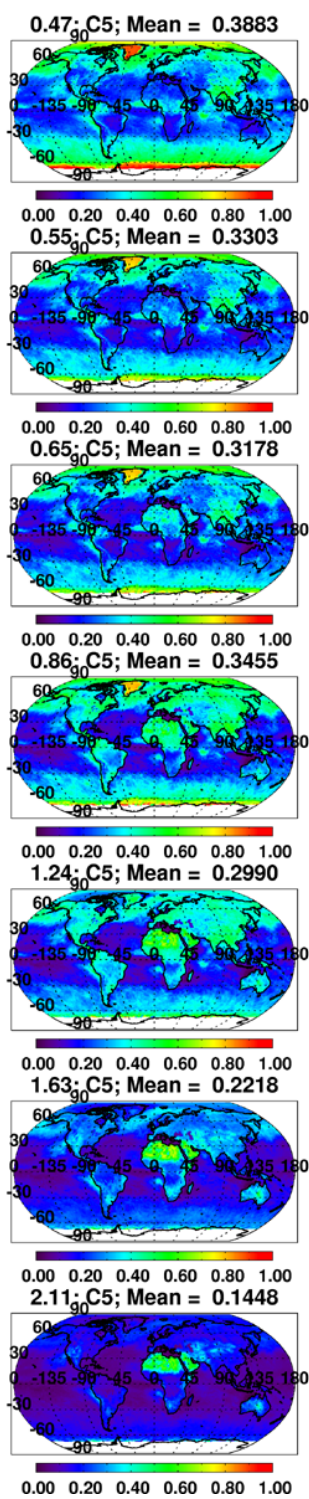

C6.-C5: Diff $=-0.0008$

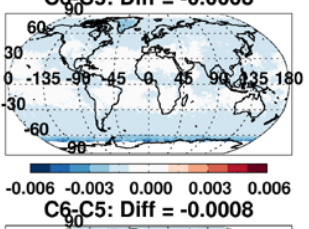

C6-C5: Diff $=-0.0008$

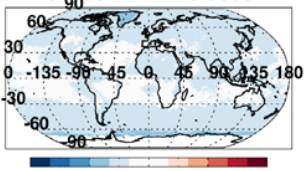

$\begin{array}{lllll}-0.006 & -0.003 & 0.000 & 0.003 & 0.006\end{array}$

C6-C5: Diff $=-0.0011$

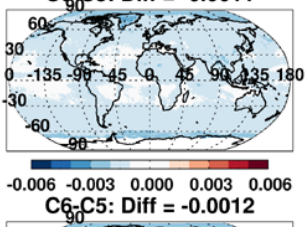

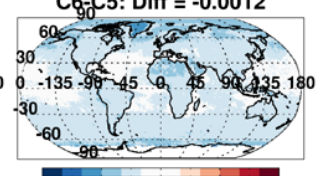

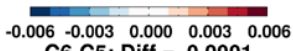
C6-C5: Diff = 0.0001
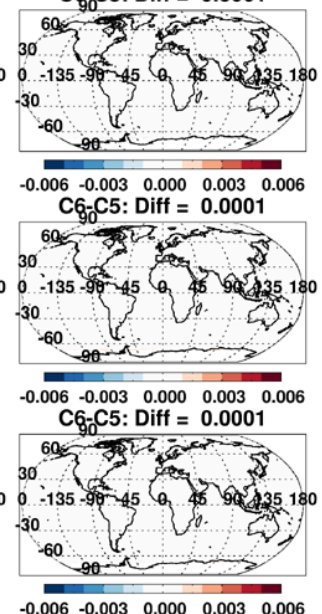

L2 Reflectance: Jul 2008 Aqua

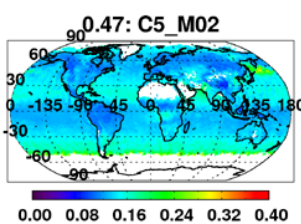

$\begin{array}{llllll}0.00 & 0.08 & 0.16 & 0.24 & 0.32 & 0.40\end{array}$

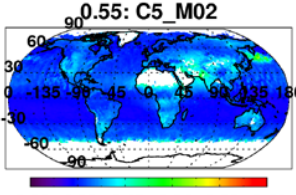

$\begin{array}{llllll}0.00 & 0.08 & 0.16 & 0.24 & 0.32 & 0.40\end{array}$ 0.65: C5_M02

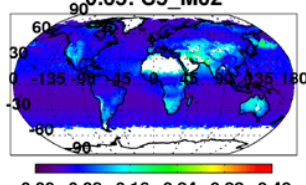

$\begin{array}{llllll}0.00 & 0.08 & 0.16 & 0.24 & 0.32 & 0.40\end{array}$ ${ }_{90}^{0.86: \text { C5_M02 }}$

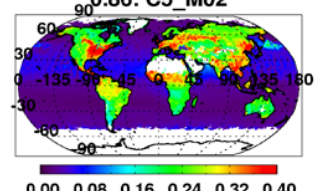

$\begin{array}{llllll}0.00 & 0.08 & 0.16 & 0.24 & 0.32 & 0.40\end{array}$ 1.24: C5_M02

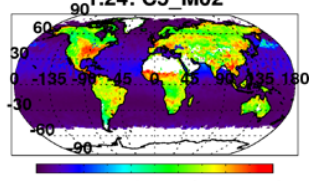

$\begin{array}{lllllll}0.00 & 0.08 & 0.16 & 0.24 & 0.32 & 0.40\end{array}$ 90 1.64: C5_M02

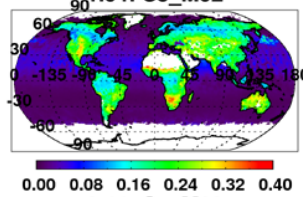
2.11: C5_M02

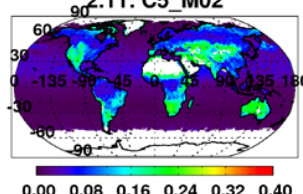

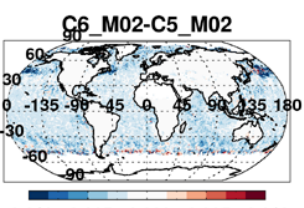

$\begin{array}{lllll}-0.010 & -0.005 & 0.000 & 0.005 & 0.010\end{array}$ C6__M02-C5_M02

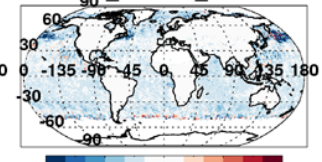

$\begin{array}{lllll}-0.010 & -0.005 & 0.000 & 0.005 & 0.010\end{array}$

C6_M02-C5_M02

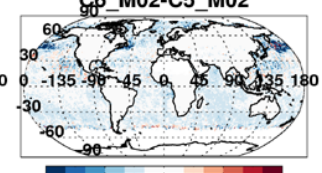

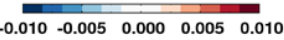
C6_M02-C5_M02

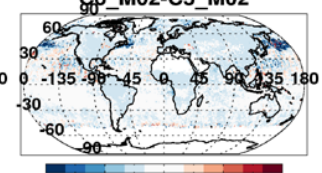

$\begin{array}{lllll}-0.010 & -0.005 & 0.000 & 0.005 & 0.010\end{array}$ C6_M02-C5_M02

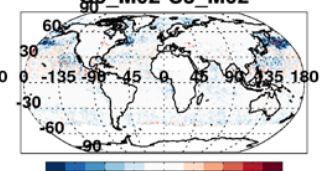

$\begin{array}{llllll}-0.010 & -0.005 & 0.000 & 0.005 & 0.010\end{array}$ C6_M02-C5_M02

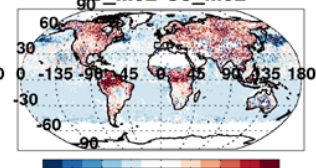

$\begin{array}{llllll}-0.010 & -0.005 & 0.000 & 0.005 & 0.010\end{array}$ C6_M02-C5_M02

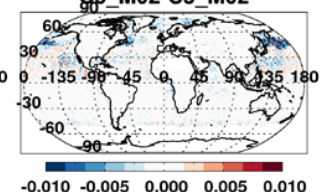

Fig. 3. Gridded "average" reflectance from Aqua for July 2008, demonstrating how small updates to L1B calibration can contribute to larger impacts on L2 products. For each wavelength band (row), the two left panels are calculated from L1B reflectance at $1 \mathrm{~km}$ (MYD021KM), and the right two panels are calculated from L2 reflectance at $10 \mathrm{~km}$ (MYD04_L2), which represents the reflectance used to derive the aerosol parameters. For the left two panels (L1B), the 1st is derived from C5 data, and the 2nd is the change due to using C6 (C6-C5). For the right panels (L2), the 1st is from the C5 aerosol algorithm if using C5 MOD02 inputs (the C5 aerosol product), whereas the 2nd shows the change if using the same C5 aerosol algorithm, but replacing with C6 MOD02 inputs. Note differences in the color scales for the two sets of panels.

missing detectors is the cause for the odd response in 1.24 and $1.63 \mu \mathrm{m}$ bands.

Interestingly, although new MYD02 has a big impact on the mean L2 reflectance (used as input to aerosol retrieval) over ocean, the effect on the over-ocean AOD is small. When reducing the number of successful retrievals by $10 \%$, fewer near-zero AOD retrievals are counted for calculation of mean AOD. Thus, the over-all effect of new input MYD02 files, (but leaving all other inputs), is a trivial decrease in mean AOD over ocean (0.001). Over land, the corresponding change in global AOD is also decrease of 0.001. Again, we note here that there are much bigger changes to Terra's C6 L1B calibration than for Aqua, which does lead to comparatively bigger changes to the resulting MxD04 aerosol product. We will discuss Terra's calibration change more fully in Sect. 8, but here we continue to focus on Aqua.

Calibration and MxD02 data processing are not the only upstream changes that impact the MODIS aerosol retrieval. 
Changes in geolocation data (MxD03; Wolfe et al., 2002) and cloud mask protocols (MxD35; Ackerman et al., 2010) also matter. As described in Sect. 2.2, the MODIS aerosol retrieval requires information as to whether the land" or "water" fork should be attempted. Coastlines, shorelines and riverbanks have complicated, fractal-like structure, and whether a particular pixel is land or water is uncertain. For the $\mathrm{C} 5$ aerosol retrieval, this information was read from the MxD35 file (at $1 \mathrm{~km}$ ). For the MxD35 SDS, there are four choices of water condition: land, water, coastal or desert. Yet, the information in MxD35 is actually determined from a choice of eight categories within the MxD03 (geolocation) file: land, coastal, ephemeral water, shallow inland water, deep inland water, shallow ocean, moderate ocean or deep ocean. The MxD03 categories of coastal, ephemeral water and shallow inland water all converged into "coastal" for MxD35, although in overall sense, pixels flagged as "coastal" in $\mathrm{C} 5 \mathrm{MxD} 35$ were rare.

For C6, geolocation is now dependent on a new $250 \mathrm{~m}$ resolution water mask (Carroll et al., 2009), which especially in the boreal regions of the Northern Hemisphere, classifies more area as water (http://landweb.nascom.nasa.gov/ QA_WWW/forPage/LWM_diff.html). The new water mask also identifies subpixel water contamination. Much of this subpixel area is then classified by MxD03 as "coastal" which leads to more "coastal" in MxD35. This is illustrated in Fig. 4. Without upgrades to the DT algorithm, there would be significantly more land area, especially in these boreal regions, where no aerosol is retrieved at all.

The so-called "Wisconsin" cloud mask (MxD35; Ackerman et al., 1998, 2010) has also been updated for C6 (http: //modis-atmos.gsfc.nasa.gov/products_C006update.html).

There are many changes (including the land/sea mask issue just discussed); however, most do not impact the MxD04 product. However, as discussed in the C5 aerosol ATBD (Levy et al., 2009b), the aerosol retrieval reads in results of three infrared tests that are reported in MxD35. One of these tests was changed, the tri-spectral IR temperature difference test, stored in bit 18 of the cloud mask. The MxD35 found that the "Bit 18 " test was overzealously masking clear sky as cloudy, and has replaced the test with a simpler $8.6-11 \mu \mathrm{m}$ brightness temperature threshold and difference test. The result of the change did increase cloud-free area over the ocean oceans; however, it also allowed more thin cirrus cases to be considered clear. Over tropical oceans, this tends to increase cloud contamination for the aerosol product.

Even for the exact same aerosol retrieval algorithm, the combination of changes to upstream products (calibration, L1B reporting protocol, land/sea mask, and cloud mask) leads to significant differences in the aerosol product. The consequence to the AOD retrieval resulting from this total difference in L1B is displayed in Fig. 2b. Here, we see the changes due to calibration (reduced AOD over ocean), due to land/sea mask changes (changes over Canada), and cloud mask changes (increases in tropical oceans). For global

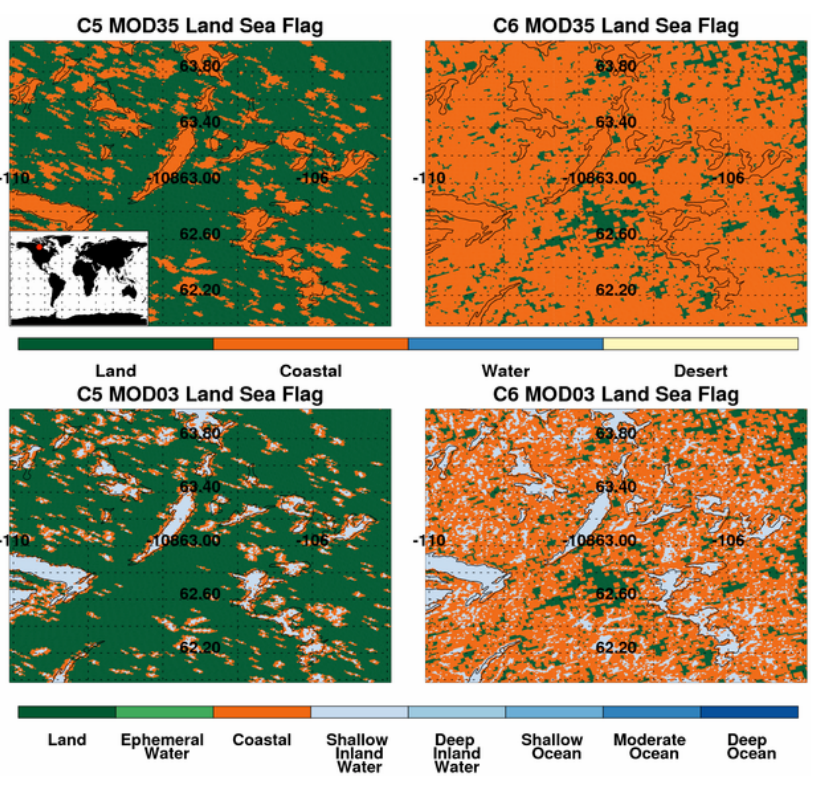

Fig. 4. Illustration of differences between C5 and C6 inputs of Land/Sea Flag, from a small region in northern Canada.

AOD, both ocean and land are reduced by 0.003 . In later sections we discuss some of the compensations made to the DT algorithms in response to these upstream changes.

\subsection{Updates to radiative transfer and LUTs}

Accurate aerosol retrieval requires accurate radiative transfer (RT) and accurate LUTs. Calculating an accurate LUT requires accurate assumptions of wavelength to calculate for. Since the MODIS LUTs include coupling of molecular scattering (Rayleigh), we also need an accurate estimate of the Rayleigh optical depth (ROD). Levy et al. (2007b) discussed the problem as applied to the $0.466 \mu \mathrm{m}$ wavelength Band 3. Specifically, since the C4 DT-land retrieval assumed $0.470 \mu \mathrm{m}$ instead of $0.466 \mu \mathrm{m}$, the ROD was assumed as 0.186 rather than 0.194 . This was corrected for $\mathrm{C} 5$, and reversed an automatic bias of at least 0.01 in retrieved AOD over the entire globe.

For C6, we explored this issue again, and for both DTland and DT-ocean. Different radiative transfer (RT) codes are used for computing the LUTs over land (Levy et al., 2007a; Evans and Stephens, 1991), and over ocean (e.g., Remer et al., 2005; Ahmad and Fraser, 1982). Motivated by studies such as Kotchenova et al. (2008), we explored whether the two LUTs would agree to within $1 \%$ criteria. They did not. Even for common geometrical conditions and a molecular-only (Rayleigh) atmosphere over a black surface, results from the two RT codes could differ by $3 \%$ or more. Some of the causes included:

- Assumptions about MODIS-band wavelength and Rayleigh optical depth (ROD) were still different over land and ocean. Neither set matched values presented 
on web pages (e.g. http://oceancolor.gsfc.nasa.gov/ DOCS/RSR_tables.html).

- The angular resolution was insufficient (quadrature angles too few).

- The subtle difference between "layers" and "levels" was confused, so that up/down transmission values over land were mistakenly computed for layer \#1 (next to the surface) rather than level \#0 (the surface).

- The over-land LUT did not include the "depolarization factor" (King, 1923; Young, 1980) for molecular dipole depolarization. It is approximately 0.0279 but varies slightly with wavelength.

- Over ocean, the RT code included correction for $\mathrm{CO}_{2}$, which was not included over land. In fact, since $\mathrm{CO}_{2}$ was already corrected for during the aerosol retrieval, this meant a double correction over ocean.

From combined Terra/Aqua MODIS-band filter functions (http://mcst.gsfc.nasa.gov/), we determined weighted center wavelengths and used formulas from Bodhaine et al. (1999) to recalculate sea level molecular ROD values (results in Appendix A). We considered unifying the land and ocean RT codes, but concluded it would introduce other complications. Instead, we corrected the issues listed. We also increased the angular/stream resolution to the limit of our computing power. Through this effort, the two RT codes had converged (to $0.1 \%$ ) in calculating TOA reflectance for a case of Rayleigh only/black surface. The net effect of taking these steps to homogenize the RT codes and aerosol LUTs resulted in a global mean increase of $0.01 \mathrm{AOD}$ over land, and a decrease of 0.005 AOD over ocean.

At the same time as deriving accurate aerosol LUTs, aerosol retrieval requires correction for the absorption of atmospheric gases. While the aerosol retrieval is performed in bands that are centered in atmospheric windows, the nontrivial width of these bands (nominally $20 \mathrm{~nm}$ ) contains absorption lines of water vapor $\left(\mathrm{H}_{2} \mathrm{O}\right)$, ozone $\left(\mathrm{O}_{3}\right)$, and other gases $\left(\mathrm{CO}_{2}, \mathrm{CH}_{4}, \mathrm{O}_{2}, \mathrm{~N}_{2} \mathrm{O}, \mathrm{NO}_{2}\right.$, etc.). However, the gas absorption corrections used for C5 included only $\mathrm{H}_{2} \mathrm{O}, \mathrm{O}_{3}$ and $\mathrm{CO}_{2}$, and being derived well before Terra launch, were not reproducible. Appendix A describes the use of the LineBy-Line RT model (LBLRTM; Clough et al., 1992, 2005) for deriving the new gas absorption coefficients used for C6. Appendix A also discusses how air mass factor is calculated and applied within the retrieval.

From Aqua, for July 2008, Fig. 5 plots gridded maps of MxD04 TOA spectral reflectance, demonstrating how the new gas corrections lead to changes to sometimes significant changes to the "observations" used to compare to LUTs and retrieve aerosol. In percentage units, relative global changes in each band $(0.47,0.55,0.65,0.86,1.24,1.64$ and $2.11 \mu \mathrm{m})$, are $+0.5 \%,-0.5 \%,+3 \%,+2 \%,+5 \%,+1 \%$ and $-1 \%$,

\section{Reflectance: Jul 2008 Aqua}
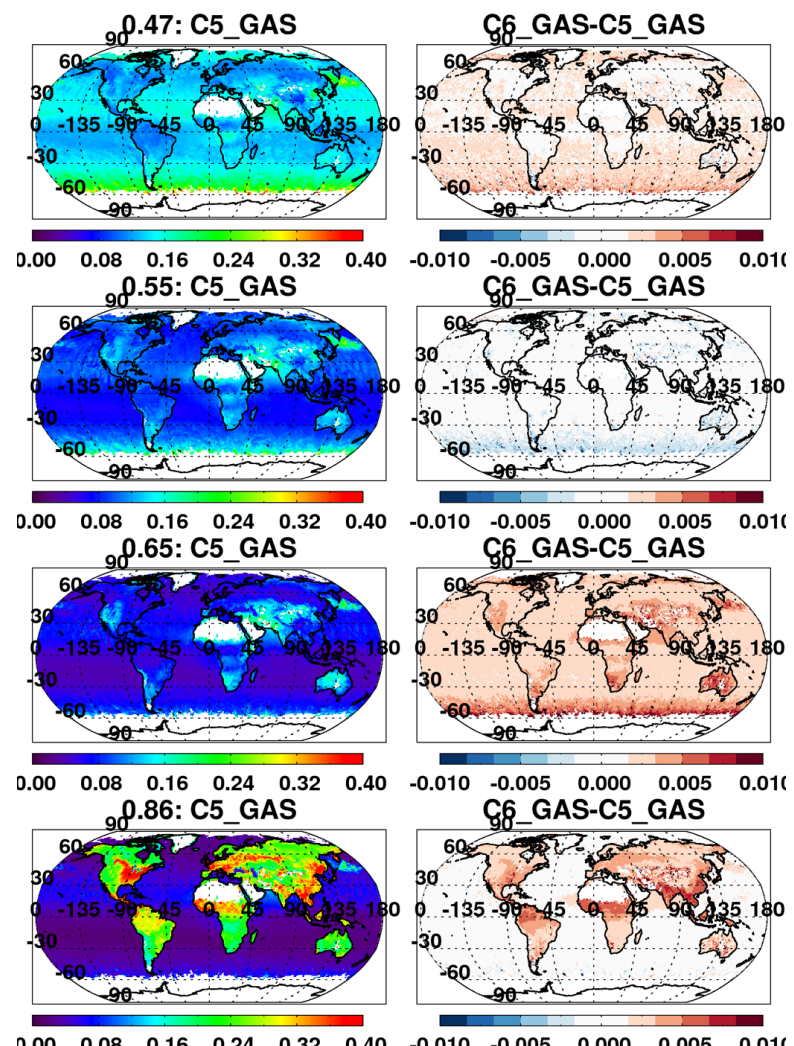

$\begin{array}{lllll}-0.010 & -0.005 & 0.000 & 0.005 & 0.011\end{array}$

C8,GAS-C5_GAS

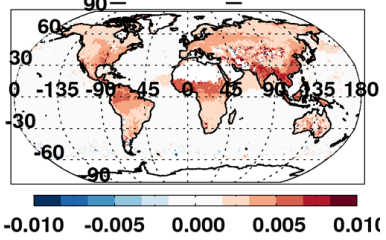

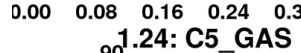

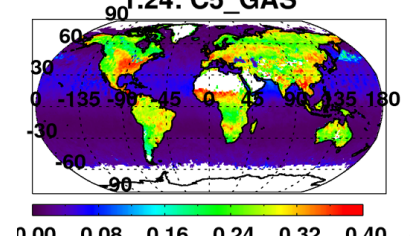

$\begin{array}{llllll}0.00 & 0.08 & 0.16 & 0.24 & 0.32 & 0.40\end{array}$
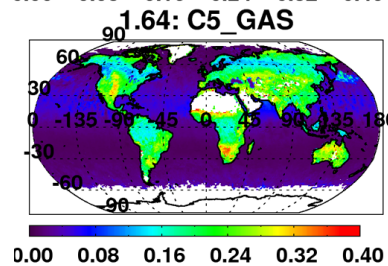
2.11: C5_GAS
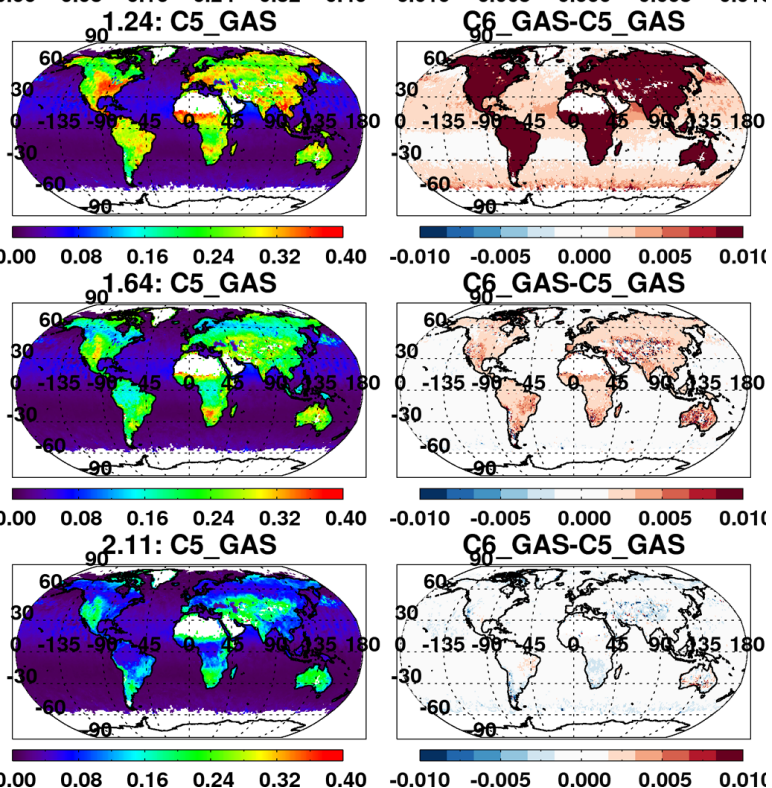

Fig. 5. Gridded "average" Level 2 reflectance from Aqua for July 2008, demonstrating impact of using new gas absorption corrections on the reflectance used to derive aerosol. For each wavelength band (each row), the left panel is produced from assumption of C5 gas absorption, and the right panel is the difference (C6-C5) when applying inputs of $\mathrm{C} 6$ gas correction. 
respectively. These changes are rather large, especially in the 0.65 and $1.24 \mu \mathrm{m}$ bands.

The updates to gas absorption have interesting impacts on retrieval of AOD. The net effect of the C6 gas correction (compared to the C5) is increase in the input reflectance values in most wavelength bands. When applying these new gas corrections, the overall, global mean AOD increased by 0.012 over both land and ocean. This result would be expected over ocean, where reflectance is systematically increased, but surprising over land. The reason is the impact of the $1.24 \mu \mathrm{m}$ channel in pre-determining the expected "VISto2.1" surface reflectance relationship. As discussed in Levy et al. (2007b), the aerosol retrieval over land uses the $1.24 \mu \mathrm{m}$ and $2.11 \mu \mathrm{m}$ channels to calculate the aerosol resistant $\mathrm{NDVI}_{\text {swir }}$, which is in turn used to estimate the VISto2.1 relationship. Figure 6 (left panel) shows a $1^{\circ} \times 1^{\circ}$ computation of $\mathrm{NDVI}_{\text {swir }}$ over land, calculated from the mean gridded values displayed in Fig. 5 (left panels). Vegetated areas have larger $\mathrm{NDVI}_{\text {swir }}$ than more arid regions. However, with the changes in $1.24 \mu \mathrm{m}$ reflectance, (right panel), there is uniform increase over all land regions, especially semiarid regions. Based on the $\mathrm{NDVI}_{\text {swir }}$ to VISto2.1 formulas in Levy et al. (2007b), the effect would be to decrease the expected surface contribution to TOA reflectance and increase the aerosols (i.e. AOD).

The other change affecting both land and ocean is the extension of retrievals to more oblique solar zenith angles that increases coverage at high latitudes. The $\mathrm{C} 5$ algorithm did not permit retrieval when the solar zenith angle $\left(\Theta_{0}\right)$ was larger than $72^{\circ}$. There were no aerosol retrievals made for relatively high latitude regions during low-light seasons, even though interesting aerosol events were seen in MODIS imagery (Crusius et al., 2011). Motivated to increase coverage of these events, we added solar zenith angles of $\Theta_{0}=78^{\circ}$ and $\Theta_{0}=84^{\circ}$ to both ocean and land LUTs, after confirming with the authors of the RT codes (Z. Ahmad, personal communication, 2011) that slant path errors should not be too large at these angles. The Fig. S8 (Supplement) within Crusius et al. (2011), demonstrates that relaxing the solar zenith angle threshold $\left(\Theta_{0} \leq 84^{\circ}\right)$ enables retrievals of dust in the Gulf of Alaska. It allows more granules to be processed (to include granules from orbits in partial darkness), and increases coverage for the pixels that are already processed. Overall, when applied to the multiple months of data the new threshold adds approximately $1 \%$ and $8 \%$ to the number of valid aerosol retrievals over land and ocean, respectively. Preliminary comparison to AERONET concluded that accuracy was not compromised.

To summarize, this section has introduced only the C6 changes that were intended to homogenize radiative transfer assumptions (wavelength bands, Rayleigh optical depths and gas absorption corrections) and increase satellite retrieval coverage (larger solar zenith angles). Figure $2 \mathrm{c}$ shows the differences in aggregated Level 2 data from Aqua for July 2008, on $1^{\circ} \times 1^{\circ}$ gridding, where the aerosol retrieval algorithm

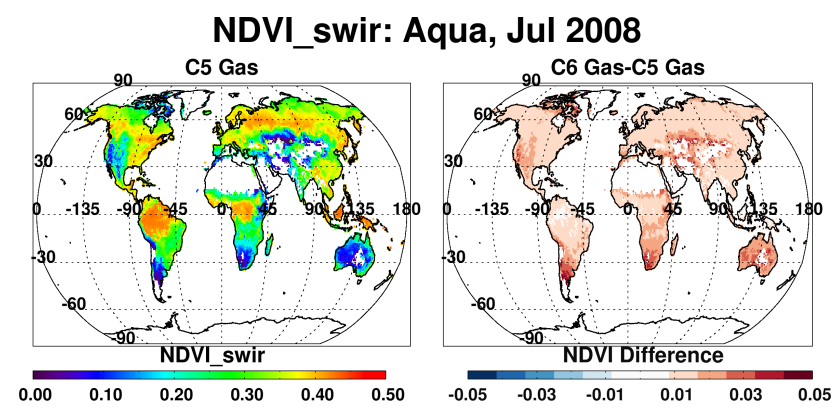

Fig. 6. Impact of gas correction assumptions on calculations of $\mathrm{NDVI}_{\text {swir. }}$ The left panel is the $1^{\circ} \times 1^{\circ} \mathrm{NDVI}_{\text {swir }}$ as calculated if using $\mathrm{C} 5$ gas correction assumptions, whereas the right panel is the impact of substituting the C6 assumptions (C6-C5).

(C5-like) and the inputs (C6 L1B and ancillary data) are held constant. Only the gas coefficients and LUTs have changed. From "old" (C5 aerosol with C6 inputs) to "new" (C5 aerosol with C6 inputs, but with new gas absorption and consistent RT coding), the overall AOD increase over ocean (by 0.008) is small, but the increase over land (by 0.022) is large.

\subsection{Changes for DT-land}

The C5 over land DT retrieval had been carefully validated using collocated sun photometer measurements (Levy et al., 2010; Bréon et al., 2011). These studies showed that, overall, the MODIS DT-land AOD is well correlated with the SP and matches within a defined expected error envelope. However, these studies also show regional situations with much poorer accuracy. Sometimes this degradation of accuracy occurs at high AOD, where model assumptions dominate the error. Such locations include South America during the biomass burning season where the slope between MODIS and SP data is much higher than 1.0, suggesting there is too much absorption in the assumed aerosol model (Ichoku et al., 2003). Sometimes the degradation of accuracy occurs at low AOD, where land surface reflectance assumptions dominate the error. For example, urban surfaces (Jethva et al., 2007; Oo et al., 2010) and dry, reddish soils are brighter in the visible than expected, which introduces positive offsets that can be as high as 0.2 . Very dark, dense vegetation sometimes creates an underprediction of visible surface reflectance, which introduces negative offsets and AOD. The following sections investigate the possibilities of modifying the $\mathrm{C} 5$ aerosol model and surface reflectance assumptions to make these regional improvements while not compromising the excellent global validation. Not all of the studied modifications were eventually implemented into the C6 algorithm.

\subsubsection{Assumed aerosol type and optical properties}

This section discusses changes to the assumed aerosol model types over land. When C5 was developed, the aerosol 
climatology was based on cluster analysis of all AERONET almucantar and size distribution retrievals archived through 2005 (Levy et al., 2007a). Since that time, there have been thousands of size distribution retrievals at the same and additional AERONET sites around the globe. In addition, there have been many updates to the AERONET retrieval itself (http://aeronet.gsfc.nasa.gov) including updates of nonspherical dust assumptions and retrieval of non-spherical fraction (Dubovik et al., 2006). Instead of using the same surface reflectance assumptions for all almucantar inversions, the newer Version 2 inversion products use surface spectral albedo climatology as determined by MODIS (Holben et al., 2006). According to studies of the version 2 AERONET products, retrieved size distributions, refractive indices and single scattering albedos, at least at some sites, have changed significantly from those reported for Version 1 (Giles et al., 2012). Since there have been changes to AERONET climatology, we investigated whether the MODIS aerosol model assumptions, based on this climatology, would require an update.

Using the same methodology as described by Levy et al. (2007a), we performed a cluster analysis of the entire AERONET climatology through 2010. Surprisingly, while a few sites showed significant differences from that observed by the prior analysis, the overall pattern was unchanged. In general, the global aerosol type could be separated into finemode dominated (fine models) and coarse-mode dominated (coarse models), with the fine models further separated into being strongly absorbing, moderately absorbing and weakly absorbing. Although there were slight changes for each fine model's optical properties, they were not significant enough to justify revision. Thus, for C6, the Table 1 from Levy et al. (2007a) remains valid for the fine-model aerosol optical properties.

Like as discussed by Levy et al. (2007a) the clustering procedure also determined the "dominant" aerosol type at each site, as a function of season. While the overall spatial distribution remained the same as defined for $\mathrm{C} 5$, there was much larger AERONET sampling, and more opportunity to fine-tune the model distribution borders. Figure 7 shows the global, seasonal distribution of aerosol type selection that is applied for C6. The obvious change from C5 is that the border contours are now drawn by hand, to account for mountainous terrain that separate aerosol regimes. Differences are seen over the Amazon (aerosol is now assumed moderately absorbing, consistent with Schafer et al., 2008), over southeastern Asia (now more absorbing), and over the western United States (now clearly separated by the Rocky mountains).

Clustering of the coarse model cases was also performed. Unlike pre-C5, we saw significant variety for absorption properties of coarse-mode, non-spherical aerosol. Over regions such as northern India, about $30 \%$ of the cases suggested the presence of an absorbing coarse-mode aerosol having visible-band $\mathrm{SSA}<0.90$. However, there was no
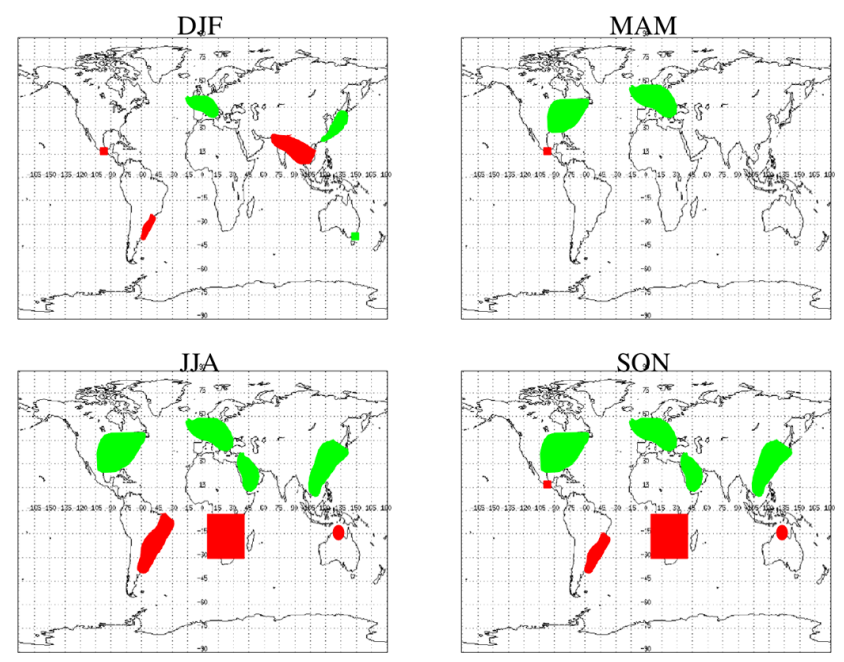

Fig. 7. New fine model map for four seasons: Northern Hemisphere winter, spring, summer, fall. For each map, over land regions, red (green) mark where strongly absorbing (weakly absorbing) aerosol models are assumed. Areas with no color are assumed as moderately absorbing.

obvious pattern that separated between "clean" dust days with low absorption (SSA > 0.95) and "dirty" dust days with higher absorption. Sensitivity tests showed that if we could correctly assign the more absorbing coarse model, the MODIS aerosol retrieval might have more sensitivity to FMF. To test, we created an absorbing coarse dust model LUT, and allowed the operational MODIS code to try and retrieve it. However, in practice, the more absorbing dust model did not give the MODIS operational algorithm any new skill. The variability of the surface was still dominating, so that a combination of absorbing dust and non-absorbing fine model was not sufficiently better than a combination of non-absorbing dust and absorbing fine model. Thus, without a clear logic for choosing between absorbing and nonabsorbing dust in the MODIS aerosol retrieval, we chose to keep only the single coarse model type (weakly absorbing, non-spherical dust); the coarse model is unchanged from C5.

\subsubsection{Land surface assumptions}

The C5 MODIS land product did not compare as well to AERONET in regions with brighter surfaces and/or mountainous terrain (e.g., US southwest, Mongolia, etc.). As the algorithm is tuned towards dark, vegetated targets, this result was not surprising. However, given that the MODIS data set had doubled since 2005 and AERONET included many new sites, we attempted to reformulate the assumed surface spectral VISto2.1 relationship (Kaufman et al., 2005; Levy et al., 2007b). Similar to the procedure described by Levy et al. (2007b), atmospheric correction was performed over the entire collection of MODIS/AERONET collocations. There were differences between these results and those using the 
Table 1. C6 DT-land data products and changes from C51.

\begin{tabular}{|c|c|c|c|}
\hline C5 SDS & C6 SDS & C6 dimension & $\begin{array}{l}\text { Noted changes from } \\
\text { C5 to C6 }\end{array}$ \\
\hline Corrected_Optical_Depth_Land & Corrected_Optical_Depth_Land & $X, Y, 3 \mathrm{a} \lambda$ & \\
\hline Corrected_Optical_Depth_Land_wav2p1 & Corrected_Optical_Depth_Land_wav2p1 & $X, Y:($ at $2.11 \mu \mathrm{m})$ & \\
\hline Optical_Depth_Ratio_Small_Land & Optical_Depth_Ratio_Small_Land & $X, Y:($ at $0.55 \mu \mathrm{m})$ & \\
\hline Surface_Reflectance_Land & Surface_Reflectance_Land & $X, Y, 3 \mathrm{a} \lambda$ & \\
\hline Fitting_Error_Land & Fitting_Error_Land & $X, Y:($ at $0.65 \mu \mathrm{m})$ & \\
\hline Quality_Assurance_Land & Quality_Assurance_Land & $X, Y, 5 \mathrm{~B}$ & \\
\hline Aerosol_Type_Land & Aerosol_Type_Land & $X, Y$ & \\
\hline Angstrom_Exponent_Land & & & deleted \\
\hline Mass_Concentration_Land & Mass_Concentration_Land & $X, Y$ & \\
\hline Optical_Depth_Small_Land & & $X, Y, 4 \lambda$ & deleted \\
\hline Mean_Reflectance_Land & Mean_Reflectance_Land & $X, Y, 10 \lambda$ & Added 3 wavelengths \\
\hline STD_Reflectance_Land & STD_Reflectance_Land & $X, Y, 10 \lambda$ & Added 3 wavelengths \\
\hline Cloud_Fraction_Land & Aerosol_Cloud_Fraction_Land & $X, Y$ & Renamed \\
\hline Number_Pixels_Used_Land & Number_Pixels_Used_Land & $X, Y, 10 \lambda$ & Separate tally each $\lambda$ \\
\hline Path_Radiance_Land & & & deleted \\
\hline Error_Path_Radiance_Land & & & deleted \\
\hline Critical_Reflectance_Land & & & deleted \\
\hline Error_Crit_Reflectance_land & & & deleted \\
\hline Error_Critical_Reflectance_Land & & & deleted \\
\hline Quality_Weight_Path_Radiance_Land & & & deleted \\
\hline \multirow[t]{2}{*}{ Quality_Weight_Crit_Reflectance_Land } & & & deleted \\
\hline & Topographic_Altitude_Land & $X, Y$ & New diagnostic \\
\hline
\end{tabular}

$X, Y$ refers to a 2-dimensional array along/across the swath (at a particular wavelength $\lambda$ ). Some parameters have a third dimension. A dimension of "\# $\lambda$ " refers to \# wavelengths. \# = 3a: $0.47,0.55$ and $0.65 \mu \mathrm{m}$. \# = 3b: $0.47,0.55$ and $2.11 \mu \mathrm{m}$. \# = 4: $0.47,0.55,0.65$ and $2.11 \mu \mathrm{m} . \#=7: 0.47,0.55,0.65,0.86,1.24,1.63$ and $2.11 \mu \mathrm{m}$. \# = 10: $0.47,0.55,0.65,0.86,1.24,1.63,2.11,0.41,0.44$ and $0.76 \mu \mathrm{m}$. A dimension of " $5 \mathrm{~B}$ " refers to the number of bytes (5) of the QA Flags.

2005 data base. However, any attempt to tune a new parameterization relating VIS surface reflectance to $2.11 \mu \mathrm{m}$ reflectance using these new results introduced no improvement compared to C5.

However, even though theoretically the land surface parameterization will remain unchanged from that described in Levy et al. (2007b), in practice a large change will be implemented in C6. On more than one occasion, the MODIS data users have inquired about the validity of the $\mathrm{NDVI}_{\text {swir }}$ in estimating the VISto2.1 relationships. Personal communications (L. Yang, 2012; P. Gupta, 2011) had suggested that Fig. 3 and Eq. (10) from Levy et al. (2007b) were both counterintuitive. We determined that the plot legend had been reversed, as well as the equation, which had also been coded into the software. Thus, for C6, we fix this mistake, and the expected impact to the global picture is shown in Fig. $2 \mathrm{~g}$. The bug affected how the assumed surface reflectance is dependent on NDVISWIR. Fixing the bug creates a large change in the retrieved AOD and introduces a distinctive spatial pattern in which AOD increases over vegetated surfaces and decreases over arid surfaces.

We also considered alternatives to surface reflectance parameterization. One idea was to abandon the on-the-fly VISvs2.1 assumptions and instead rely on climatology of MODIS albedo (e.g., Moody et al., 2005, 2008; Schaaf et al.,
2011). While direct application of gridded MODIS-derived albedo (instead of surface reflectance) introduced significant errors to the aerosol retrieval, we saw promise when using ratios of spectral surface albedo in place of assumed VISvs2.1 parameterization. In general, improvements were made (reducing bias compared to AERONET) in the relatively brighter arid regions without harming the comparisons over most vegetated surfaces. However, without discussing details, successful application of the albedo data set required a huge amount of processing and computer overhead, and we found issues with latitude/longitude registration over highly heterogeneous surfaces (e.g., urban areas). Therefore, while the application of surface albedo climatology may be a good step for the future, we decided to abandon this approach for now. For C6, we use the VISvs2.1 surface reflectance parameterization but with reversed NDVI $_{S W I R}$ dependence, originally introduced for C5 (Levy et al., 2007b).

\subsubsection{Cloud mask and pixel selection over land}

The success of the MODIS dark-target retrieval depends on its ability to throw out unsuitable pixels. At a minimum, the over-land DT algorithm throws out $70 \%$ of the observed $500 \mathrm{~m}$ resolution data, (darkest $20 \%$ and $50 \%$ brightest when sorted by $0.66 \mu \mathrm{m}$ reflectance). However, in most 
cases, some pixels are completely unsuitable for aerosol retrieval, including clouds, snow and inland water bodies.

The most critical step is accurate cloud masking. Failure to fully remove clouds leads to cloud contamination, and too strong a cloud mask leads to insufficient aerosol coverage. Because the standard MODIS cloud mask (MxD35_L2) is designed to mask pixels that are unsuitable for land-surface retrieval (clouds and heavy aerosol loadings) and at the same time find pixels suitable for cloud product retrieval (not aerosol), it was viewed to be both overly cloud conservative and yet not clear-sky conservative enough for aerosol retrieval (Remer et al., 2012). Therefore, based on unpublished work analogous to Martins et al. (2002), the overland aerosol retrieval applies tests for visible-band $(0.47 \mu \mathrm{m})$ brightness and spatial variability at $500 \mathrm{~m}$ resolution, in conjunction with tests for brightness and variability in $1.38 \mu \mathrm{m}$ (the "cirrus" channel) at $1 \mathrm{~km}$. Values for C5 thresholds were based on visual analyses of multiple granules and statistical analyses of global data, and were documented in the online C5-ATBD (Levy et al., 2009b).

However, both Witte et al. (2011) and van Donkelaar et al. (2011) noted that operational MODIS aerosol retrieval failed to capture the extreme Russian fire events of 2010. Although in some cases the retrieval failed because the final value of AOD (> 5.0) was extrapolated outside of the lookup table, there were also many cases where failure occurred because the aerosol cloud mask thresholds were exceeded. Retrieval of the extremely heavy smoke (AOD $\gg 1.0$ ) in the middle of the plumes required either turning off the cloud mask, or finding a suitable aerosol "call-back" test. Since fine-dominated smoke has weaker signal in $2.11 \mu \mathrm{m}$ than $0.47 \mu \mathrm{m}$, and the region around Moscow has relatively small surface spatial variability at $2.11 \mu \mathrm{m}$, clouds and smoke might be separated by the spectral dependence of their spatial variability. Thus a $2.11 \mu \mathrm{m}$ spatial variability test $\left(\sigma_{2.11}\right.$ was implemented, such that areas that failed the $0.47 \mu \mathrm{m}$ variability test could be recovered by passing the new $2.11 \mu \mathrm{m}$ test. Aerosol coverage for the Moscow fires was increased by $20 \%$.

While successful for the Moscow region, the $2.11 \mu \mathrm{m}$ aerosol recovery test did not work globally. Surface variability at $2.11 \mu \mathrm{m}$ is often so much larger than it is at $0.47 \mu \mathrm{m}$, so that the combined surface/aerosol variability may be indistinguishable from clouds. While looking for alternatives, we found that combining two $0.47 \mu \mathrm{m}$ spatial variability tests sometimes could help. There is the "absolute standard deviation" of the reflectance within a $3 \times 3$ box (std_ 047 or $\sigma_{0.47}$, as well as the "mean weighted standard deviation" (mstd_047 or $\sigma_{0.47}^{*}$,

$\sigma^{*}=\sigma \bar{\rho} / \sqrt{n}$

where $\bar{\rho}$ is the mean reflectance (mean_047) and $n=9(3 \times 3$ pixel box). Since the possibility of being flagged as "cloud" increases with both the variability and the magnitude of the reflectance, the $\sigma^{*}$ test might be mistaking brighter, less variable smoke for darker, more variable clouds, which could be called back with regular $\sigma$. Therefore, instead of using a $2.11 \mu \mathrm{m}$ test to recover heavy aerosol, C6 will use regular standard deviation $\left(\sigma_{0.47}\right)$ as an aerosol call back test. This is in addition to the mstd_047 test that is retained from C5.

Thus, the C6 over-land cloud mask is a combination of tests using absolute magnitude and spatial variability at $0.47 \mu \mathrm{m}$ (500 m resolution) and $1.38 \mu \mathrm{m}$ ( $1 \mathrm{~km}$ resolution). Based on analyses of many individual granules, plus statistics of global, monthly data, the C6 cloud detection thresholds are set as follows. A given $500 \mathrm{~m}$ pixel is flagged as a cloud if the $0.47 \mu \mathrm{m}$ reflectance exceeds $0.4\left(\rho_{0.47}>0.4\right)$. For each $3 \times 3$ box of $500 \mathrm{~m}$ pixels, the center pixel is flagged as cloud if both $\left(\sigma_{0.47}^{*}>0.0025\right.$ and $\left.\sigma_{0.47}>0.0075\right)$. A given $1 \mathrm{~km}$ pixel is flagged as cloud if $\rho_{1.38}>0.025$. For each $3 \times 3$ box of $1 \mathrm{~km}$ pixels, the center pixel is flagged if $\sigma_{1.38}>0.003$. Note there is no $\sigma_{1.38}^{*}$ test. Finally, if any one $1 \mathrm{~km}$ pixel is indicated as cloud then the entire $2 \times 2$ box of $500 \mathrm{~m}$ pixels are considered cloud. Note that except for addition of the $\sigma_{0.47}$ requirement, all other tests and thresholds are identical to that used for C5. The final result is a binary cloud mask (yes or no) at $500 \mathrm{~m}$ resolution, which is saved in memory and used to filter pixels for final aerosol retrieval. Figure 8 is an example of a granule over northeastern South America, where 533 new pixels (5\% increase from 10108 ) have been retrieved when including the $\sigma_{0.47}$ requirement. Note that the additional pixels retrieved for $\mathrm{C} 6$ are located in areas of low optical depth $(\tau<0.15)$ as well as areas of high optical depth ( $\tau>0.75$ ) within the smoke plume. The impact of the revised cloud mask can be seen in Fig. 2e (land areas).

\subsubsection{Quality assurance over land}

The run-time Quality Assurance (QA) Plan (Hubanks, 2012) over land is essentially unchanged from C5. There are multiple tests to assess the input data, the logical flow of the algorithm, and then the believability of the results. The results of the many individual QA tests, lead to an estimate of the overall quality confidence (QAC) of the retrieved products. All QA information is coded into a five-byte SDS, such that different bits represent the results of individual tests, and are described in more detail in the Appendix.

For example, one such QA test asks whether there are a sufficient number of non-screened pixels to make a robust aerosol retrieval. If more than 50 pixels remain (out of a possible 120 , which is in turn a $70 \%$ exclusion of the original $400)$, then $\mathrm{QAC}=3$. More than 30,20 and $12(10 \%$ of 120$)$ result in $\mathrm{QAC}=2,1$ and 0 , respectively. Fewer pixels suggest increasingly marginal conditions in the retrieval box, and the retrieved AOD is expected to be less accurate.

In addition to explicit cloud masking (determining which pixels to exclude from the aerosol retrieval), the retrieval uses other tests to determine if clouds might be present and possible source of aerosol contamination. One such test is the 


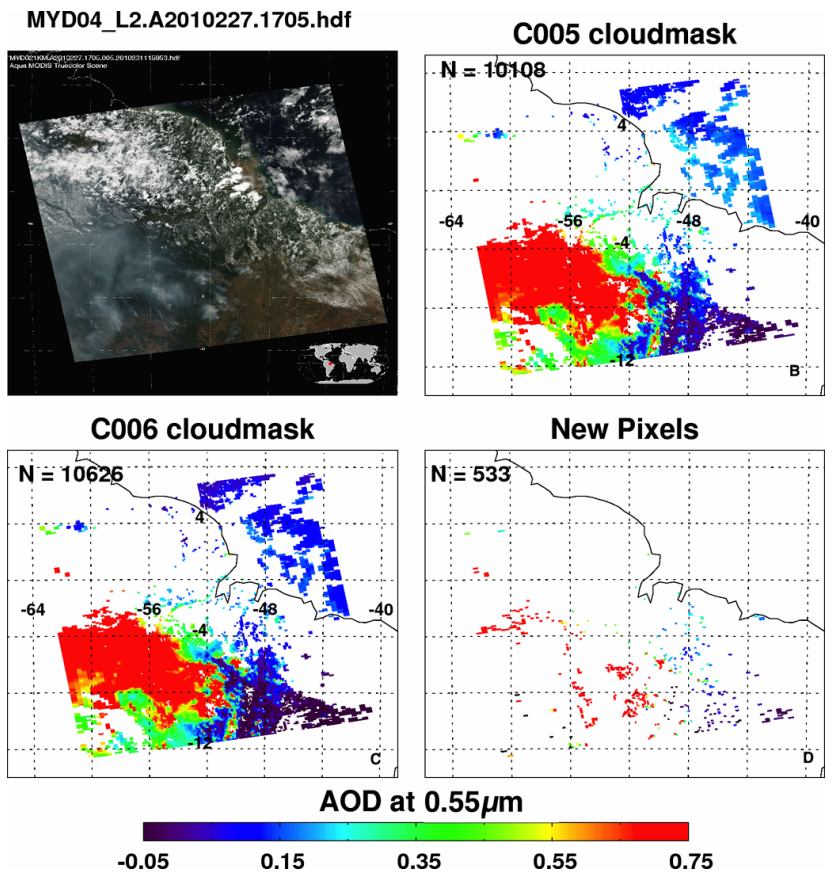

Fig. 8. Granule retrieved over northeastern South America from MODIS-Aqua on 15 August 2010 at 17:05 UTC. Top left: truecolor (RGB) showing smoke and cloud scene taken from modisatmos.gsfc.nasa.gov. (b and $\mathbf{c}$ ) Retrieved high quality ( $\mathrm{QAC}=3$ over land and $\mathrm{QAC} \geq 1$ over ocean) $\mathrm{AOD}$ at $0.55 \mu \mathrm{m}$, without and with the $0.47 \mu \mathrm{m}$ cloud mask call-back (standard deviation test) over land. (d) New (smoke) pixels over land that have been reclaimed.

thin-cirrus test. While pixels with $\rho_{1.38}>0.025$ are considered to be "cloud" and masked, pixels with $\rho_{1.38}>0.01$ are used, but flagged as "thin cirrus". These pixels may have residual contamination, but are included in the aerosol retrieval. If any "thin cirrus" pixels are present, the entire retrieval is tagged and the QAC reduced to 0 .

Yet, while this "thin cirrus" test was included within the C5 algorithm, the test was coded in error, such that if the $\mathrm{QAC}=0$ tag could be overwritten. In some of these cases, "thin cirrus" detection was mistakenly assigned $\mathrm{QAC}=3$ (high quality). This coding logic error led to biased AOD statistics, especially over tropical land surfaces. Figure 9 shows a granule with clouds visible in the middle-right of the true-color RGB image over Africa. Without the cirrus coding fix, there were potentially cirrus-contaminated pixels that would have been tagged with $\mathrm{QAC}=3$. With the fix, highconfidence AOD data are not retrieved as close to this cloudy area, resulting in a $10 \%$ pixel reduction for this granule. The overall impact of the cirrus fix to the monthly AOD is shown in Fig. 2d, where the bulk of the changes are in tropical land regions where the AOD has decreased. When including both the $\sigma_{0.47}$ call-back test (Sect. 4.4.3) and this $\rho_{1.38}$ thin-cirrus correction, results in a near cancel of the positive and negative impacts. There is a modest increase (less than $0.1 \%$ ) in the the number of global high-quality pixels.
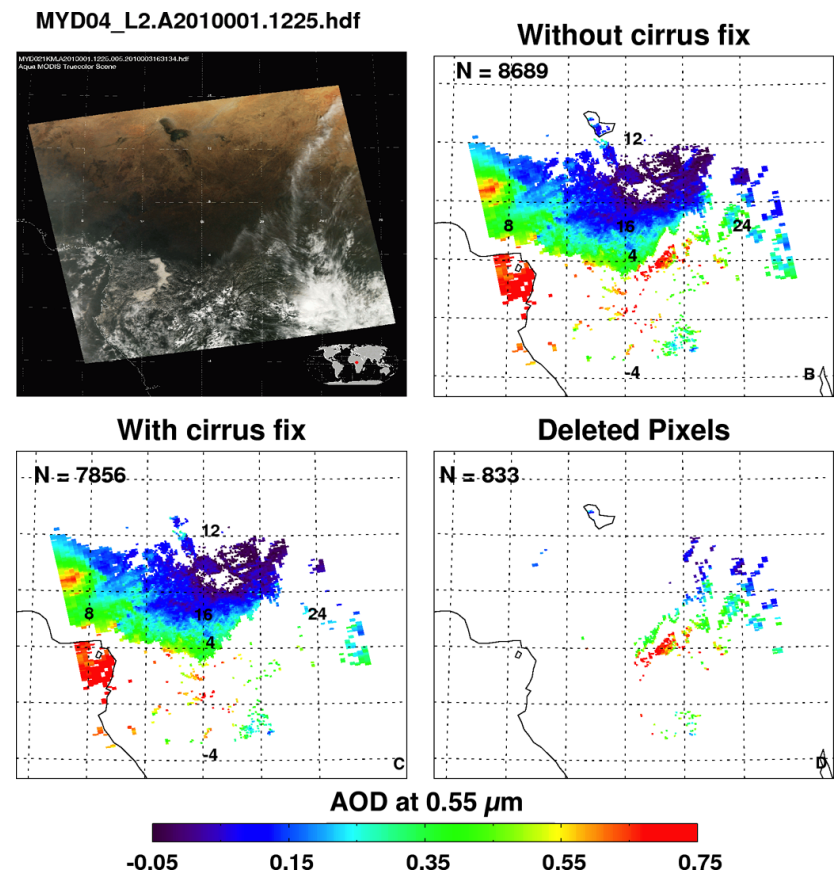

Fig. 9. MODIS-Aqua granule over central Africa, observed on 1 January 2010 at 12:25 UTC. Top left: true-color image constructed from red/green/blue channels [modisatmos.gsfc.nasa.gov). (b and c) Retrieved, high quality (QAC $=3$ over land, $\mathrm{QAC} \geq 1$ over water) $\mathrm{AOD}$ at $0.55 \mu \mathrm{m}$ before/after the cirrus bug fix. (d) Pixels that have been deleted over land as a result of degraded QAC.

Other than the changes to logic related to the cirrus flag, the QA plan for C6 over land remains the same as for C5. Table $\mathrm{C} 1$ in the Appendix details the QA plan applied for c6.

\subsubsection{Deleted and new over-land products}

For the Level 2 product (MxD04_L2), the list of over-land SDSs in C6 are compared to those from C5 (Table 1). The most significant change is that the ETA parameter (FMF: Optical_Depth_Ratio_Small_Land) will be the only reported aerosol size characteristic. On a global basis, we and others have found little quantitative skill in MODIS-retrieved aerosol size parameters over land (e.g., Levy et al., 2010; Mielonen et al., 2011). We have decided to discontinue further attempts at validating Ångström Exponent (AE) and fine-AOD. However, since the ETA parameter is part of the retrieval solution, and a necessary diagnostic, it will continue to be reported for C6. A user can still choose to derive $\mathrm{AE}$ (from spectral AOD) or fine-AOD (from product of $\tau \eta$ ) and evaluate the results themselves.

For C6, there are new, deleted, and renamed products (see Table 1). The diagnostic product, "Topographic_Altitude_Land" is new, and represents the elevation of the land target's center. We now report 
dark-target reflectance ("Mean_Reflectance_Land") and subpixel $(1 \mathrm{~km}$ resolution) counts in three additional wavelengths $(0.41,0.44$ and $0.76 \mu \mathrm{m})$. To reduce confusion related to an experimental product that was never properly validated, all SDSs related to calculation of critical reflectance and path radiance have been deleted. Finally, to reduce confusion between users of the MODIS "Aerosol" cloud mask, and the "Wisconsin" cloud mask (MxD35_L2), our internal cloud mask fraction has been renamed to "Aerosol_Cloud_Fraction_Land". Although the "Corrected_" prefix of "Corrected_Optical_Depth_Land" may be misleading to some users (there is only one retrieval and nothing to correct), a sufficient number of MODIS data users requested the SDSs name be continued for C6, and thus it remains unchanged.

\subsubsection{Global AOD resulting from all changes over land}

At this point, we have introduced the changes applied to the DT-land aerosol retrieval algorithm, including changes to Rayleigh assumptions, gas correction, aerosol retrieval boundaries, cirrus fix, cloud mask, and QAC revision. How do all these changes affect the DT-land aerosol products on a global scale?

As discussed in Sect. 3, we processed eight full months of aerosol products from Aqua (January and July from 2003, 2008 and 2010, plus April and October from 2008). Table 2 reports global, Level 2 pixel statistics for the four months in 2008, illustrating the following changes:

- There are additional granules processed for C6 as compared to $\mathrm{C} 5$, which also increases the potential aerosol sampling (15\% increase for Total PixCount).

- The net result is approximately 2-3\% additional coverage (Valid PixCount), depending on month.

- The QAC (overall Confidence) is reduced. There is near doubling of retrievals with $\mathrm{QAC}=0$, which better illustrates the confidence related to "coastal" retrievals and retrievals near clouds. Cases of $\mathrm{QAC}=3$ (which is the recommended QAC filter over land) are reduced on the order of $10 \%$.

- For the filtered, QAC=3 data), global mean AOD decreased sharply in January (from 0.195 to 0.179 ) and in April (from 0.203 to 0.183), increased during July (from 0.130 to 0.149 ), and remained nearly constant in October (0.165 to 0.164$)$.

Plotted in Fig. 10 are histograms for the same four months in 2008, showing filtered AOD data for both C5 (red) and C6 (blue). In January and April, we see that, while the number of near-zero AOD retrievals (e.g. less than 0.05) remain constant, the number of moderate (less than 0.4) and high AOD (greater than 0.4) retrievals are reduced. In July, the number of near-zero AOD retrievals is reduced while the higher
AOD number is constant. Finally, in October, only the number of moderate AOD cases is impacted (reduced). Because of the negative value bins, a log-normal plot cannot be created, however the selection of bins is suggestive of log scale (adding a constant), and that regardless of season, the median is near 0.05 . The large number of negative AOD retrievals will remain a problem for C6. On the other hand, with mean global mean AOD being greater than 0.15 in all months, we see that much of the globe is actually very clean (retrieved AOD within \pm 0.05 of zero).

Returning to Figs. 1 and 2, one can see where the C6 algorithm produces the largest absolute changes. In general, changes in AOD are largely positive over the tropics, especially in the northern part of South America and southeast Asia, while changes are largely negative over mid-latitude continents. Some of these changes are large (0.1). While all factors discussed above in Sects. 4.2 to 4.4, and illustrated in the different panels of Fig. 2, contribute to the net effect seen in Fig. 1, the global spatial pattern is very much linked to the changes introduced into $\mathrm{C} 6$ from correcting the surface reflectance ratio dependency on $\mathrm{NDVI}_{\text {SWIR }}$ (panel g) and to changes in the cloud mask in East Asia and other places with high AOD smoke (panel e). Only in the US Midwest, equatorial Africa and northern Australia, are there changes resulting from the updated assumed aerosol model boundaries (Sect. 4.1).

\subsubsection{Comparison of AOD over land with AERONET}

We see now how the global picture looks for C6, how well does it compare with with AERONET? In Fig. 11, we compare MODIS versus AERONET, for the entire eight months of Aqua test data. Here, we use the revised protocol developed by Petrenko et al. (2012), where satellite and sun photometer are compared within a spatial radius of $\pm 25 \mathrm{~km}$ and a temporal interval of $\pm 30 \mathrm{~min}$. A valid collocation is one where there are at least three MODIS pixels and two sun photometer measurements within the spatial/temporal window. While there is a decrease in total filtered pixel counts between $\mathrm{C} 5$ and $\mathrm{C} 6$, there is a $6 \%$ increase in the number of valid MODIS/AERONET collocations. Although there might be less MODIS sampling in the cloudy tropics (few or no AERONET sites), there is increased MODIS coverage where there are AERONET sites to match with (e.g. northern Europe with low sun angles). Although the slope and offset of the regression curve changes slightly between $\mathrm{C} 5$ and $\mathrm{C} 6$, the high skill at retrieving AERONET-observed AOD is retained. Overall, for C6, the correlation is $R=0.86$, and that $69.4 \%$ of MODIS AOD fall within expected uncertainty of $\pm(0.05+15 \%)$. Like Levy et al. (2010), we plot MODISAERONET (e.g. MODIS error) compared to equal frequency bins of AERONET AOD. Overall, the pattern is unchanged from $\mathrm{C} 5$ to $\mathrm{C} 6$, however, there is improvement for the lowest AOD bins. Much of this improvement comes from reversing the NDVI ${ }_{\text {SWIR }}$ dependence, and resulting retrieval of lower 
Table 2. C5/C6 Comparison of DT-land statistics for Aqua; January, April, July and October 2008.

\begin{tabular}{|c|c|c|c|c|c|c|c|c|c|c|}
\hline Month & $\mathrm{COOX}$ & $\begin{array}{r}\text { Granule } \\
\text { Count }\end{array}$ & $\begin{array}{r}\text { Total } \\
\text { PixCount }\end{array}$ & $\begin{array}{r}\text { Valid } \\
\text { PixCount }\end{array}$ & QA0 & QA1 & QA2 & QA3 & $\begin{array}{r}\text { Filtered } \\
\text { PixCount }\end{array}$ & $\begin{array}{r}\text { Mean } \\
\text { AOD } \\
\text { Filtered }\end{array}$ \\
\hline Jan & $\mathrm{C} 005$ & 4158 & 114005610 & 3187292 & 521140 & 365688 & 469625 & 1830839 & 1830839 & 0.1951 \\
\hline Jan & $\mathrm{C} 006$ & 4816 & 132046605 & 3253880 & 941393 & 291971 & 366687 & 1653829 & 1653829 & 0.1789 \\
\hline Apr & $\mathrm{C} 005$ & 4014 & 110057400 & 4335817 & 756950 & 545946 & 704984 & 2327937 & 2327937 & 0.2038 \\
\hline Apr & $\mathrm{C} 006$ & 4637 & 127136115 & 4427344 & 1472804 & 421636 & 534469 & 1998435 & 1998435 & 0.1830 \\
\hline Jul & $\mathrm{C} 005$ & 4132 & 113265405 & 7454064 & 1032922 & 885790 & 1146568 & 4388784 & 4388784 & 0.1300 \\
\hline Jul & $\mathrm{C} 006$ & 4763 & 130592655 & 7688190 & 1945905 & 771671 & 977257 & 3993357 & 3993357 & 0.1491 \\
\hline Oct & $\mathrm{C} 005$ & 4175 & 114472170 & 5099319 & 962804 & 635469 & 822342 & 2678704 & 2678704 & 0.1657 \\
\hline Oct & $\mathrm{C} 006$ & 4858 & 133198155 & 5373753 & 1518307 & 541475 & 700534 & 2613437 & 2613437 & 0.1635 \\
\hline
\end{tabular}
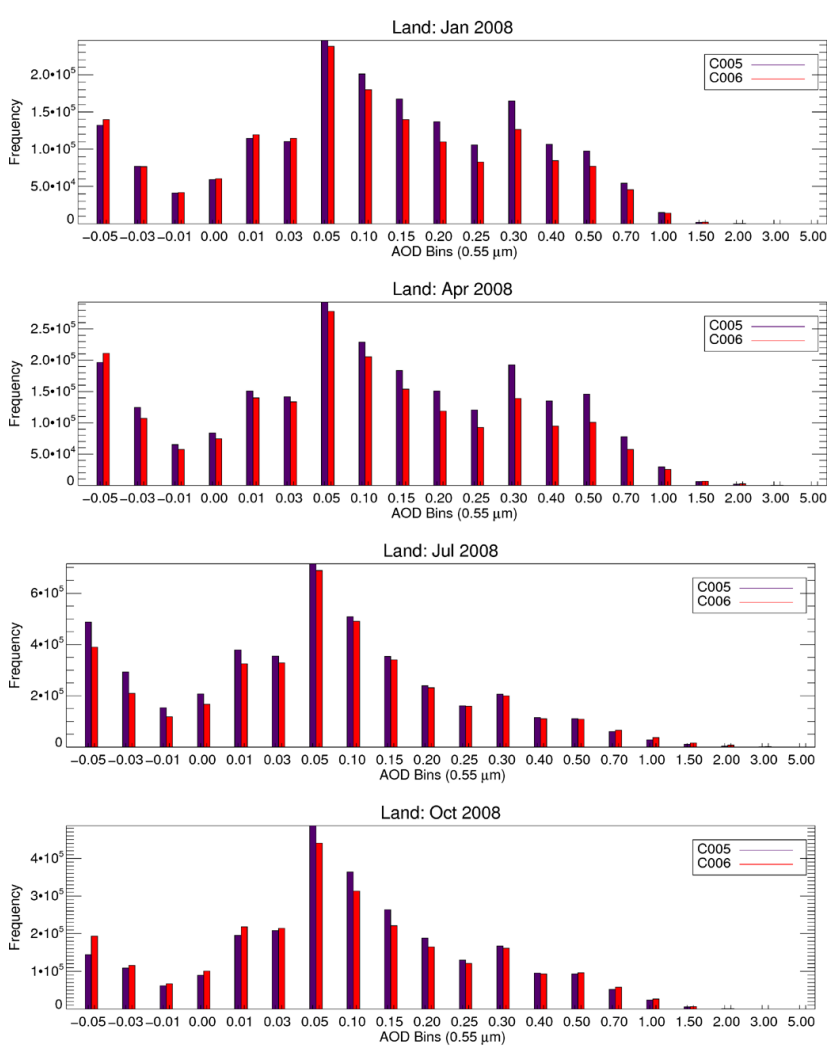

Fig. 10. Histograms for global retrieved Level 2 DT-land AOD (at $0.55 \mu \mathrm{m})$ from Aqua for four months. Plotted are data from C5 and C6.

AOD over semi-arid regions. Interestingly while there are many retrievals of negative AOD in the histogram (Fig. 10), they are constrained to regions (e.g. Australia) where there are not so many AERONET sites.
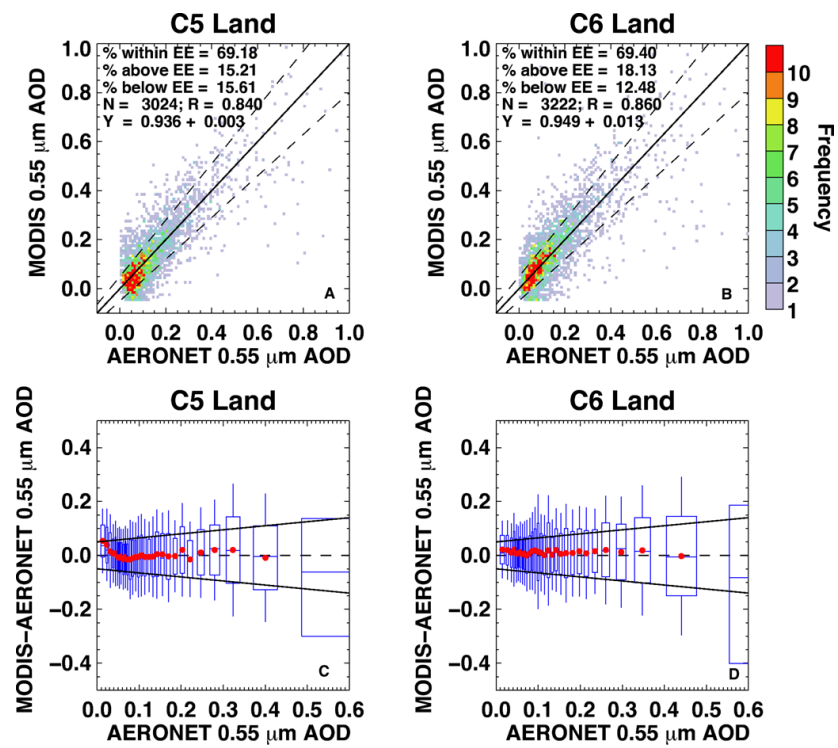

Fig. 11. Top row: frequency scatter plots for AOD at $0.55 \mu \mathrm{m}$ over dark-land compared to AERONET, plotted from 6 months of Aqua (January and July; 2003, 2008 and 2010), computed with C5 algorithm (a) and C6 algorithm (b). One-one lines and EE envelopes $\pm(0.05+15 \%)$ are plotted as solid and dashed lines. Collocation statistics are presented in each panel. Bottom row: the same information plotted as AOD error (MODIS-AERONET) versus AERONET, broken into equal number bins of AERONET AOD for C5 c) and C6 (d). One-one line (zero error) is dashed and EE envelopes are solid. For each box-whisker, its properties and what they represent include: width is $1-\sigma$ of the AOD bin, whereas height, whiskers, middle line and red dots are the 1- $\sigma, 2-\sigma$, mean and median of the AOD error, respectively.

\subsection{Changes for DT-ocean}

In several previous studies, good comparability was reported between MODIS and SP data, such that AOD retrieved from MODIS agreed to within $\pm(0.03+5 \%)$ (e.g., Remer et al., 2005, 2008). However, the same level of agreement was not 
achieved at all sites under all conditions. Errors could be traced to the presence of non-spherical dust (e.g., Levy et al., 2003) or absorbing smoke (e.g., Ichoku et al., 2003), instead of the spherical, weakly absorbing aerosol conditions that are assumed in the retrieval. Errors can also result from wrong assumptions of the oceanic surface contributions. Uncertainties in water leaving radiance, glint, and white foam properties would introduce an error that is larger relative to low AOD cases, but also may be non-negligible even when AOD is high. Considering that optical depths are low over most of the ocean, an error in the surface contribution can have a significant impact on the global AOD. Finally, unlike the DT products over land, the comparability with AERONET was not monotonic with QAC value. Bréon et al. (2011) demonstrated that, statistically, the most accurate MODIS over-ocean data set required $\mathrm{QAC} \geq 1$, not just $\mathrm{QAC}=3$.

Previously in Sects. 4.2 and 4.3 we described upstream changes to the aerosol algorithms' inputs and changes to the algorithm's gas correction module and LUTs. As described above, these general modifications affect the ocean product, as well as land. Here, in the following subsections, we detail the particular changes made specifically to the DT-ocean aerosol retrieval algorithm, including assumptions as to surface dependence on wind speed, cloud masking logic, and assignment of QAC.

\subsubsection{LUT and wind speed dependence over ocean}

Zhang and Reid (2010) noted there is uncertainty of the surface boundary condition due to variability of the near-surface wind field. Near-surface wind patterns could significantly influence ocean wave and glint patterns, and wrong assumptions about these patterns would bias the subsequent aerosol retrieval. Since the C5 DT-ocean retrieval assumed a constant wind speed of $6 \mathrm{~m} \mathrm{~s}^{-1}$, there should be systematic biases all over the globe. Concurrently, Kleidman et al. (2012) compared MODIS C5 DT-ocean data with SP data from the Marine Aerosol Network (MAN) (Smirnov et al., 2009) and found that there were residual MODIS errors related to wind speed. Sensitivity studies suggested that the problem would be enhanced closer to glint. Following other algorithm teams (e.g., Sayer et al., 2012a; Herman et al., 2005; Kahn et al., 2007), we now introduce wind speed dependence to the MODIS DT-ocean aerosol retrieval. This takes on the form as an additional step in interpolation of the MODIS LUT.

Like the C5 LUT (e.g., Remer et al., 2005), our C6 LUT employs the MODRAD (Ahmad et al., 1982) radiative transfer (RT) code to simulate TOA reflectance for a coupled ocean/atmosphere. Embedded within MODRAD are wind speed dependent models to account for the "roughness" of the sea surface (waves and whitecaps, Cox and Munk, 1954) and the foam fraction (Koepke, 1984). In addition to the standard $6 \mathrm{~m} \mathrm{~s}^{-1}$ wind speed having $0.16 \%$ foam, the C6 LUT includes simulations for three additional wind speeds, $2 \mathrm{~m} \mathrm{~s}^{-1}$, $10 \mathrm{~m} \mathrm{~s}^{-1}$ and $14 \mathrm{~m} \mathrm{~s}^{-1}$, having foam fraction of $0.01 \%, 1 \%$ and $3 \%$, respectively (e.g. Monahan and Muircheartaigh, 1980). Note that for the atmospheric contribution, we have installed the slight changes to the MODIS band central wavelengths and assumed Rayleigh optical depths (Sect. 4.2).

We do not go into the details of the over-ocean aerosol inversion process, as they are described previously (e.g., Remer et al., 2005, 2008). As before, there are nine aerosol models (modes: four fine, five coarse), and that a solution is the weighted combination fine and coarse modes that best approximates the observed spectral reflectance. The main difference is the addition of the extra interpolation step; that is, the interpolation of the LUT with respect to actual wind speed. Here, the wind speed comes from the $2 \mathrm{~m}$-altitude wind speed, reported within the NCEP $1^{\circ} \times 1^{\circ}$ analysis that is already used as inputs to the MODIS processing stream. Wind speeds less than $2 \mathrm{~m} \mathrm{~s}^{-1}$ are assumed to be $2 \mathrm{~m} \mathrm{~s}^{-1}$, and greater than $14 \mathrm{~m} \mathrm{~s}^{-1}$ are assumed to be $14 \mathrm{~m} \mathrm{~s}^{-1}$; otherwise the LUT is linearly interpolated between the nearest two indices.

Figure 12 shows an Aqua granule (18 January 2010, 14:40 UTC), where the multiple wind speed LUT was applied. The left panel is the retrieved AOD using a constant wind speed of $6 \mathrm{~m} \mathrm{~s}^{-1}$ overlaid upon a true-color (RGB) image, showing a strong glint pattern. Panel $b$ shows the the NCEP $2 \mathrm{~m}$ wind speed, and panel $\mathrm{c}$ shows the difference between the AODs retrieved from the multiple wind speed LUT and the $6 \mathrm{~m} \mathrm{~s}^{-1}$ LUT. Note that these wind speeds are from the nearest six-hour interval for GDAS analysis, in this case from 12:00 UTC. Clearly, the C6 algorithm will retrieve lower (higher) values of AOD when wind speed is higher (lower) than $6 \mathrm{~m} \mathrm{~s}^{-1}$. Also, the same wind speed difference leads to large AOD difference when closer to the glint $\left(40^{\circ}\right.$ from the specular direction).

Figure $2 \mathrm{~h}$ shows the net effect of replacing the static wind speed algorithm with a multiple wind speed LUT. The new algorithm tends to reduce global AOD over the ocean, especially near glint, and in the "Roaring Forties" of the southern oceans. Near to the specular direction, increasing wind speed diffuses the glitter pattern (e.g. Cox and Munk, 1954). The $40^{\circ}$ glint mask was chosen so that under most conditions, the sea surface remains nearly glitter free outside this envelope. However, where wind speed is dramatically higher than $6 \mathrm{~m} \mathrm{~s}^{-1}$, the glitter pattern can spill outside of the glint mask, causing a positive bias to retrieved AOD. On the other hand, far from glint (e.g., in the Roaring Forties), the wind speed is known to be consistently higher than $6 \mathrm{~m} \mathrm{~s}^{-1}$, so that the main additional contribution from the ocean surface is windinduced foam.

\subsubsection{Cloud masking, sediment masking, and pixel selection over ocean}

As in the over land algorithm, the success of the DT-ocean algorithm is dependent on the ability to discard unsuitable pixels. At a minimum, the over-ocean DT algorithm throws 

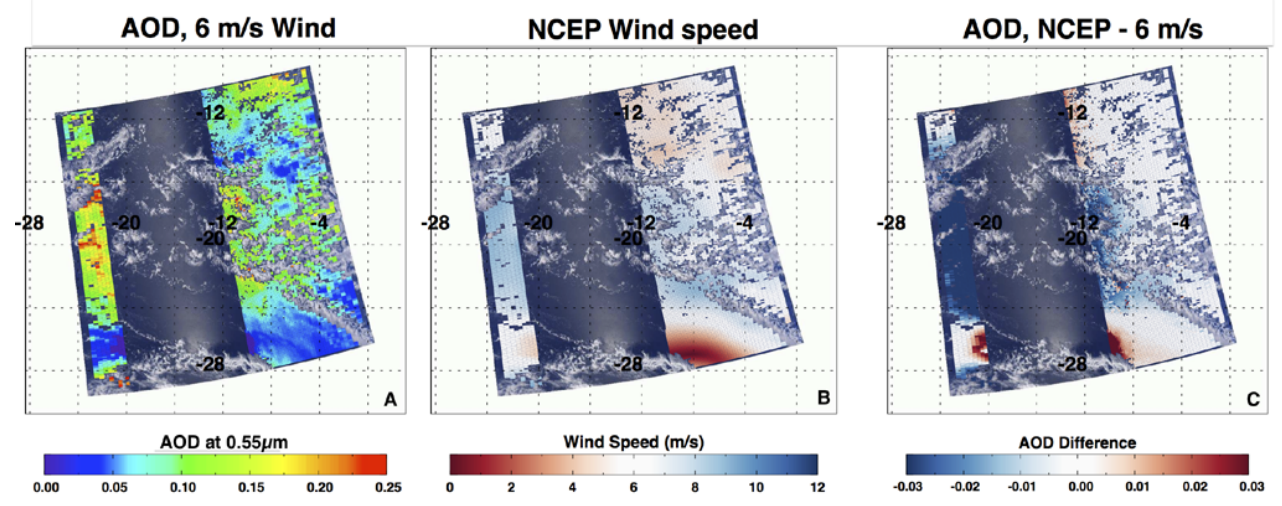

Fig. 12. Granule retrieved over the Atlantic Ocean from MODIS-Aqua taken on 18 January 2010 at 14:40 UTC. (a) True-color image (RGB), over plotted with AOD using assumed $6 \mathrm{~m} \mathrm{~s}^{-1}$ wind speed. (b) Interpolated NCEP $1^{\circ} \times 1^{\circ}$ wind speed. (c) Change in AOD with use of wind information.

out $50 \%$ of the data (darkest and brightest $25 \%$ when sorted by $0.86 \mu \mathrm{m}$ reflectance). However, there are many other unsuitable pixels, including those that are cloudy, having visible sediments, or too near the specular angle.

The main problem is to separate "clear" aerosol pixels from "clouds". We want maximal aerosol coverage with a minimum of cloud contamination. There is no perfect cloud mask. Unless an algorithm is willing to restrict itself to only very specific meteorological conditions, there will always be clouds in the scene (e.g., Koren et al., 2008). In general, the methodology of the algorithms for deselecting over-ocean pixels (including cloud masking) has been retained from C5 (ATBD, Levy et al., 2009b). However, we have made changes, so we briefly describe here.

Internal cloud masking depends on spatial variability (within a $3 \times 3$ box) and absolute reflectance of visible (VIS) and shortwave-infrared (SWIR) channels (Martins et al., 2002). The VIS tests make use of $500 \mathrm{~m}$ resolution data. For each 500 pixel, we determine the reflectance in $0.47 \mu \mathrm{m}$ $\left(\rho_{0.47}\right), 3 \times 3$ standard deviation of reflectance at $0.55 \mu \mathrm{m}$ $\left(\sigma_{0.55}\right)$ and the ratio of $0.47 \mu \mathrm{m}$ to $0.65 \mu \mathrm{m}\left(\rho_{0.47} / \rho_{0.65}\right)$. The logic is that a pixel is labeled "cloudy" if it is either bright $\left(\rho_{0.47}>0.4\right)$, or highly variable $\left(\sigma_{0.55}>0.0025\right)$ but not brown dust $\left(\rho_{0.47} / \rho_{0.65}<0.75\right)$. The SWIR tests look for high cirrus clouds using $1 \mathrm{~km}$ data (Gao et al., 2002), including absolute reflectance at $1.38 \mu \mathrm{m}\left(\rho_{1.38}\right)$ and the ratio of that to the reflectance in $1.24 \mu \mathrm{m}\left(\rho_{1.38} / \rho_{1.24}\right)$. These tests are performed concurrently with the visible tests. However, since $1.38 \mu \mathrm{m}$ is at $1 \mathrm{~km}$ resolution, results of the tests apply to all four $500 \mathrm{~m}$ pixels within. At the same time, due to high amounts of water vapor over the tropical ocean, the internal SWIR cirrus detection algorithm is not always sufficient to mask out high, thin cirrus. Therefore, three thermal infrared (IR) test results are selected from the upstream MODIS cloud mask file (MxD35_L2, Ackerman et al., 1998, 2010). Each IR test result is encoded into the MxD35 product as one "Bit", having the value of 0 ("not applied") or 1 ("applied") (Hubanks et al., 2012).

The three IR tests are the "Thin Cirrus (IR) Test" (Bit 11), the "High Cloud $(6.7 \mu \mathrm{m})$ Test" (Bit 15), and the "IR Temperature Difference Test" (Bit 18). If any of these three tests register as "applied", then the $2 \times 2$ box of $500 \mathrm{~m}$ pixels $(1 \mathrm{~km}$ MxD35 pixel) is denoted as "cloudy", and none of these pixels are retained for aerosol retrieval. However, during C6 development, the MODIS cloud mask team also made changes to the MxD35 algorithm (http://modis-atmos.gsfc.nasa.gov/ products_C006update.html). Specifically, the Bit 18 test was relaxed in order to reduce the number of falsely identified tropical cirrus cases. The goal was to prevent ambiguous cirrus clouds from being targeted for cloud retrieval, but it also resulted in additional cirrus contamination for the aerosol retrieval.

To undo the extra cirrus contamination, we strengthened the internal SWIR cirrus-masking test. As before, it is applied in a three-step process, but the logic is changed. Now, if $\left(\rho_{1.38}>0.03\right)$ then the $1 \mathrm{~km}$ pixel (and the four $500 \mathrm{~m}$ pixels) is considered "cloudy". If $\left(0.005<\rho_{1.38} \leq 0.03\right)$ then apply the ratio, which means that if $\left(\rho_{1.38} / \rho_{1.24}>0.30\right)$, then the pixel is cloudy. If the pixel survives as "not cloudy", then the algorithm checks if there still might be residual cirrus, which means if $\left(0.005<\rho_{1.38} \leq 0.03\right.$ AND $0.10<\rho_{1.38} / \rho_{1.24} \leq 0.30$ AND $\left.\rho_{0.65}>1.5 \rho_{0.65}^{\text {Rayleigh }}\right)$ then the presence of cirrus is ambiguous and the pixel will be included, but the entire MODIS retrieval box will have degraded QAC value. Note that the extra "AND" statement makes sure that there is enough visible signal (in the $0.65 \mu \mathrm{m}$ channel compared to Rayleigh-only reflectance) to care about residual cirrus contamination.

The overall effect of a weakened MxD35 test and strengthened internal NIR test tends is to slightly reduce aerosol coverage (compared to C5) in the mid-latitude oceans. This is demonstrated with the granule plotted in Fig. 13, observed over the Pacific, by Aqua on 1 January 2010. The effect on 
the magnitude of the AOD is to slightly reduce AOD over the western tropical Pacific, and slightly increase AOD in heavy aerosol plumes such as dust off of the Sahara, off the coast of Siberia and the volcanic plume from Hawaii, as seen in the changes to the cloud mask in Fig. 2e.

To this point, a $500 \mathrm{~m}$ pixel will be deselected from aerosol retrieval if any of the following tests are failed: (1) within glint mask of $40^{\circ}$, (2) any of the three MxD35 IR tests, (3) any internal SWIR test, (4) any internal VIS test. Also, an ocean pixel may fail the ocean sediment test. The ocean sediment test is designed to identify ocean scenes that are contaminated by river or other coastal sediments ( $\mathrm{Li}$ et al., 2002), by comparing observed VIS $(0.55 \mu \mathrm{m})$ reflectance with that expected from interpolating between measurements at $0.47 \mu \mathrm{m}$ and SWIR channels. While the sediment mask threshold is unchanged from $\mathrm{C} 5$, the $\mathrm{C} 6$ protocol of using fill values for missing detector reflectance data in the L1B (Sect. 4.2), means that fewer channels are used to compute the expected $0.55 \mu \mathrm{m}$ reflectance.

Finally after de-selection of individual $500 \mathrm{~m}$ pixels, and $1 \mathrm{~km}$ groups of $500 \mathrm{~m}$ pixels, the ocean algorithm makes final pixel selection. Here, as documented previously (e.g., Remer et al., 2005, 2012) the data within a $10 \mathrm{~km}$ box are sorted by $0.86 \mu \mathrm{m}$ reflectance. The brightest $25 \%$ and darkest $25 \%$ are removed, leaving at most 200 pixels (out of original 400) to be averaged for final retrieval. Nothing has specifically changed in this process, except the reflectance values themselves may have changed, which will cause a different sorting and selection result.

\subsubsection{Quality assurance over ocean}

During the retrieval process, there are a number of tests that infer the "satisfaction" of the retrieval. This is known as the Quality Assurance (QA) plan, and its ultimate product is the assignment of the QA Confidence (QAC), having values between " 0 " (no confidence) and " 3 " (high confidence). The detailed tests of the DT-ocean QA plan are reported in the Appendix. For the most part, the general methodology of QA assignment is the same as for C5. However, there are some changes that are described in this section.

Bréon et al. (2011) and Sayer et al. (2012b) noted that for C5 over ocean, MODIS comparability with AERONET was not monotonic with QAC value. It was shown that cases with $\mathrm{QAC}=3$ were no better than cases where $\mathrm{QAC}=1$, and in some statistics (fraction within EE), the higher QAC cases compared worse. Looking closer at the data, we determined that the cases with low confidence tended to have lower retrieved AOD. In other words, lower QAC was assigned even when it was obvious that the scene was clear (no aerosol). We also noted that there were many cases where $\mathrm{QAC}=0$ (no confidence) and the AOD was reported as exactly zero.

In retrieval operation, there are two places where the observed reflectance in the $0.86 \mu \mathrm{m}$ channel $\left(\rho_{0.86}\right)$ is compared to that modeled for a Rayleigh-only atmosphere $\left(\rho_{0.86}^{\text {Rayleigh }}\right)$.

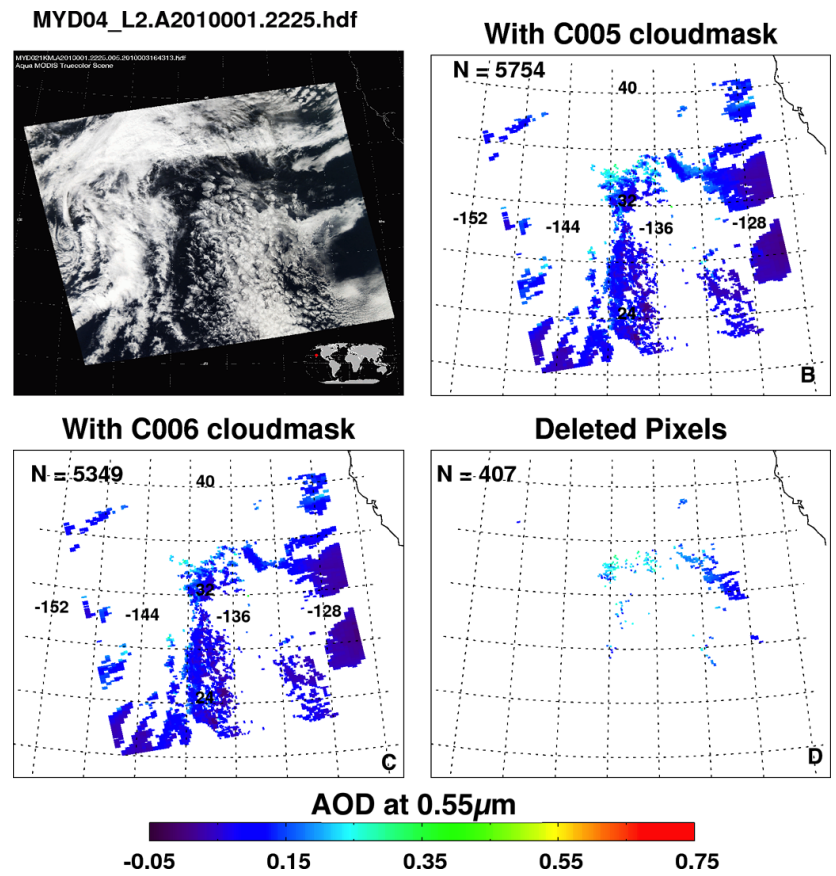

Fig. 13. Granule retrieved over the Pacific Ocean from MODISAqua taken on 1 January 2010 at 22:25 UTC. Top left: truecolor (RGB) showing scene taken from modis-atmos.gsfc.nasa.gov. (b and c) Retrieved high quality (QAC $\geq 1$ over ocean) AOD at $0.55 \mu \mathrm{m}$, without/with the revised $1.38 \mu \mathrm{m}$ cloud mask test. (d) Cirrus contaminated pixels that have been removed over ocean.

For the C5 algorithm, the logic was if $\rho_{0.86}<1.1 \rho_{0.86}^{\text {Rayleigh }}$, then there was not enough aerosol signal (AOD $\sim 0.002$ in $0.86 \mu \mathrm{m}$ ) to do a meaningful retrieval (both AOD and size). Thus, the AOD (in $0.55 \mu \mathrm{m}$ ) was set to exactly 0.0 and the QAC was also set to zero. While it is true that there is no aerosol size information, these extremely clean ocean retrievals were discarded when daily and monthly statistics were computed, thus biasing results. Another test was that if $\rho_{0.86}>1.5 \rho_{0.86}^{\text {Rayleigh }}$, then the retrieval would be attempted, but the QAC value assigned to 1 . This is equivalent to AOD $\sim 0.01$ in $0.86 \mu \mathrm{m}$, which (if we assumed molecular and aerosol have similar spectral dependence) would mean AOD $\sim 0.05$ in $0.55 \mu \mathrm{m}$. These cases would be included in global statistics, but would be weighted less heavily (for QA weighting statistics) than higher AOD cases. In either situation, the result forced the under-sampling of clean cases $(\tau<0.05)$ and produced a high bias to global AOD. There should be more confidence given to obviously "clean" aerosol cases.

For C6, QA logic has been redesigned, so that the extremely clean cases do not automatically receive lower QAC weighting. Cases where there is no retrieval (and AOD assigned to 0.0 ) are given $\mathrm{QAC}=1$, where cases where there could be AOD retrieval (but not robust retrieval of size 
parameter) are given $\mathrm{QAC}=3$. Size parameters are not reported for either of these cases.

\subsubsection{New and changed ocean products}

Table 3 lists the over-ocean aerosol SDSs within the Level 2 (MxD04) product. There are no deleted SDSs over ocean, however there is one new SDS, three SDSs with larger dimensions, one with smaller dimensions and two renamed SDSs. The new SDS, "Wind_Speed_NCEP_Ocean", represents the wind speed used in the retrieval (as reported by the NCEP $1^{\circ}$ re-analysis). The SDSs representing reflectance and the number of pixels used have been increased to ten wavelengths (adding values for 0.41, 0.44 and $0.76 \mu \mathrm{m}$ ). The Ångström exponent SDS is reduced to 2-D from 3-D, where only the "average" value is retained. The cloud fraction variable now has the prefix "Aerosol_", to reduce confusion between cloud fraction for the cloud retrievals and cloud masking for aerosol. Finally, what used to be "Cloud_Condensation_Nuclei" in C5, is now "PSML003_Ocean" (Particles of the Small Mode Larger than $0.03 \mu \mathrm{m}$ ), which better denotes the physical meaning of the parameter.

\subsubsection{Global AOD resulting from all changes over land}

In the preceding, we have introduced the changes applied to the DT-ocean aerosol retrieval algorithm and Level 2 product listing. Updates include changes to Rayleigh assumptions, gas correction, wind speed interpolation, cloud mask, and QAC revision. What is the net effect to the DT-ocean aerosol products on a global scale? As described in Sect. 4.4.6, eight full months of aerosol products from Aqua (January and July, from 2003, 2008, and 2010; and April and October 2008) were processed with a near-final version of the retrieval algorithms. Analogous to our DT-land description in Sect. 4.4.6, we evaluate $\mathrm{C} 5 \rightarrow \mathrm{C} 6$ algorithm changes on these test data.

Table 4 reports global, Level 2 pixel AOD statistics for the four months in 2008 over ocean, demonstrating major changes:

- The net result is approximately 3-8\% additional coverage (Valid PixCount), depending on month.

- The QAC (overall Confidence) is increased. The number of $\mathrm{QAC}=0$ and $\mathrm{QAC}=1$ retrievals is decreased, so that the number of $\mathrm{QAC}=3$ is more than doubled.

- For the filtered, QAC $\geq 1$ data), global mean AOD decreased in all months (by 0.016-0.019).

Plotted in Fig. 14 are global histograms of the four months of retrieved AOD data in 2008 for both C5 (red) and C6 (blue), filtered for $\mathrm{QAC} \geq 1$. We see that, overall, the number of retrievals has increased $(7 \%)$ and that there is a significant increase in low AOD cases with a slight decrease in the number of high AOD cases.
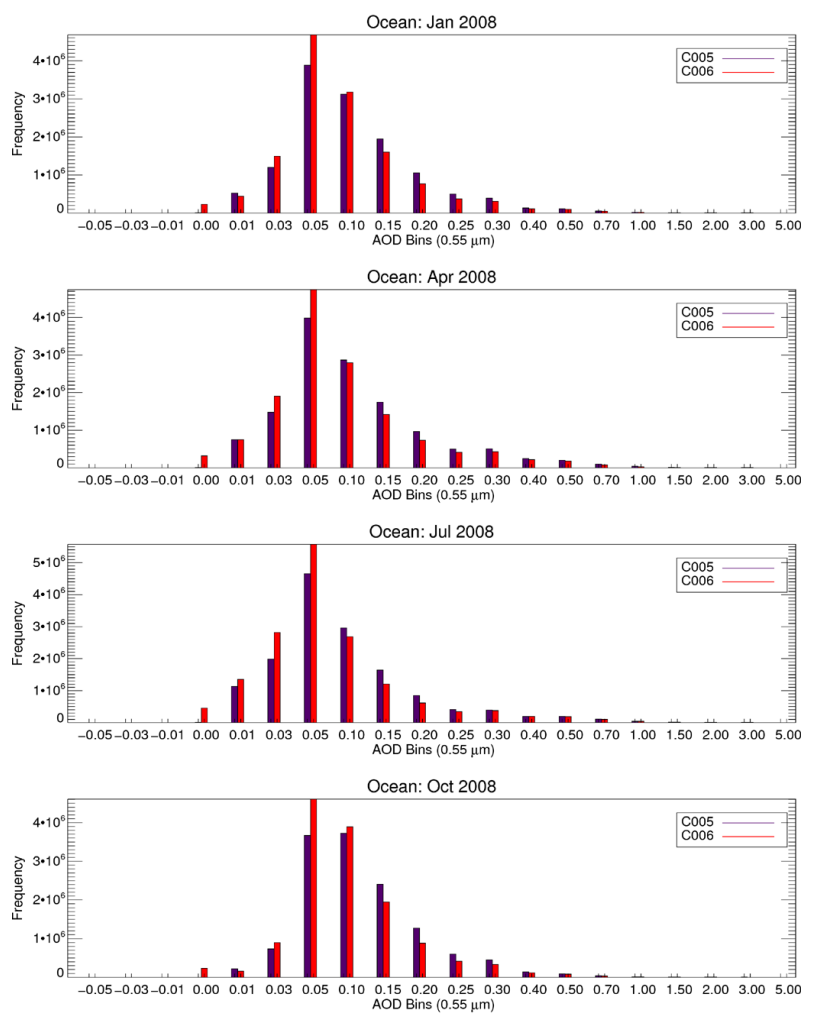

Fig. 14. Histograms for global retrieved Level 2 DT-ocean AOD (at $0.55 \mu \mathrm{m}$ ) from Aqua for four months. Plotted are data from C5 and C6.

Focusing now on changes to size parameter over ocean, namely the Angström exponent (AE), Fig. 15 plots $1^{\circ} \times 1^{\circ}$ $\mathrm{AE}$, calculated from 0.55 and $0.86 \mu \mathrm{m}$ for each of the four months of 2008, both collections and the difference between collections. Each monthly mean value is the average of all filtered (QAC $\geq 1)$ L2 values, within the latitude/longitude grid box, collected during the month., Although this is not necessarily a preferred way of deriving a mean $\mathrm{AE}$ value, the plots clearly show how mean $\mathrm{AE}$ is expected to increase for C6, especially where AOD is expected to decrease when accounting for wind speed. This indicates that C6 may derive generally smaller-sized aerosol over the global ocean.

Returning to Figs. 1 and 2, and AOD, one can see where the $\mathrm{C} 6$ algorithm produces the largest absolute changes over ocean. In general, changes in AOD are largely negative over the global oceans. As indicated in Table 4, the average decrease for the four months is about 0.018, although there are regions of larger decrease and regions of little decrease (or slight increase). For the most part, the large decreases $(\sim 0.04$ or more) are in the mid-latitudes of both summer hemispheres (e.g., the Roaring Forties), where there are systematically higher wind speeds. These decreases in AOD are driven by the addition of variable wind speed in the retrieval (Fig. 2h). The only places where AOD is expected to be higher in $\mathrm{C} 6$ than in $\mathrm{C} 5$ over ocean are in specific tropical 
Table 3. C6 DT-ocean data products and changes from C51.

\begin{tabular}{|c|c|c|}
\hline C6 SDS & C6 dimensions & Noted changes from $\mathrm{C} 51$ to $\mathrm{C} 6$ \\
\hline Effective_Optical_Depth_Average_Ocean & $X, Y, 7 \lambda$ & \\
\hline Effective_Optical_Depth_Best_Ocean & $X, Y, 7 \lambda$ & \\
\hline Optical_Depth_Ratio_Small_Ocean_0_55micron & $X, Y, 2 \mathrm{~S}$ & \\
\hline Solution_Index_Ocean_Small & $X, Y, 2 \mathrm{~S}$ & \\
\hline Solution_Index_Ocean_Large & $X, Y, 2 \mathrm{~S}$ & \\
\hline Least_Squares_Error_Ocean & $X, Y, 2 \mathrm{~S}$ & \\
\hline Effective_Radius_Ocean & $X, Y, 2 \mathrm{~S}$ & \\
\hline Optical_Depth_Small_Best_Ocean & $X, Y, 7 \lambda$ & \\
\hline Optical_Depth_Small_Average_Ocean & $X, Y, 7 \lambda$ & \\
\hline Optical_Depth_Large_Best_Ocean & $X, Y, 7 \lambda$ & \\
\hline Optical_Depth_Large_Average_Ocean & $X, Y, 7 \lambda$ & \\
\hline Mass_Concentration_Ocean & $X, Y, 2 \mathrm{~S}$ & \\
\hline Asymmetry_Factor_Best_Ocean & $X, Y, 7 \lambda$ & \\
\hline Asymmetry_Factor_Average_Ocean & $X, Y, 7 \lambda$ & \\
\hline Backscattering_Ratio_Best_Ocean & $X, Y, 7 \lambda$ & \\
\hline Backscattering_Ratio_Average_Ocean & $X, Y, 7 \lambda$ & \\
\hline Ångstrom_Exponent_1_Ocean (0.55/0.86 micron) & $X, Y, 2 \mathrm{~S}$ & \\
\hline Angstrom_Exponent_2_Ocean $(0.86 / 2.1$ micron $)$ & $X, Y, 2 \mathrm{~S}$ & \\
\hline PSML003_Ocean & $X, Y, 2 \mathrm{~S}$ & Renamed from "Cloud_Condensation_Nuclei_Ocean" \\
\hline Optical_Depth_by_models_Ocean & $X, Y, 9 \mathrm{M}$ & \\
\hline Aerosol_Cloud_Fraction_Ocean & $X, Y$ & Renamed from "Cloud_Fraction_Ocean" \\
\hline Number_Pixels_Used_Ocean & $X, Y, 10 \lambda$ & Separate tally for each of ten wavelength \\
\hline Mean_Reflectance_Ocean & $X, Y, 10 \lambda$ & Added 3 wavelengths \\
\hline STD_Reflectance_Ocean & $X, Y, 10 \lambda$ & Added 3 wavelengths \\
\hline Quality_Assurance_Ocean & $X, Y, 5 \mathrm{~B}$ & \\
\hline Wind_Speed_Ncep_Ocean & $X, Y:$ & New diagnostic \\
\hline
\end{tabular}

$X, Y$ refers to a 2-dimensional array along/across the swath (at a particular wavelength $\lambda$ ). Some parameters have a third dimension. A dimension of "\# $\lambda$ " refers to \# wavelengths. \# = 7: $0.47,0.55,0.65,0.86,1.24,1.63$ and $2.11 \mu \mathrm{m}$. \# = 10: $0.47,0.55,0.65,0.86,1.24,1.63,2.11,0.41,0.44$ and $0.76 \mu \mathrm{m}$. A dimension of " $5 \mathrm{~B}$ " refers to the number of bytes (5) of the QA Flags. A dimension of "9M" is number of modes (9). A dimension of " 2 S" is two solutions ("average" and "best").

Table 4. C5/C6 comparison of DT-ocean statistics for Aqua; January, April, July and October 2008.

\begin{tabular}{|c|c|c|c|c|c|c|c|c|c|c|}
\hline Month & $\mathrm{COOX}$ & $\begin{array}{r}\text { Granule } \\
\text { Count }\end{array}$ & $\begin{array}{r}\text { Total } \\
\text { PixCount }\end{array}$ & $\begin{array}{r}\text { Valid } \\
\text { PixCount }\end{array}$ & QA0 & QA1 & QA2 & QA3 & $\begin{array}{r}\text { Filtered } \\
\text { PixCount }\end{array}$ & $\begin{array}{r}\text { Mean } \\
\text { AOD } \\
\text { Filtered }\end{array}$ \\
\hline Jan & $\mathrm{C} 005$ & 4158 & 114005610 & 13229745 & 257966 & 10134241 & 2 & 2837536 & 12971779 & 0.1380 \\
\hline Jan & $\mathrm{C} 006$ & 4816 & 132046605 & 13609700 & 252879 & 7470105 & 36 & 5886680 & 13356821 & 0.1224 \\
\hline Apr & $\mathrm{C} 005$ & 4014 & 110057400 & 13707350 & 283592 & 10437236 & 124 & 2986398 & 13423758 & 0.1454 \\
\hline Apr & $\mathrm{C} 006$ & 4637 & 127136115 & 14369884 & 351043 & 7626932 & 183 & 6391726 & 14018841 & 0.1261 \\
\hline Jul & $\mathrm{C} 005$ & 4132 & 113265405 & 14934253 & 326704 & 11720230 & 101 & 2887218 & 14607549 & 0.1331 \\
\hline Jul & $\mathrm{C} 006$ & 4763 & 130592655 & 16195323 & 230455 & 9217243 & 161 & 6747464 & 15964868 & 0.1148 \\
\hline Oct & $\mathrm{C} 005$ & 4175 & 114472170 & 13481206 & 118821 & 10531122 & 1 & 2831262 & 13362385 & 0.1475 \\
\hline Oct & $\mathrm{C} 006$ & 4858 & 133198155 & 13906624 & 288436 & 7678165 & 63 & 5939960 & 13618188 & 0.1298 \\
\hline
\end{tabular}

regions that experience an increase in AOD due to modifications to the cloud mask (Fig. 2e) and to the changes in LUT and gas correction (Fig. 2c). At this point, we have introduced the changes applied to the DT-ocean aerosol retrieval algorithm and Level 2 product listing. Updates include changes to Rayleigh assumptions, gas correction, wind speed interpolation, cloud mask, and QAC revision.

\subsubsection{Comparison with C5 products and AERONET and MAN over ocean}

The C6 products over ocean are expected to be different than C5. How do they validate, as compared to surface sun photometer? Figures 16 and 17 compare products derived from MODIS and SP for the entire eight 


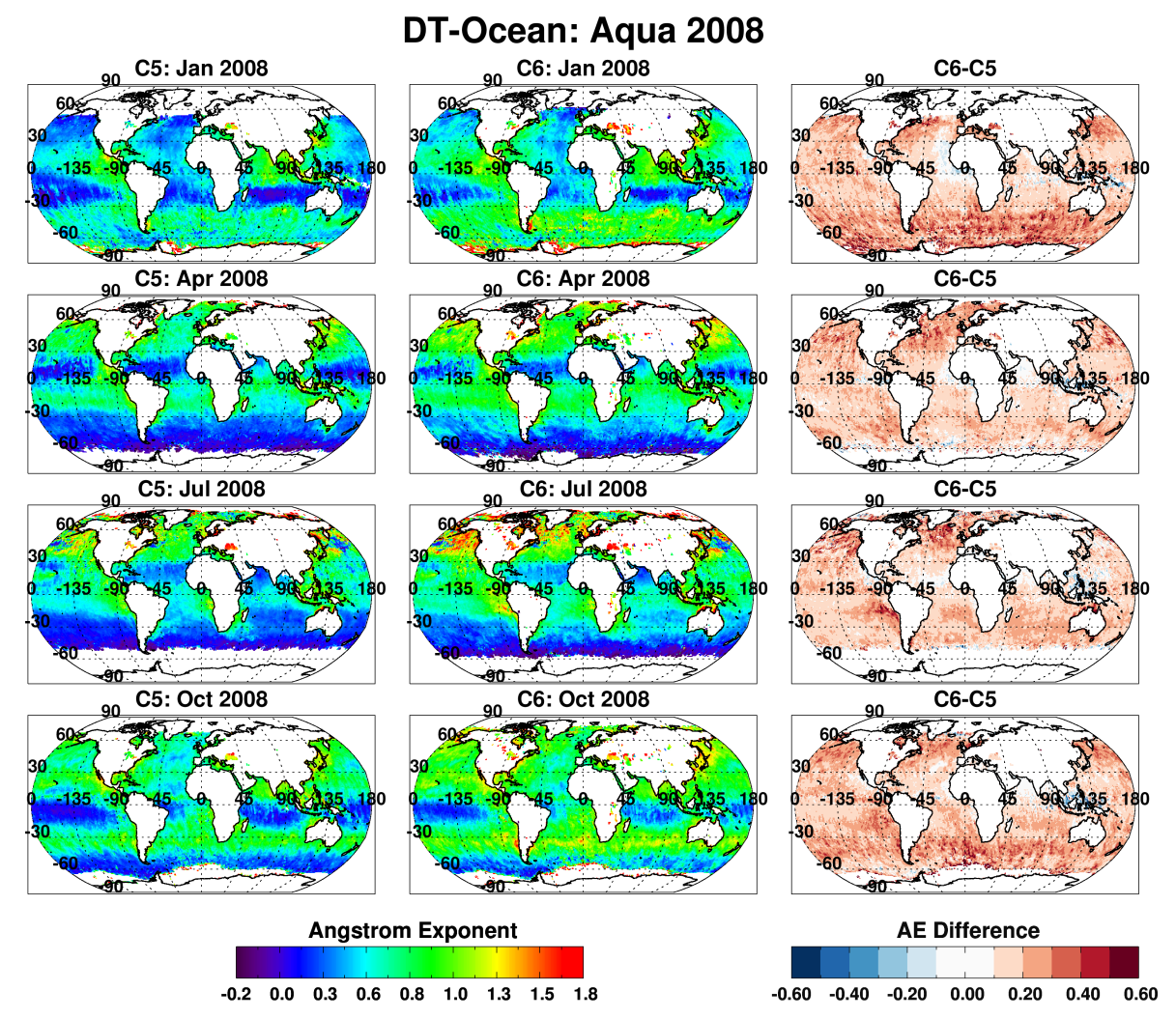

Fig. 15. Gridded, monthly averaged $1^{\circ} \times 1^{\circ} \mathrm{AE}($ at $0.86 / 0.55 \mu \mathrm{m})$ over ocean retrieved from Aqua for January, April, July and October 2008 . For each row, the left panel is an aggregated product produced from $\mathrm{C} 5$, the middle panel is from C6, and the right panel are differences C6-C5.

months of Aqua data. Figure 16 plots AOD from C5, on the left, and $\mathrm{C} 6$, on the right. Figure 17 compares the Ångström exponent (AE), computed for 0.55 versus $0.86 \mu \mathrm{m}$. As explained in Sect. 4.4.6, we use the modified collocation protocol of Petrenko et al. (2012), where the MODIS radius is $\pm 25 \mathrm{~km}$ and the sun photometer time interval is $\pm 30 \mathrm{~min}$ of satellite overpass. In addition to plotting MODIS versus AERONET, we also display comparisons for MODIS versus the ship-based sun photometers of the Maritime Aerosol Network (MAN; http://aeronet.gsfc.nasa.gov/ new_web/maritime_aerosol_network.html, Smirnov et al., 2009). For each panel, the square symbols (grey and colored) represent frequency of MODIS/AERONET collocations at each ordered pair (0.01 intervals), whereas the black circles are collocations for MODIS versus MAN. Comparison statistics in all panels are for MODIS versus AERONET only.

While there was a $6 \%$ increase in total filtered $(\mathrm{QAC} \geq 1)$ pixel counts between $\mathrm{C} 5$ and $\mathrm{C} 6$, there is a $30 \%$ increase in the number of valid MODIS/AERONET AOD collocations (from 830 to 1141) and a similar increase for MODIS/MAN (33 to 41). There is an improvement in regression slope (from 0.88 to 0.97 ) and trivial improvement in correlation (from 0.928 to 0.937 ). Visually, there is slightly less scatter for MAN. The bottom panels of Fig. 16 show that the improvement occurs throughout the range of AOD, with high biases at low AOD decreasing and low.

Even after improvements, Fig. 16d clearly shows that there remains a MODIS high bias at low AOD. Also, the scatter for high AOD is significantly larger than the $\mathrm{EE}$ of $\pm(0.03+5 \%)$ as determined by previous validation studies (e.g. Remer et al., 2008). Therefore, we take this opportunity to refine the EE envelope for MODIS over ocean to better represent the asymmetry of Fig. 16d. Here, we claim expected EE for C6 as $(+(0.04+10 \%),-(0.02+10 \%))$, where we also note the asymmetry. These new EE lines are drawn in all panels of Fig. 16.

Because definitions of fine-mode fraction (FMF) can be ambiguous (Kleidman et al., 2005), we focus on comparisons of Ångström exponent (AE) as recommended by Anderson et al. (2005). Due to the expected accuracy of the sun photometer data, they are interpolated to MODIS wavelengths, rather than vice-versa. Figure 17 shows $22 \%$ more collocated points in $\mathrm{C} 6$ than in $\mathrm{C} 5$. Here, the EE is drawn as \pm 0.40 , which captures nearly $63 \%$ of collocations for all values of AE. Resetting at \pm 0.41 captures $68 \%$. While there is no significant overall improvement for AE comparability in C6, there are fewer cases where MODIS is retrieving the limiting values for $\mathrm{AE}$. This suggests that improved pixel screening or 

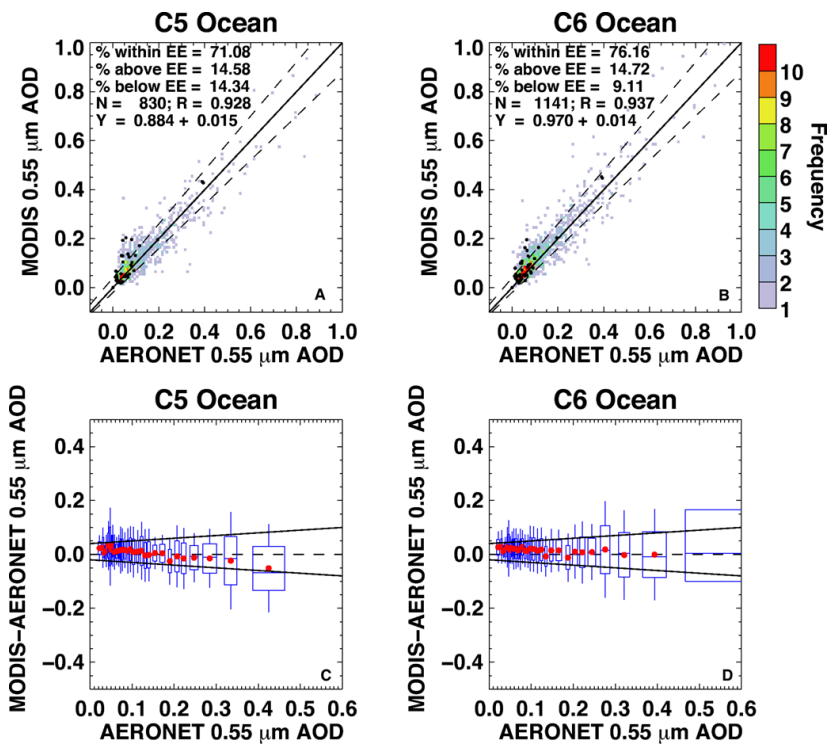

Fig. 16. Top row: frequency scatter plots for AOD at $0.55 \mu \mathrm{m}$ over DT-ocean compared to AERONET (gray and color dots) and MAN (black dots), plotted from 6 months of Aqua (January and July; 2003, 2008 and 2010), computed with C5 algorithm (a) and C6 algorithm (b). One-one lines and EE envelopes $(+(0.04+10 \%)$, $-(0.02+10 \%)$, asymmetric) are plotted as solid and dashed lines. Collocation statistics are presented in each panel. Bottom row: the same information (AERONET only) plotted as AOD error (MODIS-AERONET) versus AERONET, broken into equal number bins of AERONET AOD. One-one line (zero error) is dashed and EE envelopes are solid. For each box-whisker, its properties and what they represent include: width is $1-\sigma$ of the AOD bin, whereas height, whiskers, middle line and red dots are the $1-\sigma, 2-\sigma$, mean and median of the AOD error, respectively.

other corrections (Rayleigh, gas) may be providing the DTocean retrieval with more consistent information. The same reasoning may be responsible for the decrease in the scatter with relation to MAN-derived AE; that allows the C6 retrieval to make better use of the information.

\subsection{Combined DT-land and DT-ocean products}

In Sects. 4.4 and 4.5, we described changes to the algorithm and products related to the separate DT-land and DT-ocean retrievals. At the completion of either algorithm, some parameters are merged into a joint dark-target aerosol product. Some of the parameters are filtered by QAC, meaning that the joint named SDS will only report values with sufficiently high confidence. This enables a "best-of" product that we consider to be useful for most quantitative purposes. These joint products, along with changes from C5 to C6, are listed in Table 5.

We expect that the primary product for most users is the SDS named "Optical_Depth_Land_And_Ocean". This SDS contains only AOD values for the filtered, quantitatively useful retrievals over dark targets. Specifically, this
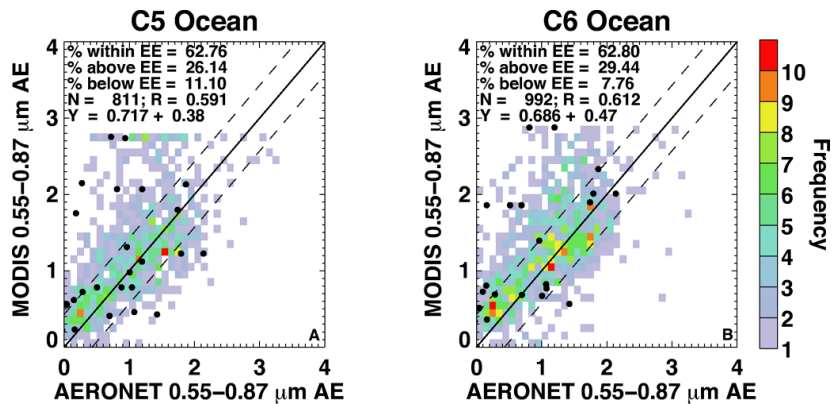

Fig. 17. Frequency scatter plots for $\mathrm{AE}$ at $0.55 / 0.86 \mu \mathrm{m}$ over DTocean compared to AERONET (gray and color dots) and MAN (black dots), plotted from 6 months of Aqua (January and July; 2003, 2008 and 2010), computed with C5 algorithm (a) and C6 algorithm (b). One-one lines and EE envelopes $( \pm 0.45)$ are plotted as solid and dashed lines. Collocation statistics are presented in each panel.

SDS includes any DT-ocean retrieval having $\mathrm{QAC} \geq 1$, and any DT-land retrieval having $\mathrm{QAC}=3$. On the other hand, the C6 product continues to offer the SDS named "Image_Optical_Depth_Land_And_Ocean" which contains all AOD values, regardless of QAC value. This SDS is intended for more qualitative purposes, such as imagery and data continuity. Because Levy et al. (2010) demonstrated there is not even significant "qualitative" value for the ratio product (FMF) over land, the joint ratio SDS has been deleted for C6.

At the same time, we have added two new "diagnostic" SDSs to the product list. These are the "Land_Sea_Flag", reported directly from the MxD35_L2 file used for land/ocean decision making, and the "Land_Ocean_Quality_Flag", which is simply reporting the QAC value contained within the top bytes of the separate "Quality_Assurance_Land" and "Quality_Assurance_Ocean" SDSs. Both of these flags are short integers, and are intended to make it easier for users (and our own algorithm development team) to interpret retrieval results. However, if the user wants to delve into more depth as to why a particular quality was assigned to the retrieval, the separate (bit-packed) QA products are still available.

\subsection{New cloud-diagnostic products}

For C6, there will be a new array of cloud diagnostics reported in the MxD04 file, including two products offered at $500 \mathrm{~m}$ resolution (Table 6). During the cloud masking operations (separate for land and ocean), the algorithm keeps track of whether a given $500 \mathrm{~m}$ pixel is considered to be "cloudy" or "clear". This information is carried along in an array of bits $(0=$ cloudy, $1=$ clear $)$ and reported as "Aerosol_Cldmsk_Land_Ocean". As this cloud mask is created, the algorithm also determines the distance from every pixel to the nearest "cloud" pixel. This is "Cloud_Distance_Land_Ocean". The intention is that users 
Table 5. C6 joint land and ocean data products that are changed from C5.

\begin{tabular}{|c|c|c|c|}
\hline C5 SDS & C6 SDS & $\begin{array}{l}\text { C6 } \\
\text { dimension }\end{array}$ & $\begin{array}{l}\text { Noted changes } \\
\text { from } \mathrm{C} 5 \text { to } \mathrm{C} 6\end{array}$ \\
\hline \multirow[t]{3}{*}{$\begin{array}{l}\text { Optical_Depth_Land_And_Ocean } \\
\text { Optical_Depth_Ratio_Small_Land_And_Ocean }\end{array}$} & Optical_Depth_Land_And_Ocean & $X, Y$ & $\begin{array}{l}\text { Revised QA filtering: Land QAC }=3 \text { Ocean } \mathrm{QAC} \geq 1 \\
\text { Deleted }\end{array}$ \\
\hline & Land_Sea_Flag & $X, Y$ & New parameter: integer land and sea \\
\hline & Land_Ocean_Quality_Flag & $X, Y$ & New parameter: integer value for QA \\
\hline
\end{tabular}

Table 6. C6 New "aerosol” cloud products.

\begin{tabular}{lll}
\hline C6 SDS & C6 dimension & New parameter description \\
\hline Aerosol_Cldmsk_Land_Ocean & $X(500 \mathrm{~m}), Y(500 \mathrm{~m}):$ & $500 \mathrm{~m}$ resolution cloud mask used in retrieval \\
Cloud_Distance_Land_Ocean & $X(500 \mathrm{~m}), Y(500 \mathrm{~m}):$ & Distance each pixel to nearest cloudy pixel (pixels) \\
Average_Cloud_Distance_Land_Ocean & $X(10 \mathrm{~km}), Y(10 \mathrm{~km}):$ & Average distance to cloud in $10 \mathrm{~km}$ box \\
\hline
\end{tabular}

$X, Y$ refers to a 2-dimensional array along/across the swath, with the spatial resolution in parentheses.

concerned about aerosol retrievals affected by cloud adjacency effects (3-D effects) or by humidified aerosols and cloud fragments in cloud fields (twilight zone) can trace exactly which pixels were used in the retrieval or plot the retrievals as a function to the nearest cloud. There is also a $10 \mathrm{~km}$ product that offers the average distance to the nearest cloud of all the pixels within the $10 \mathrm{~km}$ box used by the retrieval, i.e., “Average_Cloud_Distance_Land_Ocean”. An example of the $500 \mathrm{~m}$ parameters is shown in Fig. 18.

\subsection{Deep blue/dark target merged products}

The dark target algorithm over land (e.g., Levy et al., 2007a and $b$ ) is not designed to retrieve aerosol over bright surfaces, including desert. This leaves significant holes in global aerosol sampling. However, in recent years, Hsu et al. (2004, 2006) have developed an algorithm that retrieves aerosol properties over brighter surfaces. This algorithm, known as Deep Blue (DB), makes use of the observation that even visually bright desert scenes are relatively "dark" and relatively stable in the deep-blue wavelengths (e.g., 0.41 and $0.47 \mu \mathrm{m}$ ). The DB algorithms have also been revised for C6, and notably will now also provide coverage over vegetated land surfaces, although not over oceans (Sayer et al., 2013; Hsu et al., 2012).

Here, we do not discuss the DB-land algorithm and product validation. We note, however, that the DB algorithm was applied to MODIS data and included as part of Collection 5.1 (C51), Rather than create an entirely new MODIS product, DB products were provided as appended SDSs onto the existing (C5) MxD04_L2 product. For C6, DB products will continue to be reported within MxD04_L2.

Unlike the clear separation between land and ocean within the DT framework, there are land areas that may be retrieved by both DB and DT algorithms. Essentially, all vegetated terrain falls into this category, as DT excludes bright desert surfaces (e.g., the Sahara desert) and both the DT and DB algorithms exclude snow-covered surfaces. Both algorithms report AOD at $0.55 \mu \mathrm{m}$, and both may report with high QA confidence. How should a user decide which one to use and under what conditions?

As only DB data are available for bright arid regions, there is no choice to be made in this case. Conversely, in the areas with densest vegetation, the DT algorithm is more mature and better characterized than the comparatively new expanded DB algorithm, and performs well; thus, a sensible choice is to use DT in these areas. This leaves a number of transition regions which have comparatively low vegetation cover but are sufficiently dark for the DT algorithm to be applied; perhaps most notable are the African Sahel, which is a transition region between desert and tropical forest, and the arid southwest of the United States. Although there have been multiple validation efforts, there are insufficient number of AERONET sites in these transition zones to conclude clear superiority of one retrieval or another. It is known that the DT algorithm tends to be biased high in brighter regions (e.g., Levy et al., 2010), but is expected to have lower bias for C6 (Sect. 4.4.7). It has also had been shown that DB (C51) was biased low in some of the same regions. The algorithms are built for different assumptions, and it is not obvious how to create an algorithm that leverages only the strengths of both.

For C6, the solution is to simply merge the products from the two algorithms in these transition regions, thus creating a "best-of" AOD product that combines DB, DT-land and DT-ocean. This will be reported by the SDS named "Dark_Target_Deep_Blue_Optical_Depth_550_Combined". Essentially, a climatology from the MODIS-derived, monthly, gridded NDVI product (MYD13C2, Huete et al., 2011) is used as a map for assigning which algorithm takes precedence. This database is a set of 12 multiannual monthly means, gap-filled using the nearest month. If (NDVI $>0.3)$ then use the results from DT $\left(\tau_{-} \mathrm{DT}\right)$. If $(\mathrm{NDVI}<0.2)$ then use results from DB $\left(\tau_{-} \mathrm{DB}\right)$. For the transition areas 
Table 7. C6 New combined Dark Target/Deep Blue SDSs.

\begin{tabular}{lll}
\hline C6 SDS & C6 dimension & New parameter description \\
\hline Dark_Target_Deep_Blue_Optical_Depth_550_Combined & $X, Y$ & "best of” AOD \\
Dark_Target_Deep_Blue_Optical_Depth_550_Combined_QA & $X, Y$ & QAC assignment \\
Dark_Target_Deep_Blue_Optical_Depth_550_Combined_AlgFlag & $X, Y$ & Which product? \\
\hline
\end{tabular}
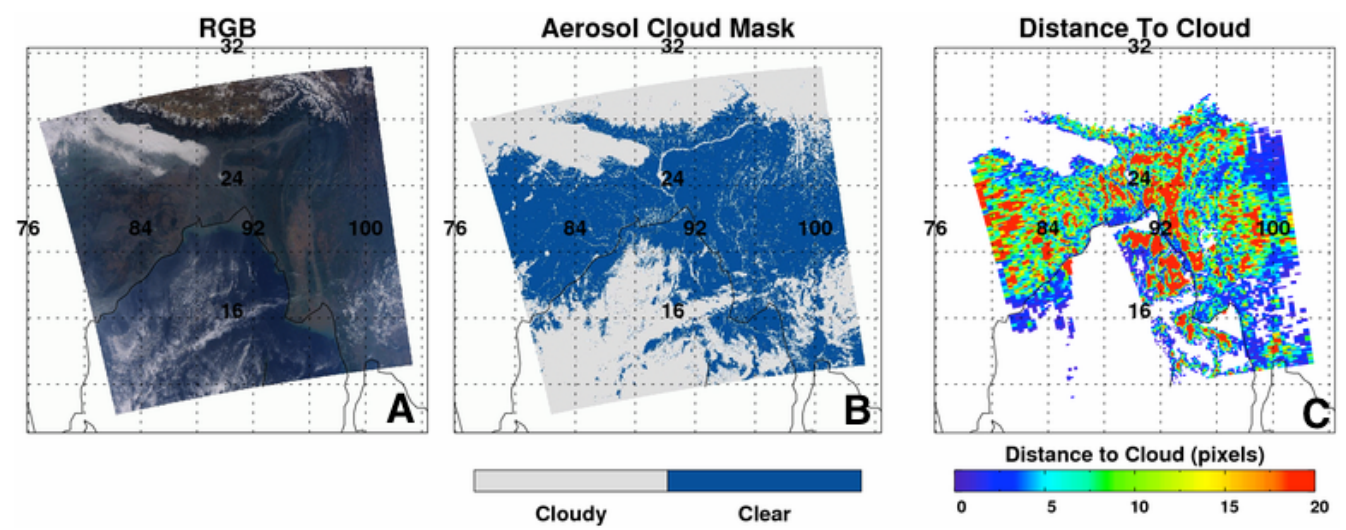

Fig. 18. New aerosol cloud mask variables, both from an AQUA granule on 3 January 2010 at 07:20 UTC. (a) RGB, (b) Aerosol cloud mask. (c) Distance to cloud (in pixels).

$(0.2 \leq \mathrm{NDVI} \leq 0.3)$, the routine considers the confidence as indicated by QAC values (Q_DT and Q_DB), where high confidence means $Q \_D T=3$ or $Q \_D B \geq 2$. If both are high confidence, the AOD is the average of the two, in other words,

$\tau=\left(\tau \_\mathrm{DT}+\tau \_\mathrm{DB}\right) / 2$.

If only one has high confidence, then the AOD is assigned to that one. However, if neither has high confidence, then the combined AOD remains undefined. Table 7 reports the new SDSs referring to the DT/DB merging. Figure 19 shows this combined product (DBDT) for the four months of 2008, and compares it with the original DT product. DBDT increases coverage over both dark and bright surfaces (except snow and clouds), and in certain geographical regions, such as Australia and southwestern Asia, DBDT not only increases coverage but also modifies the AOD.

Although these new "Combined" products are offered for C6, we note that they are not yet validated. At the initial stage, the primary intended purpose of this merged SDS is visualization or for applications where coverage is more important than quantitative accuracy. In an ideal case, users could perform analyses using both DT and DB data where available. It is expected that there may be future adjustments in the NDVI thresholds and/or the exact protocol in which the merging occurs between publication of this document and actual implementation of the algorithm into operational processing. Users should acquire updated documentation for details.

\section{Protocol for $\mathrm{L3}$}

Until this point, our discussion has focused on describing changes to L2 ("swath") algorithm and products. Since many applications rely on gridded aerosol data (e.g., L3), here we describe updates for the L3 product. As reported on the MODIS-Atmosphere website (http://modis-atmos.gsfc.nasa. gov), there are daily (MxD08_D3), eight-day (MxD08_E3) and monthly (MxD08_M3) data products. The D3 files contain roughly 600 statistical data sets that are derived from approximately 80 scientific parameters from four different L2 product files, including the MxD04_L2 aerosol product. Statistics are sorted into $1^{\circ} \times 1^{\circ}$ cells on an equal-angle grid that spans a $24 \mathrm{~h}(00: 00$ to $23: 59$ UTC) interval. There is a range of different statistical summaries that are computed, depending on the parameter being considered. For example, from any derived L2 aerosol parameter, the daily (D3) product may include:

- Simple (mean, minimum, maximum, standard deviation, pixel counts) statistics.

- Histograms of the quantity within each grid box.

- Histograms of the confidence placed in each measurement.

- Confidence weighted statistics (QA mean, QA standard deviation).

- Joint histograms of one variable compared to another. 


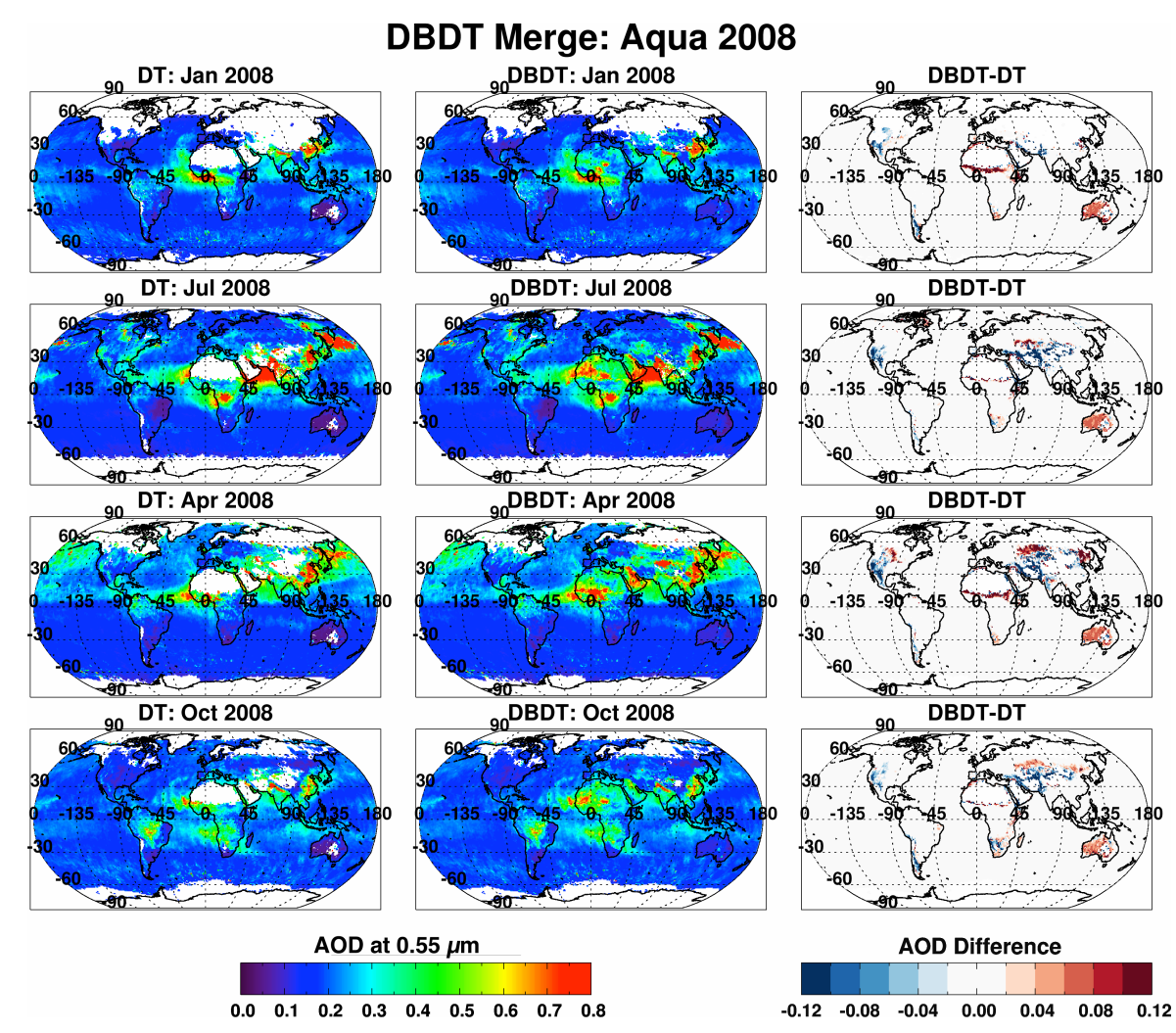

Fig. 19. Global map of Aqua-derived AOD (at $0.55 \mu \mathrm{m}$ ) for four months (January, April, July and October) in 2008. Plotted for each month are: DT only (left), merged DT/DB (center), and differences between DBDT and DT, for grids where DT retrieves (right).

As explained by Levy et al. (2009a), "how" one derives the gridded, global product is very important. Analogous to the selection process when going from L1B to L2 (cloud masking, pixel selection, whether $\mathrm{N}$ pixels are sufficient for retrieval, etc.), there is a selection process when going from $\mathrm{L} 2$ to L3 and then from D3 to M3. Here the questions involve retrieved pixel selection, QAC filtering, and again, whether $\mathrm{N}$ retrievals are sufficient. We have considered many assumptions and the changes from $\mathrm{C} 5$ to $\mathrm{C} 6$ are reported here.

For the D3 product, there is no significant change in how most aerosol parameters are computed. For many of the individual, separately retrieved (DT-land, DT-ocean, DB-land) aerosol SDSs, other than the addition of a median statistic, the set of statistics will be the same as in C5. However, the prefix "Aerosol_" has been prepended to all D3 aerosol statistics to reduce confusion with such D3 products as cloud optical depth. Yet, many SDSs have been removed from the product list. These include the deleted L2 size parameters over DT-land (Sect. 4.4.5) as well as any other parameter describing intensive aerosol properties (e.g. Ångström Exponent or aerosol size) that cannot be easily "averaged". To illustrate the problem, consider two aerosol observations, one of $\mathrm{AOD}=0.5$ with $\mathrm{AE}=0.5$, the other of $\mathrm{AOD}=1.5$ with $\mathrm{AE}=1.5$. Yes, the average $\mathrm{AOD}$ (loading) may be 1.0 , but the average $\mathrm{AE}$ is clearly not 1.0. These intensive variables, such as AE and FMF, must be weighted by the total AOD, but is becomes too complicated within the standard L3 processing framework. Therefore, all SDSs with "Ratio" or "Angstrom_Exponent" in the title have been discontinued. On the other hand, since the statistics of spectral AOD and fine-model AOD (both are "extensive" aerosol properties) are retained, a user can compute their own $\mathrm{AE}$ or FMF statistics. In addition, while the new D3 product will not include statistics of $\mathrm{AE}$, it will include joint histograms of AE compared to AOD.

At the same time as simple statistics, the D3 product will continue to report so-called quality weighted statistics, where each L2 retrieval is weighted by their QAC value. We have improved the QA logic for both DT-land and DT-ocean, so that the QAC value better represents the expected quality of the retrieval. For the combined AOD products (e.g., "Optical_Depth_Land_And_Ocean", and "Dark_Target_Deep_Blue_Optical_Depth_550_Combined") it is assumed that QAC filtering has been done within the L2 algorithm, so no additional Confidence weighted statistics are produced.

As explained by Levy et al. (2009a), instead of going back to L2 data, the M3 (and E3) products are computed from D3 products. There are two paths from $\mathrm{L} 2$ to $\mathrm{D} 3$ to $\mathrm{M} 3$ products, one that includes confidence weighting (“_QA_Mean” in D3 


\section{DT-Combined: Aqua 2008}

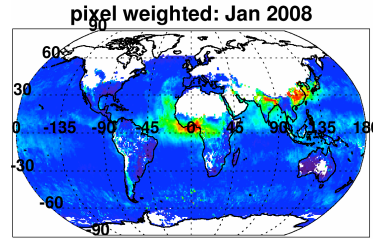

pixel weighted: Jul 2008
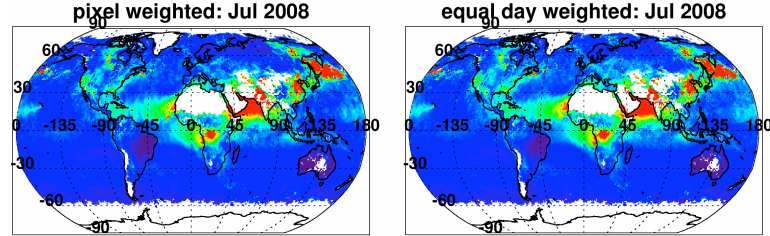

AOD at $0.55 \mu \mathrm{m}$

$\begin{array}{llllllllll}0.0 & 0.1 & 0.2 & 0.3 & 0.4 & 0.5 & 0.6 & 0.7 & 0.8\end{array}$
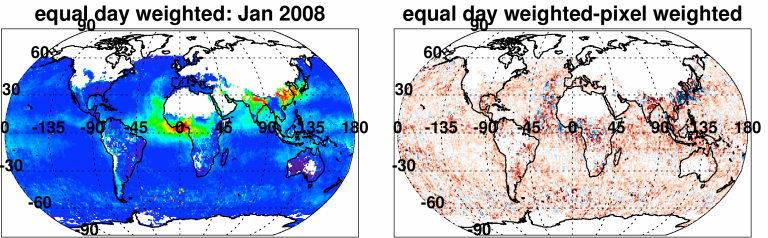

equal dagy weighted-pixel weighted

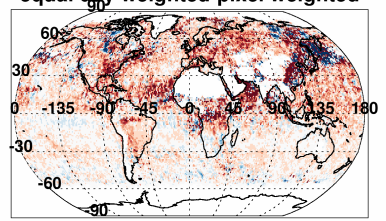

AOD Difference

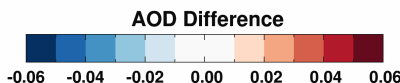

Fig. 20. Maps of gridded $\left(1^{\circ} \times 1^{\circ}\right)$ monthly mean Level $3($ MxD08_M3) product (Optical_Depth_Land_And_Ocean_Mean), for January 2008 (top row) and July 2008 (bottom row). For each row, the left panel is C5-like, pixel-weighted AOD, the middle panel is the C6-like, equal-day weighted AOD, and the right panel plots the differences in each grid (C6-C5).

and "QA_Mean_Mean" in M3) and the other, which does not (_"Mean" in D3 and “_Mean_Mean”in M3). For C5, both of the M3 products were also "pixel weighted" where contribution from each day is weighted by the number of pixels for the day.

Pixel weighting has the effect of biasing the global statistics toward the sampling of the sensor. This means that pixel weighting may be appropriate for describing statistics of cloud properties (e.g., King et al., 2013). Clouds are retrieved whether or not aerosol is present, so that days with more retrieved cloud pixels should have greater weight than days with fewer cloud pixels. Aerosol properties, however, are only retrieved by MODIS under clear (not cloudy) skies. Statistics of aerosol are inherently clear-sky biased, so that pixel weighting makes it even more so.

Therefore, for C6, the monthly (M3) and eight-day (E3) aerosol SDSs computations have dropped the pixel weighting step. Now, as long as a given day has sufficient number of clear pixels $(N \geq 6)$ in the grid box, its value is counted equally as any other day. This reduces the clear-sky bias in the multi-day aerosol products. As seen from Fig. 20, the change to equal day weighting will tend to increase gridded, mean AOD, especially in regions of the globe already dominated by higher AOD.

As of this writing, although we have a fairly firm understanding of expected changes in L3 products, at least as related to aerosol, the full suite of L3 changes is still in development. A detailed list of all L3-atmosphere SDSs (D3, E3 and M3) will be available soon (http://modis-atmos.gsfc. nasa.gov).

\subsection{Calibration issues and expected impact on Terra products}

Because the upstream calibration changes for $M_{\mathrm{A}}$ were small, we have focused our discussion to impacts on MODIS on Aqua. In fact all figures, (Figs. 1-20) illustrated changes to Aqua's products. However, as introduced in Sect. 2.4, there were curious differences between time series of $M_{\mathrm{A}}$ and $M_{\mathrm{T}}$, and we suspected calibration issues.

When the MODIS algorithm was upgraded from $\mathrm{C} 4$ to $\mathrm{C} 5$, all testing was performed based on $\mathrm{C} 4$ inputs. Remer et al. (2008) showed that for C4, global monthly mean AOD from MODIS on Terra $\left(M_{\mathrm{T}}\right)$ and Aqua $\left(M_{\mathrm{A}}\right)$ agreed along the one-to-one line. However, in C5, $M_{\mathrm{T}}$ suddenly "jumped" so that $M_{\mathrm{T}}>M_{\mathrm{A}}$ for all months. Simple analyses (e.g. using the Giovanni visualization tool; http://giovanni.gsfc. nasa.gov/giovanni/) of $\mathrm{C} 5$, show that over land, $M_{\mathrm{T}}>M_{\mathrm{A}}$ prior to 2004 and $M_{\mathrm{T}}<M_{\mathrm{A}}$ after. These tendencies are also noted by Levy et al. (2010) for MODIS/AERONET "comparability", where $M_{\mathrm{T}} \gg$ AERONET prior to 2004 and $M_{\mathrm{T}}><$ AERONET afterwards.

Because the band is used for atmospheric correction, Wang et al. (2012) explained how systematic changes in Terra's blue-band $(0.47 \mu \mathrm{m})$ calibration could be responsible for the observed NDVI product divergence. Furthermore, our own sensitivity tests demonstrated that a $1-2 \%$ drift in only the blue channel (less than the stated accuracy maintained by MCST) was sufficient to produce a trend in one sensor, or a multi-sensor divergence in the MODIS aerosol products. At the same time, a slight offset in observed red $(0.65 \mu \mathrm{m})$ and near-IR $(0.86 \mu \mathrm{m})$ reflectance might be consistent with global offsets over ocean. The ocean color team had previously 
identified drifting calibration to be a source of error in their data (e.g. Franz et al., 2007; Meister et al., 2012), which could be corrected by vicarious calibration (comparing reported radiances to some ground truth). However, until recently, the problem was thought to be confined to the shortest blue wavelengths $(0.41$ and $0.44 \mu \mathrm{m})$, and was not believed to be a significant problem in the land/aerosol blue channel $(0.47 \mu \mathrm{m})$ and longer wavelengths. Deep Blue, with its reliance on $0.41 \mu \mathrm{m}$ was using ocean color team corrections (Jeong et al., 2011). Calibration differences were also suspected to be causing divergences in derived cloud optical properties (e.g. King et al., 2013) between Terra and Aqua.

The trends seen in our dark-target aerosol product, as well as the NDVI and cloud products, clearly indicated that there were also issues in longer wavelengths and they could not be ignored. At that point, the collective MODIS algorithm teams (aerosols, clouds, land surface, ocean, etc.) initiated a bilateral relationship with the MCST. If calibration was going to be updated for $\mathrm{C} 6$, then there should be ample opportunity to test and understand why and how changes would be made and how this change would impact the downstream science products including aerosol.

The details of "how" MCST identified and later corrected for the calibration drift, are explained in Sun et al. (2012) and references therein. We provide a simple explanation here. In addition to the radiometric calibration of each channel for each sensor, MCST quantifies the "response versus scan angle" (RVS). The RVS characterizes the imperfections and geometrical issues that lead to a non-Lambertian response by the MODIS instrument, meaning that each observation must be corrected for the RVS corresponding to that particular viewing angle. Prior to launch, RVS for each channel, and for each MODIS sensor, was characterized in laboratory. Once in orbit, the calibration would be continually updated by making repeated observations of MODIS' onboard reflectance calibrator (known as the solar diffuser) as well as the moon's disc. It was assumed that the pre-launch RVS would remain throughout the mission. However, it is now understood that the angular characteristics of the solar diffuser (the reference for calibration) are also changing during MODIS lifetime, which would result in a time-dependent RVS. If unaccounted for, there would be a residual RVS error, which would lead to biases in L1B reflectance, leading to biases in aerosol or other products. This residual RVS error was identified by taking long-term measurements of "pseudo-invariant" ground sites such as remote deserts (Chander et al., 2010), and comparing instrument response at later dates with earlier measurements. It was in this way that MCST could confirm that there was a drift in the blue $(0.47 \mu \mathrm{m})$ channel that was consistent with trend in retrieved AOD over land. Once the residual drifts were identified they could be corrected for. As a result of these studies, the MCST introduced a new method (Sun et al., 2012) that was later adopted for deriving time and angular dependent calibration coefficients. This method has

\section{L1B Reflectance: Jul 2008 Terra}

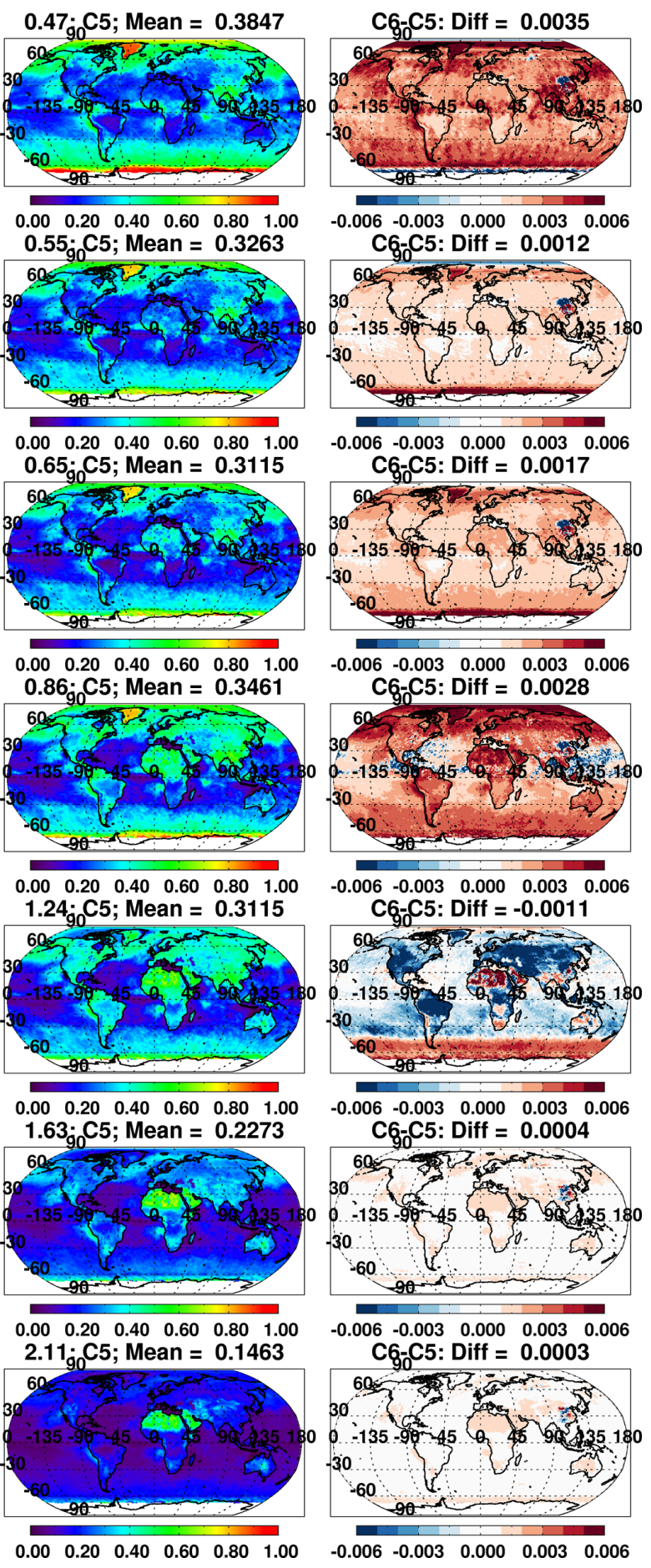

Fig. 21. Gridded "average" Level 1B (1KM) reflectance from Terra for July 2008, demonstrating change of L1B reflectance calibration. For each wavelength band (each row), the left panel is produced from inputs of $\mathrm{C} 5$ reflectance, and the right panel is the difference (C6-C5). Can be compared with Fig. 3 (for Aqua). 


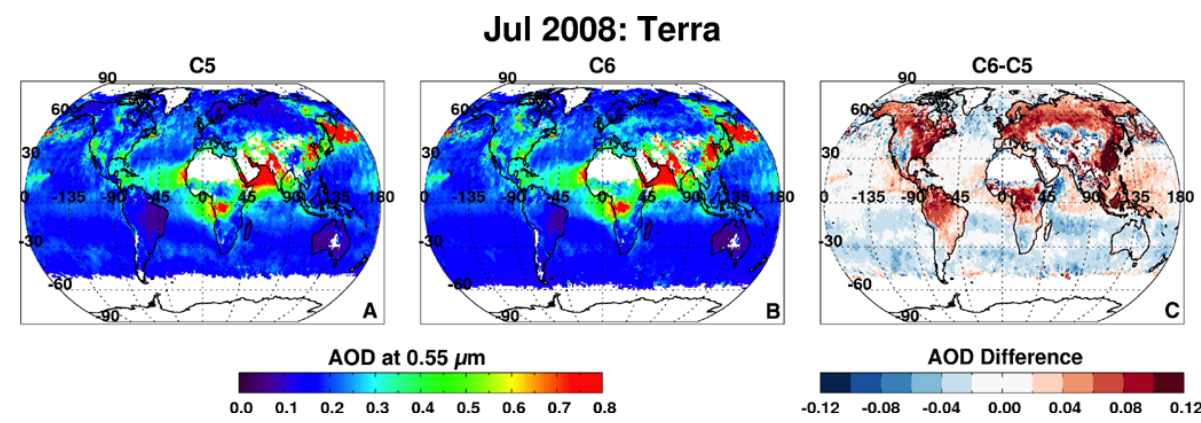

Fig. 22. Gridded, monthly averaged $1^{\circ} \times 1^{\circ}$ AOD (at $0.55 \mu \mathrm{m}$ ) over land and ocean retrieved from Terra for July 2008. (a) Aggregated product produced from C5. (b) Aggregated from from C6. (c) Differences where both products have values in grids (C6-C5). Note that the C6-C5 difference for Terra is different than C6-C5 for the same month for Aqua (Fig. 2).

now been applied to create a set of new, C6 MxD02 files, (which are now archived at http://ladsweb.gsfc.nasa.gov).

Like Fig. 3 (for Aqua), Fig. 21 summarizes the changes to the Terra's L1B TOA aerosol reflectance (MOD021KM), also for July 2008. While all reflectance changes for $M_{\mathrm{A}}$ were on the order of $\pm 0.3 \%$ or less, the corresponding changes for $M_{\mathrm{T}}$ are significantly larger. Specifically, in $0.47 \mu \mathrm{m}$ Band \#3, TOA reflectance increases by $1 \%$. While changes to $0.55 \mu \mathrm{m}$ Band $\# 4$ and $0.65 \mu \mathrm{m}$ Band \#1 are less than $0.4 \%, 0.86 \mu \mathrm{m}$ Band \#2 is increased by $0.8 \%$. The $1.24 \mu \mathrm{m}$ Band \#5 has huge changes, asymmetric over land versus ocean. We do not plot the corresponding changes to L2 TOA reflectance (e.g. Fig. 3), but we note that there are also surprising non-linearities with respect to pixel selection and successful aerosol retrieval.

Figure 22 presents the overall changes to $M_{\mathrm{T}}$ that are analogous to the overall changes in $M_{\mathrm{A}}$ (Fig. 2a, k and f). As compared to the overall differences shown in Fig. $2 \mathrm{f}$ the corresponding overall change for $M_{\mathrm{T}}$ over ocean looks like $M_{\mathrm{A}}$, but is less negative in the semi-arid regions and more positive over vegetation. Essentially, the extra difference over land is driven by the increase in Terra's blue band reflectance, as compared to little or no change in the other bands used for DT-land retrieval. The calibration change is in addition to the other upstream (geolocation and cloud mask) and retrieval algorithm changes.

We restate here (from Sect. 2.4) that this is not a calibration or a trend paper. However, since we have already processed eight months of "test data" for both Terra and Aqua, we ask whether Terra/Aqua AOD inconsistencies might remain for C6. Following Tables 2 (for land) and 4 (for ocean), we calculate global, monthly mean AOD for each month, for Terra and Aqua separately, and for both C5 and expected C6 data. The results are plotted as Fig. 23, where C5 (C6) is plotted in blue (red), and Terra and Aqua are plotted as " $T$ " and "A". Over land (left panel), it is clear that $M_{\mathrm{T}}$ and $M_{\mathrm{A}}$ did not well track each other for C5, and that $M_{\mathrm{T}}>M_{\mathrm{A}}$ in 2003, but reversed for 2008 and 2010. Even though the retrieval algorithm was updated for C6, the identical DT-land algorithm is still being used for both sensors' data. For C6, we should expect to see better tracking of $M_{\mathrm{T}}$ with $M_{\mathrm{A}}$, although an offset of $\sim 0.015$ remains. Over the ocean (right panel), there will be a significant drop of 0.018 in all months, however the $\sim 0.01$ offset (described by Remer et al., 2008) will remain for C6. Reducing the Terra/Aqua offset is a topic of future study, but a vicarious gain correction (e.g Franz et al., 2007) may be an option.

At this point, we cannot determine fully how the revised calibration efforts will impact global trends and divergence of Terra and Aqua. However, the preliminary result is that, in fact, the trending differences will most likely be mitigated by the new calibration effort. Unlike the situation in 2007 when the $\mathrm{C} 5$ aerosol algorithms were put into operation after testing only on $\mathrm{C} 4$ inputs, for $\mathrm{C} 6$, we are accounting for expected upstream changes.

\section{New MODIS $3 \mathrm{~km}$ product (MxD04_3K)}

Prior to Terra launch, the MODIS aerosol algorithms were designed to retrieve at $10 \mathrm{~km}$ resolution (at nadir). This, in part, was seen as a compromise between signal-to-noise of the instrument, of surface variability, and expected aerosol variability (e.g Anderson et al., 2003). The $10 \mathrm{~km}$ was reasonable for deriving global aerosol climatology, while producing a manageable volume of information.

One unexpected application of the MODIS aerosol product was its use as a proxy for estimating surface-level particulate pollution (Chu et al., 2003; Wang and Christopher, 2003; Engel-Cox et al., 2004). However, some studies (e.g., $\mathrm{R}$. R. Li et al., 2005) indicated that the $10 \mathrm{~km}$ resolution was not fine enough to resolve local variability, especially near and within cities where most of the human population lives. Therefore, in recent years, the air quality community in particular has been advocating for higher resolution aerosol retrieval data to monitor and model pollution threats to our human population. Other research applications for a higher resolution data product include, but are not limited to, efforts in characterizing smoke plumes from fires, resolving 

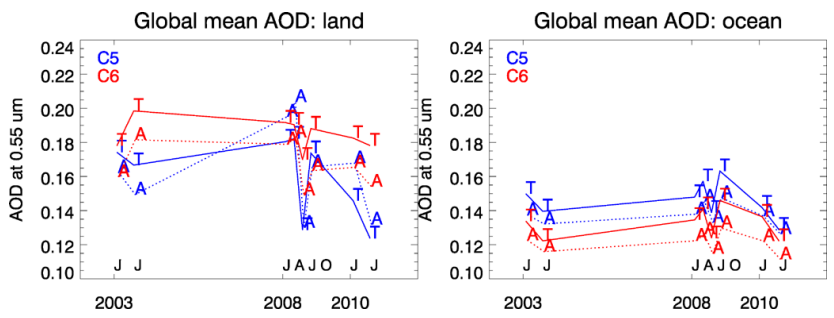

Fig. 23. Global monthly mean AOD for DT-land (left) and DTocean (right) for eight test months (January and July for 2003, 2008 and 2010, plus April and October 2008) as computed for Terra (T) versus Aqua (A), and C6 (red) versus C5 (blue).

aerosol loading in complex terrain and studying aerosolcloud processes.

Because the MODIS $10 \mathrm{~km}$ aerosol algorithms were designed with climate applications in mind, they were constructed in such a way to suppress noise in the retrieval. The danger in producing a higher-resolution data set is that there is the possibility of introducing noise into the product. The standard DT aerosol retrieval throws out at least $50 \%$ (over ocean) and $70 \%$ (over land) of its available $500 \mathrm{~m}$ pixels. This has been proven to reduce noise due to land surface variability, cloud contamination and other non-aerosol signals. Blindly going to a $500 \mathrm{~m}$ (or $1 \mathrm{~km}$ ) resolution global retrieval will lead to retrieval errors.

However, because there is such a strong need for a global fine resolution aerosol product, we have developed a compromise algorithm that retains sufficient pixel screening and statistics. For C6, this will take the form of a separate Level 2 aerosol data product at $3 \mathrm{~km}$ resolution (Remer et al., 2012), and will be archived as "MxD04_3K". Compared to the standard $10 \mathrm{~km}$ algorithm, the $3 \mathrm{~km}$ algorithm will have the same methodology and structure, and use the same inversion method, surface optical property assumptions, and lookup tables. The differences arise only in the manner in which pixels are selected and grouped for retrieval. Since global $3 \mathrm{~km}$ product file dimensions will be so much larger, the new MxD04_3KM file will provide only a subset of the SDSs offered by the standard MxD04_L2 file. The algorithms and products are discussed further in two recent papers (Munchak et al., 2013; Remer et al., 2013).

Plotted in Fig. 24, are two examples of granules retrieved by both $10 \mathrm{~km}$ and $3 \mathrm{~km}$ retrieval algorithms. Both are located over Maryland during July 2010. Cloud masking is the same for both algorithms. However, the sorting and discarding processes are slightly different, meaning that the input reflectances (from L1B) are organized into groups of $6 \times 6$ pixels for the $3 \mathrm{~km}$ algorithm, versus $20 \times 20$ pixels for the $10 \mathrm{~km}$ algorithm. Therefore, pixels that might be discarded during the sorting and discarding procedure at $10 \mathrm{~km}$ might be kept at $3 \mathrm{~km}$. This has the potential to make the $3 \mathrm{~km}$ product noisier than at $10 \mathrm{~km}$. On the other hand, if sufficient pixels escape the masking and discarding procedure at $10 \mathrm{~km}$,

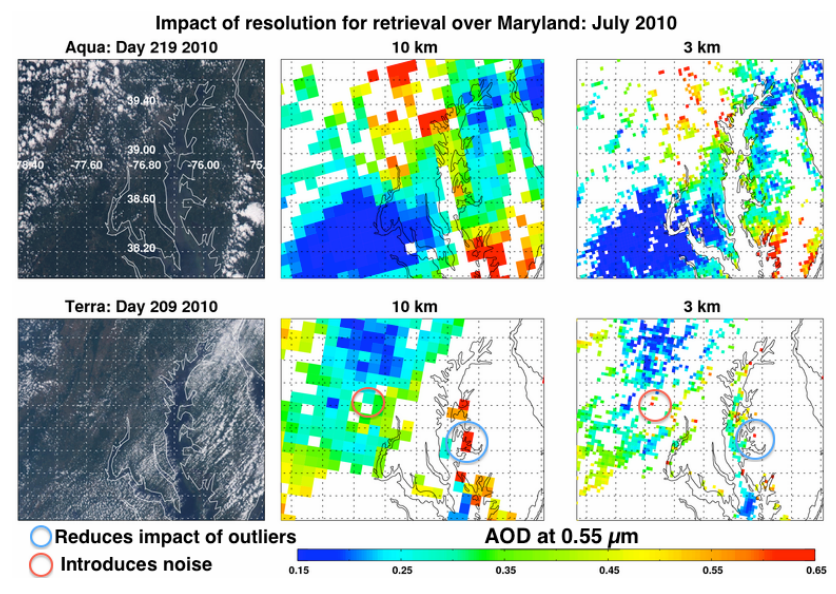

Fig. 24. Plots of true-color RGB, $10 \mathrm{~km}$ AOD and $3 \mathrm{~km}$ AOD, derived from two granules observed over Maryland during the summer of 2010. One red circle identifies a noisy retrieval introduced by the $3 \mathrm{~km}$ product that does not exist at $10 \mathrm{~km}$. The purple circle identifies a region in which cloud effects are accentuated in the $10 \mathrm{~km}$ product but are put into better perspective in the finer resolution product.

then an entire $10 \mathrm{~km}$ box might appear to have inaccurate AOD, which is given substantial weight in an areal weighting of a spatial average. In the $3 \mathrm{~km}$ product these outlying AOD retrievals can be confined to a smaller area and play a lesser role in an areal weighting of a regional average. Figure 24 shows both situations.

The formal evaluation of the $3 \mathrm{~km}$ product is currently underway, however, preliminary analyses have been performed on global data (Remer et al., 2013) as well as local data (Munchak et al., 2013; Livingston et al., 2013). These references have detailed descriptions of the data, their QA plan, and lists of included SDSs. While, initially (for C6) the $3 \mathrm{~km}$ product includes only DT retrievals (over land and ocean), DB retrievals may be added later. There is no operational Level 3 product derived from this $3 \mathrm{~km}$ data set.

\section{Discussion, including transition to NPP-VIIRS}

To this point, we have described the many improvements and updates to the MODIS along-orbit, dark-target aerosol algorithms and products. Except for introducing wind speed dependence over ocean, we have made only minor adjustments to the science behind the DT retrieval procedures. The theoretical basis of the DT-algorithms is solid, at least over the intended DT-land and ocean surfaces. However, we have made substantive adjustments to characterizing boundary conditions (center wavelengths, gas absorption correction, instrument calibration) as well as pixel selection (e.g., cloud masking) and quality assurance (including assigning confidence). In Sects. 3, 4 and 5, we described many changes to the MODIS DT aerosol retrieval. Many of the changes 
involve ensuring that assumptions and diagnostics are "consistent", including such exercises as re-calculating center wavelengths, ROD, and gas corrections, as well as making sure that different RT codes converge for calculating path radiance for common geometry and conditions. There are new diagnostic SDSs reported within the aerosol product file, including the wind speed information over ocean, the topographic elevation over land, land-sea masks, cloud distances and other parameters over both land and ocean. At the same time, the MCST and Wisconsin group updated calibration, geolocation and cloud mask products that are upstream to the aerosol retrieval. This meant in addition to updating the aerosol retrieval itself, we also made changes (cloud masking, sediment masking, etc.) to compensate for the upstream improvements. We have computed expected error (EE) over both land and ocean for our test data, maintaining $\pm(0.05+15 \%)$ over land, but changing to $(+(0.04+10 \%$, $-(0.02+10 \%))$ over ocean to reflect consistent asymmetry. We have revised the protocol for aggregation to Level 3, and introduced a new high-resolution $(3 \mathrm{~km})$ global product for air quality applications.

However, no matter how much energy is put into improving the DT assumptions (surface characterization, aerosol model, pixel selection, quality assurance, etc.), there is little or no additional information within the MODIS visible through SWIR channels that can be used for on-orbit aerosol retrieval. Because desert surfaces are relatively dark in the UV (and Deep-Blue, near-UV) wavelengths, the DB-land algorithm is a useful alternative, particularly for regions where DT algorithms cannot work. To take advantage of this coverage, we have created a new "best-of" combined aerosol product that merges results from both algorithms. It is not yet validated, but it is additional source of global aerosol information. However, because of the inherent uncertainties of the surface reflectance, as well as to all other assumptions, there is a limit to the accuracy and precision of any single-view, along-orbit aerosol retrieval algorithm. Based on the assumptions and uncertainties discussed in this paper, the uncertainty of global AOD, from a single-look, multi-spectral data set cannot be reduced below \pm 0.03 , or $15-20 \%$ of global mean AOD. This is in comparison with the precision $( \pm 0.01-$ 0.02; e.g., McComiskey et al., 2008) needed to reduce uncertainties in global aerosol forcing. While there are potential improvements, such as retrieval of aerosol optical depth above clouds (Jethva et al., 2013) and corrections for threedimensional scattering effects (e.g. Wen et al., 2013), these may not be enough to significantly reduce the global AOD uncertainty.

There are alternatives to along-orbit algorithms. One very promising alternative is the temporal/spatial MAIAC algorithm (Lyapustin et al., 2011). MAIAC adds the knowledge that land surfaces change very little over a short timescale. Using multi-day measurements from MODIS, coupled with some constraints about surface spectral BRDF, one can retrieve land surface and aerosol properties simultaneously.
MAIAC has been proven to provide accurate AOD over many surface types, including vegetated and desert surfaces. The main problem with MAIAC is its practicality - multi-day inversions require more computer resources than the DT or DB algorithms, and may be difficult to perform in real time.

On 25 October 2011, the Visible Infrared Imaging Radiometer Suite (VIIRS) was launched by the National Polarorbiting Partnership (NPP) aboard the Suomi-NPP satellite. Suomi-NPP is a joint NASA/NOAA mission that is intended to provide continuity between NASA's EOS program, and the future Joint Polar Satellite System (JPSS) program. Specifically, VIIRS was designed to have similar capabilities as MODIS, and Suomi-NPP is flying with a similar equator crossing time as Aqua. In terms of aerosol retrieval, the standard VIIRS algorithm is based on the joint heritage of the MODIS DT-retrieval algorithms and the MODIS atmospheric correction algorithms to derive land surface properties (Vermote and Kotchenova, 2008). Sensitivity tests and radiative transfer studies indicate that the VIIRS algorithm for VIIRS should provide an aerosol product with similar quality to that produced by MODIS. However, there are many small differences between VIIRS and MODIS (satellite altitude, spatial resolution, exact wavelength bands, etc.) as well as differences in retrieval algorithms (cloud masking, pixel selection, fitting algorithm, etc.) that suggest that the VIIRS aerosol record will not exactly follow MODIS.

A climate data record is defined by the National Research Council (NRC, 2004) as "a time series of measurements of sufficient length, consistency, and continuity to determine climate variability and change". While we have taken many steps with the MODIS instrument, calibration, and retrieval algorithms to attain consistency, it is debatable whether ten or twelve years is sufficient length and continuity. While MODIS may orbit for another few years, it will not have provided a multi-decade data record. Yet, the MODIS DT-algorithm is a mature algorithm, and we expect that the MODIS-derived DT products will continue to be useful for research and applications. Specifically, after corrections for Terra calibration, we believe that the MODIS retrievals can be a reliable "standard" for creating an aerosol climate data record. Since similar wavelength bands are used by the aerosol retrieval on VIIRS, and we better understood how to calculate things such as center wavelength and gas correction assumptions, we may be able to port exactly the MODIS retrieval algorithm to VIIRS and future instruments. This will lead to a smooth transition across multi-instrument data records, and the possibility for creating an aerosol climate data record. However, even with consistent attention to detail, a global uncertainty of \pm 0.03 may be too much to constrain aerosol forcing. In this case the global AOD observations from MODIS will be used as an anchor for studies that combine models, in situ observations, and other satellite data sets for reducing the uncertainty (e.g. Kahn, 2011).

The DT-algorithm is a mature algorithm, with known uncertainties and a continually improving track record. Even 
though there are promising new algorithms for retrieving aerosol from MODIS and other sensors, they are not yet capable of producing global information, quickly and reliably. In addition to running as standard products in the MODAPS environment, the MODIS DT-algorithm is operating in nearreal time (Rapid Response, http://earthdata.nasa.gov/data/ near-real-time-data/rapid-response). MODIS DT data are reliably being used in operational applications of data assimilation (e.g., Zhang et al., 2008; Benedetti et al., 2009; Reid et al., 2011), weather forecasting (e.g., Carmona et al., 2008), fire monitoring (Kaufman et al., 2003) and air quality applications (e.g., Hoff et al., 2009). Even with the known limits of the DT products, we expect that Collection 6 of the MODIS retrievals (both Terra and Aqua) will provide an anchor for developing a long-term aerosol climate data record.

\section{Appendix A}

\section{Radiative transfer updates: MODIS band center wavelengths, Rayleigh optical depths and gas absorption correction}

Radiative transfer calculations of the aerosol lookup tables (LUTs) require inputs of weighted center wavelength $\left(\mathrm{CW}_{B}\right)$ values and sea-level Rayleigh optical depth $\left(\mathrm{ROD}_{B}\right)$ for each MODIS band $(B)$. For each band (from minimum $(\lambda 1)$ to maximum ( $\lambda 2$ ) wavelength in band)

$\mathrm{CW}_{\lambda}=\int_{\lambda 1}^{\lambda 2} \operatorname{RSR}_{\lambda i} \operatorname{IRR}_{\lambda i} d \lambda$

and

$\operatorname{ROD}_{\lambda}=\int_{\lambda 1}^{\lambda 2} \operatorname{RSR}_{\lambda i} \operatorname{IRR}_{\lambda i} \operatorname{ROD}_{\lambda i} d \lambda$,

where

$\operatorname{ROD}_{\lambda i}=0.0021520\left(\frac{1.0455996-31.29061 \lambda i^{-2}-0.90230850 \lambda i^{2}}{1+0.002759889 \lambda i^{-2}-85.968563 \lambda i^{2}}\right)$.

Here, $\lambda i$ is wavelength in $\mathrm{nm}$, and Eq. (A3) is from Bodhaine et al. (1999) for sea level at $45^{\circ} \mathrm{N}$. Tabulated band-by-band relative spectral response (RSR) and spectral TOA solar irradiance (IRR) come from the MCST web site (http://mcst. gsfc.nasa.gov/calibration/parameters). Note that the RSR and IRR tables are resampled to common wavelengths, the integrations are only for "in-band" response (RSR > 1\%), and that the RSR is furthermore an integration across all detectors (10, 20 or 40 depending on band) and across both MODIS mirrors.

Table A1 lists $\mathrm{CW}_{\lambda}$ and $\mathrm{ROD}_{\lambda}$, both for C5 (noting differences between land and ocean), and for C6 (noting differences between MODIS on Terra and Aqua). The final numbers used for $\mathrm{C} 6$ are based on the average of Terra and Aqua.
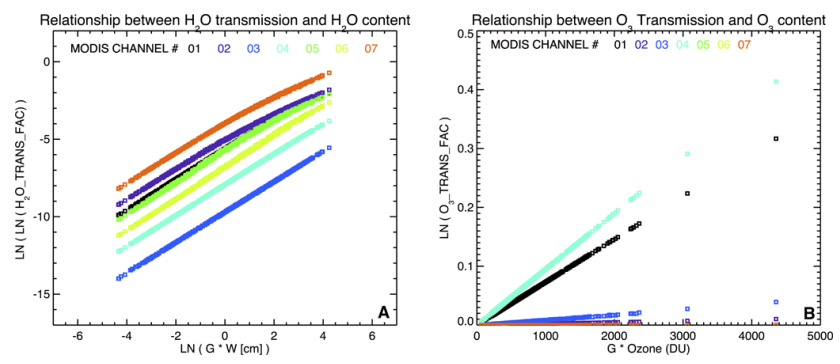

Fig. A1. Relationship between Gas Transmission and Gas Content in the first 7 MODIS bands (a) $\mathrm{H}_{2} \mathrm{O}$ Transmission Factor vs. $\mathrm{H}_{2} \mathrm{O}$ content (cm) (b) $\mathrm{O}_{3}$ Transmission Factor vs. $\mathrm{O}_{3}$ content (DU).

As compared to that assumed for C5 (over ocean), $\mathrm{ROD}_{\lambda}$ has changed by $-0.0034,-0.0017,-0.0013$ and -0.0003 , for Bands \#3, 4, 1 and 2, respectively. For the other bands, differences from $\mathrm{C} 5$ were in the fifth digit or smaller.

Accurate aerosol retrieval also requires appropriate correction for the absorption of atmospheric gases. While the aerosol retrieval is performed in bands that are centered in atmospheric windows, the non-trivial width of these bands (nominally $20 \mathrm{~nm}$ ) contains absorption lines of water vapor $\left(\mathrm{H}_{2} \mathrm{O}\right)$, ozone $\left(\mathrm{O}_{3}\right)$, carbon dioxide $\left(\mathrm{CO}_{2}\right)$, methane $\left(\mathrm{CH}_{4}\right)$, oxygen $\left(\mathrm{O}_{2}\right)$, nitrous oxide $\left(\mathrm{N}_{2} \mathrm{O}\right)$, nitrogen dioxide $\left(\mathrm{NO}_{2}\right)$, and other trace gases. The aerosol retrieval wants a "gas-free" spectral TOA reflectance, so that it can be compared with the LUT. This means that the L1B values $\left(\rho_{\lambda}^{\mathrm{L} 1 \mathrm{~B}}\right)$ are multiplied by the total gas transmission correction factor $\left(\dot{T}_{\lambda}^{\text {gas }}\right)$ to derive the corrected spectral reflectance $\left.\left(\rho_{\lambda}^{m}\right)\right)$, in other words,

$\rho_{\lambda}^{m}=\dot{T}_{\lambda}^{\text {gas }} \rho_{\lambda}^{\mathrm{L} 1 \mathrm{~B}}$,

where the total gas transmission correction is the product of the individual gases,

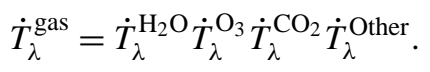

But $\dot{T}_{\lambda}^{j}$ is $1 / T_{\lambda}^{j}$, where $T^{j} \leq 1.0$ is the gas transmittance. Therefore,

$\dot{T}_{\lambda}^{j}=\exp \left(G^{j} \tau_{\lambda}^{j}\right) \approx 1+G^{j} \tau_{\lambda}^{j}$,

where $G^{j}$ is the air mass factor and $\tau_{\lambda}^{j}$ is the optical depth of a particular gas constituent $j$. Depending on the spectral band, the total gas optical depth can be as large as 0.05 or greater. Neglect of (or errors in calculation of) gas absorption can lead to significant errors in the TOA reflectance that is in turn matched with the aerosol LUTs to retrieve aerosol optical depth.

As documented in the online C5 ATBD (Levy et al., 2009b), the C5 aerosol retrieval used spectral coefficients $K_{i, \lambda}^{j}$ to correct for the $\mathrm{H}_{2} \mathrm{O}$ column ( $w$ in $\mathrm{cm}$ ) and the $\mathrm{O}_{3}$ column ( $O$ in Dobson units), such that $T_{\lambda}^{j}=$ function $\left(K_{i, \lambda}^{j}, j, c, G\right)$. Here, $c$ is column concentration of 
Table A1. MODIS band number, central wavelengths (CW) and Rayleigh optical depths (ROD) for C6 compared to C5. Bold font refers to the final values that are used in the C6 retrieval. Included (non-bold) are two columns showing the slight differences for Terra versus Aqua.

\begin{tabular}{lrrrrrrr}
\hline Band \# & C5 CW $(\mu \mathrm{m})$ & C5 ROD Ocean & C5 ROD Land & Terra CW & Aqua CW & C6 CW & C6 ROD \\
\hline 1 & 0.644 & 0.0521 & 0.0509 & 0.6454 & 0.6458 & $\mathbf{0 . 6 4 5 6}$ & $\mathbf{0 . 0 5 0 8}$ \\
2 & 0.855 & 0.0165 & 0.0164 & 0.8566 & 0.8562 & $\mathbf{0 . 8 5 6 4}$ & $\mathbf{0 . 0 1 6 2}$ \\
3 & 0.466 & 0.1954 & 0.1948 & 0.4660 & 0.4657 & $\mathbf{0 . 4 6 5 9}$ & $\mathbf{0 . 1 9 2 0}$ \\
4 & 0.553 & 0.0963 & 0.0963 & 0.5538 & 0.5536 & $\mathbf{0 . 5 5 3 7}$ & $\mathbf{0 . 0 9 4 6}$ \\
5 & 1.243 & 0.0037 & 0.0038 & 1.2414 & 1.2420 & $\mathbf{1 . 2 4 1 7}$ & $\mathbf{0 . 0 0 3 6}$ \\
6 & 1.632 & 0.0012 & 0.0013 & 1.6280 & 1.6293 & $\mathbf{1 . 6 2 8 6}$ & $\mathbf{0 . 0 0 1 2}$ \\
7 & 2.119 & 0.0004 & 0.0005 & 2.1131 & 2.1133 & $\mathbf{2 . 1 1 3 2}$ & $\mathbf{0 . 0 0 0 4}$ \\
\hline
\end{tabular}

Table A2. C6 gas absorption correction coefficients and climatology.

\begin{tabular}{|c|c|c|c|c|c|c|c|c|c|}
\hline $\begin{array}{l}\text { MODIS } \\
\text { Band }\end{array}$ & Wave & & & & & & & & \\
\hline 3 & 0.466 & $-9.58 \times 10^{0}$ & $1.23 \times 10^{0}$ & $-1.16 \times 10^{-1}$ & $8.00 \times 10^{-5}$ & $-1.14 \times 10^{-4}$ & $8.69 \times 10^{-6}$ & $2.90 \times 10^{-3}$ & $1.25 \times 10^{-3}$ \\
\hline 4 & 0.554 & $-7.91 \times 10^{0}$ & $1.00 \times 10^{0}$ & $-1.29 \times 10^{-2}$ & $5.00 \times 10^{-4}$ & $5.18 \times 10^{-6}$ & $9.50 \times 10^{-5}$ & $3.26 \times 10^{-2}$ & $9.50 \times 10^{-4}$ \\
\hline 1 & 0.646 & $-5.60 \times 10^{0}$ & $9.40 \times 10^{-1}$ & $-1.78 \times 10^{-2}$ & $5.11 \times 10^{-3}$ & $1.16 \times 10^{-4}$ & $7.32 \times 10^{-5}$ & $2.52 \times 10^{-2}$ & $3.91 \times 10^{-3}$ \\
\hline 2 & 0.856 & $-5.07 \times 10^{0}$ & $8.77 \times 10^{-1}$ & $-2.40 \times 10^{-2}$ & $8.61 \times 10^{-3}$ & $2.80 \times 10^{-7}$ & $2.36 \times 10^{-6}$ & $8.10 \times 10^{-4}$ & $2.00 \times 10^{-5}$ \\
\hline 5 & 1.242 & $-5.65 \times 10^{0}$ & $9.81 \times 10^{-1}$ & $-2.38 \times 10^{-2}$ & $5.23 \times 10^{-3}$ & $1.19 \times 10^{-7}$ & $1.55 \times 10^{-25}$ & $0.00 \times 10^{0}$ & $1.69 \times 10^{-2}$ \\
\hline 6 & 1.629 & $-6.80 \times 10^{0}$ & $1.03 \times 10^{0}$ & $-4.29 \times 10^{-3}$ & $1.62 \times 10^{-3}$ & $1.19 \times 10^{-7}$ & $5.17 \times 10^{-26}$ & $0.00 \times 10^{0}$ & $9.98 \times 10^{-3}$ \\
\hline 7 & 2.113 & $-3.98 \times 10^{0}$ & $8.86 \times 10^{-1}$ & $-2.56 \times 10^{-2}$ & $2.53 \times 10^{-2}$ & $6.29 \times 10^{-7}$ & $7.03 \times 10^{-8}$ & $2.00 \times 10^{-5}$ & $1.63 \times 10^{-2}$ \\
\hline 8 & 0.412 & $-1.42 \times 10^{1}$ & $1.21 \times 10^{0}$ & $1.55 \times 10^{-1}$ & $0.00 \times 10^{0}$ & $-8.74 \times 10^{-6}$ & $2.36 \times 10^{-7}$ & $7.00 \times 10^{-5}$ & $4.00 \times 10^{-5}$ \\
\hline 9 & 0.442 & $-8.14 \times 10^{0}$ & $1.02 \times 10^{0}$ & $-2.42 \times 10^{-2}$ & $3.80 \times 10^{-4}$ & $-5.65 \times 10^{-5}$ & $2.94 \times 10^{-6}$ & $9.81 \times 10^{-4}$ & $3.70 \times 10^{-4}$ \\
\hline 15 & 0.747 & $-6.73 \times 10^{0}$ & $1.06 \times 10^{0}$ & $-1.22 \times 10^{-2}$ & $1.90 \times 10^{-3}$ & $-7.48 \times 10^{-5}$ & $1.10 \times 10^{-5}$ & $3.74 \times 10^{-3}$ & $0.00 \times 10^{0}$ \\
\hline
\end{tabular}

Note that the $K$ coefficients are used when NCEP data are valid, whereas the US1976 optical depths are used when NCEP data are missing. In case of "other" gases, global average optical depth is assumed. Other gas includes $\mathrm{CO}_{2}, \mathrm{CO}, \mathrm{N}_{2} \mathrm{O}, \mathrm{NO}_{2}, \mathrm{NO}, \mathrm{CH}_{4}, \mathrm{O}_{2}, \mathrm{SO}_{2}$ and other trace gases.

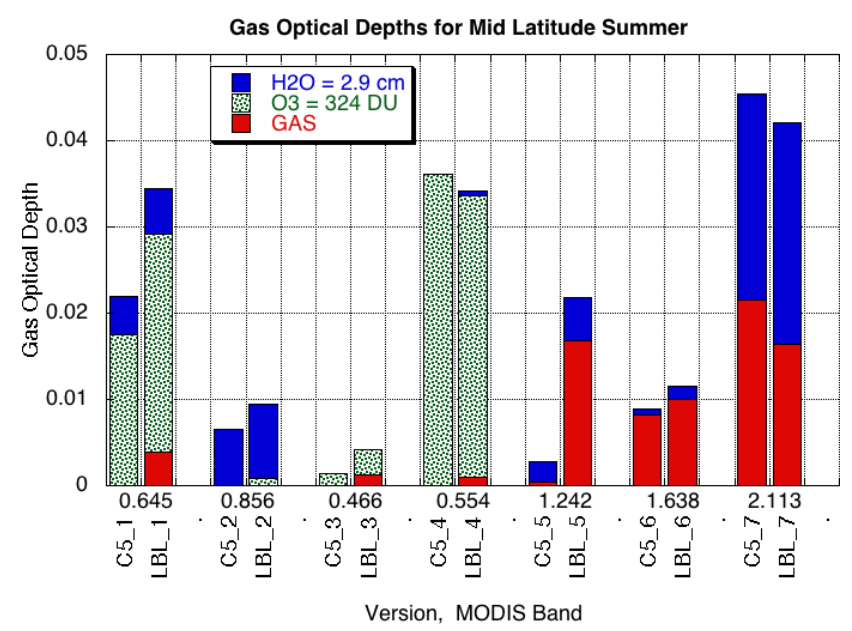

Fig. A2. Comparison of gas optical depths calculated for midlatitude summer atmosphere using C5 and C6 (LBL) gas correction coefficients. Different colors represent constituent gases $\left(\mathrm{H}_{2} \mathrm{O}=\right.$ blue, $\mathrm{O}_{3}=$ green, "other" gases $\left.=\mathrm{red}\right)$.

gas $j$ (provided by ancillary NCEP data in appropriate units), and the function is an empirical fit to many RT simulations. Unfortunately, these coefficients, calculated prior to Terra launch, were not reproducible. In the following, we explain the derivation of new gas corrections for C6. Also, in C5, only $\mathrm{CO}_{2}$ was assumed to be important (outside of $\mathrm{H}_{2} \mathrm{O}$ and $\mathrm{O}_{3}$ ), whereas other gases may also contribute.

We used the Line-By-Line Radiative Transfer Model (LBLRTM, Clough et al., 1992, 2005) and integrated with our previously calculated RSR and IRR database. We started with many different profiles (52 profiles from ECMWF, personal communication Pubu Ciren, NOAA) of water vapor and ozone, varied the air mass factors (10 viewing zenith angles ranging from $0-80^{\circ}$ ), and computed the coefficients of regression. We were looking to fit the following formulas for calculating $\dot{T}_{\lambda}^{j}$, for water vapor ( $w$ in units of $\mathrm{cm}$ ) and ozone ( $O$ in units of DU).

$\dot{T}_{\lambda}^{\mathrm{H}_{2} \mathrm{O}}=\exp \left(\exp \left(K_{0, \lambda}^{\mathrm{H}_{2} \mathrm{O}}+K_{1, \lambda}^{\mathrm{H}_{2} \mathrm{O}} \ln \left(G^{\mathrm{H}_{2} \mathrm{O}} w\right)+K_{2, \lambda}^{\mathrm{H}_{2} \mathrm{O}}\left(\ln \left(G^{\mathrm{H}_{2} \mathrm{O}} w\right)\right)^{2}\right)\right)$

$\dot{T}_{\lambda}^{\mathrm{O}_{3}}=\exp \left(K_{0, \lambda}^{\mathrm{O}_{3}}+K_{1, \lambda}^{\mathrm{O}_{3}} G^{\mathrm{O}_{3}} O\right)$

Not surprisingly, results differed from the values documented within the C5 ATBD. The revised C6 gas correction coefficients $K_{i, \lambda}^{j}$ are reported in Table A2.

As compared to that used to model $\mathrm{H}_{2} \mathrm{O}$ for $\mathrm{C} 5$, there are significant changes to the quadratic coefficients in bands 5 and 6 , but only small changes in other bands. For $\mathrm{O}_{3}$, the quadratic coefficients changed in bands $1-4$, where $\mathrm{O}_{3}$ has absorption lines. Somewhat better linear fits to ozone are 
made when including a slope and offset (only slope used for C5). The offset is small, however.

Also listed in Table A2 are values for $\tau_{\lambda}^{j}$ "climatology". These values of gas optical depth can be used in the aerosol retrieval when there is no ancillary data provided. They have been computed for 1976 Standard atmosphere (http: //modelweb.gsfc.nasa.gov/atmos/us_standard.html), and can be used in Eq. (A6) to estimate $\dot{T}_{\lambda}^{j}$. The linear fits for both $\mathrm{H}_{2} \mathrm{O}$ and $\mathrm{O}_{3}$ are shown in Fig. A1a and b. For "Other" gases, we took climatology to be the sum of all major gases that are not $\mathrm{H}_{2} \mathrm{O}$ and $\mathrm{O}_{3}$. Thus in addition to $\mathrm{CO}_{2}$, "other" gases include $\mathrm{CO}, \mathrm{N}_{2} \mathrm{O}, \mathrm{NO}_{2}, \mathrm{NO}, \mathrm{CH}_{4}, \mathrm{O}_{2}, \mathrm{SO}_{2}$ and other trace gases. For some bands, the $\mathrm{C} 6$ "other" gas optical depths are an order of magnitude higher than the $\mathrm{CO}_{2}$-only optical depth used in C5.

Figure A2 shows a comparison of the $\mathrm{H}_{2} \mathrm{O}, \mathrm{O}_{3}$ and "Other" gas optical depths calculated for a sample atmosphere ( $w=2.9 \mathrm{~cm}, O=324 \mathrm{DU})$ using C5 and C6 gas correction coefficients. Like shown in Table A2, we see that except in Band 7, the "Other" gas correction is increased, primarily due to including more gases than just $\mathrm{CO}_{2}$. The significant difference in Band 5 stems from now modeled $\mathrm{O}_{2}$ absorption at $\sim 1.27 \mu \mathrm{m} . \mathrm{H}_{2} \mathrm{O}$ correction is also increased, due primarily to the increased spectral resolution.

In $\mathrm{C} 5$, the air mass $(G)$ factor was assumed to represent a flat earth geometry, so that $G=1 / \cos (Z)$ where $Z$ is zenith angle. However, as $Z \rightarrow 90^{\circ}, G$ should not go to infinity. At maximum allowed solar zenith angle of $84^{\circ}$, the flat earth assumption would overestimate $G$ by $10 \%$ or more, depending on gas vertical profile. While spherical shell assumption (with scale height $=8 \mathrm{~km}$ ) is better, we use the general formula of Kasten and Young (1989), but with appropriate coefficients to account for climatological differences of vertical profiles of each gas constituent (Gueymard, 1995), i.e.

$G^{j}=\left[\cos Z+a_{j, 1} Z^{a_{j, 2}}\left(a_{j, 3}-Z\right)^{a_{j, 4}}\right]^{-1}$

with coefficients listed in Table A3. At $Z=60^{\circ}$, the differences between flat earth and Eq. (9) are negligible, however the $G^{j}$ values for $84^{\circ}$ are also shown in Table A3. These values range from 7.49 (ozone) to 9.34 (water vapor) and can be compared to flat earth (9.57) and spherical earth shell (9.02) approximations. What is actually computed during the aerosol retrieval is the "two way" transmission correction, to account for the sum of downward (function of solar zenith angle, $Z=\theta_{0}$ ) and upward (function of view zenith angle, $Z=\theta$ ) gas absorptions. Therefore, $G^{j} \approx G^{j}\left(\theta_{0}\right)+G^{j}(\theta)$. For the widest valid MODIS geometry $\left(\theta_{0}=84^{\circ} ; \theta=64^{\circ}\right)$, a flat earth assumption would overestimate ozone absorption by $>20 \%$ (i.e., $9.57 \cdot 2.28 \cdot \tau_{\lambda}^{03}$ versus $7.49 \cdot 2.25 \cdot \tau_{\lambda}^{03}$ ).
Table A3. C6 air mass factor coefficients (from Kasten and Young, 1989, and Gueymard, 1995).

\begin{tabular}{lrrrrr}
\hline Gas type & $a_{j 1}$ & $a_{j 2}$ & $a_{j 3}$ & $a_{j 4}$ & $G_{j}\left(Z=84^{\circ}\right)$ \\
\hline $\mathrm{O}_{3}$ & 268.45 & 0.5 & 115.42 & -3.2922 & 7.49 \\
$\mathrm{H}_{2} \mathrm{O}$ & 0.0311 & 0.1 & 92.471 & -1.3814 & 9.34 \\
Other & 0.4567 & 0.07 & 96.484 & -1.6970 & 8.84 \\
\hline
\end{tabular}

Other gas includes $\mathrm{CO}_{2}, \mathrm{CO}, \mathrm{N}_{2} \mathrm{O}, \mathrm{NO}_{2}, \mathrm{NO}, \mathrm{CH}_{4}, \mathrm{O}_{2}, \mathrm{SO}_{2}$ and other trace gases. For comparison, flat earth geometry $\left(1 / \cos \left(84^{\circ}\right)\right.$ estimates $G=9.57$ and spherical geometry estimates $G=9.02$.

\section{Appendix B}

\section{List of C6 SDSs in MxD04_L2}

Table B1 lists the SDSs found within the C6 MxD04_L2 file. Properties given include units, scale factor, and valid range (minimum then maximum). Also listed are the dimensions of the parameter, and the descriptive "long name", given as an SDS attribute. SDSs marked with * are aggregated further into L3 data and \# are included in the C6 MxD04_3K file.

\section{Appendix C}

\section{Run-time QA flags for MxD04 (_L2)}

The Aerosol (dark target) run-time Quality Assurance (QA) flags are stored as Scientific Data Sets (SDSs), Quality_Assurance_Land, and Quality_Assurance_Ocean. The Deep Blue retrieval has its own QA flag but is not discussed here. Each of the two dark-target QA flags are five bytes that provide information on the processing (logic) path taken during the aerosol retrieval. The aerosol QA includes product quality flags, retrieval processing flags, and input data resource flags which are designed separately for land and ocean because of the differences of retrieval algorithms. Particular flags may indicate: (a) conditions why retrieval was not attempted at all (e.g. input data outside of boundary conditions), (b) cases where input data quality may be poor (e.g. large cloud fraction), so that the retrieval is performed with lower confidence, or (c) cases where retrieval may have been performed but the results were poor (e.g. results outside of realistic conditions). Aerosol QA arrays are produced at product resolution and for daytime only.

The Quality Assurance Confidence (QAC) flags summarize the QA logic, and are referred to in the main text of this paper. The QAC flags are the "Estimated quality flag of aerosol optical thickness" for land and the "Estimated quality of aerosol parameter of average solution" for ocean retrievals. These flags appear embedded in the bits of the 5-byte "Quality_Assurance_Land" and "Quality_Assurance_Ocean", but they also appear as straightforward integers in "Land_Ocean_Quality_Flag". 


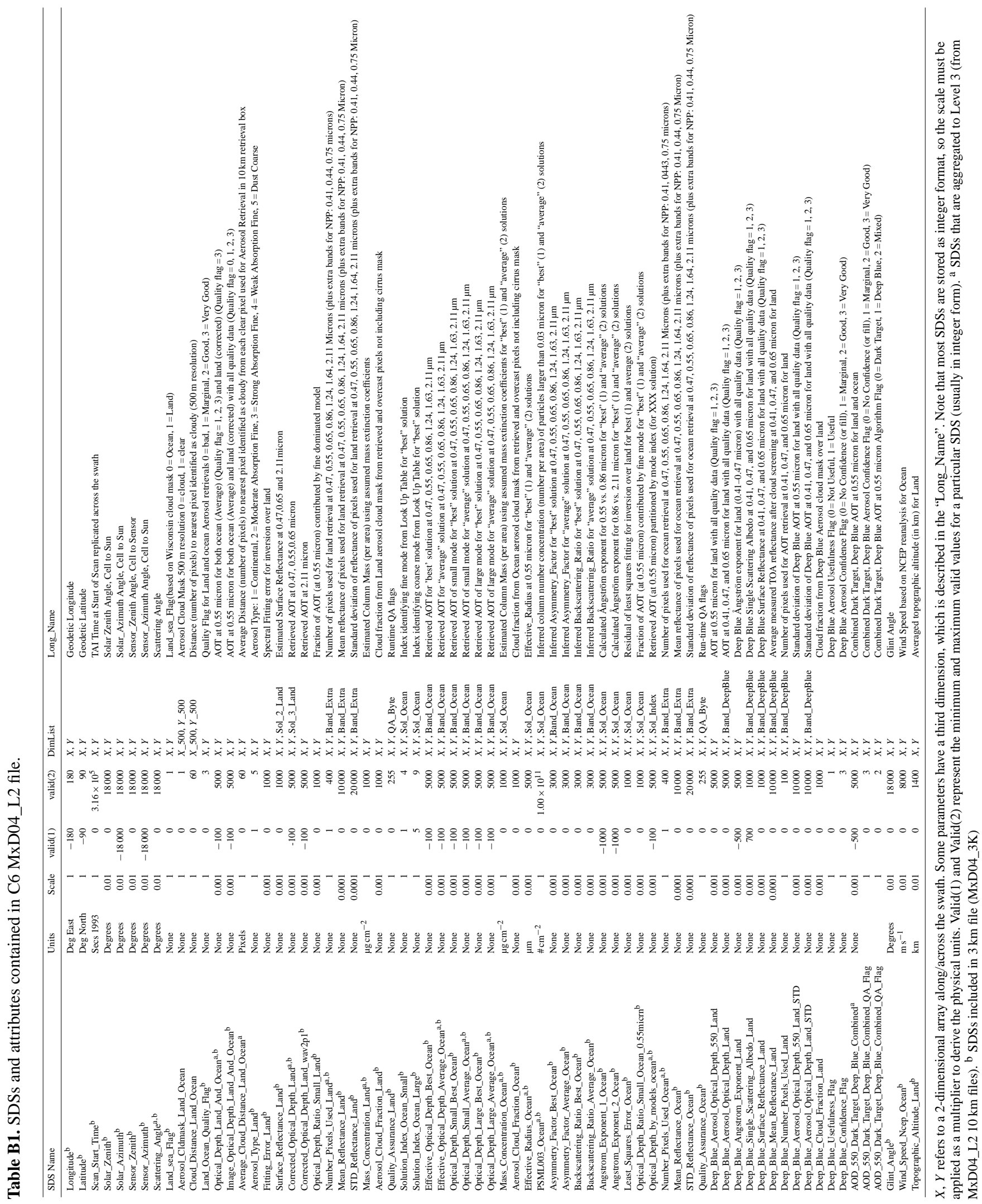


Table C1. Product quality and retrieval processing QA flags over land.

\begin{tabular}{|c|c|c|c|c|}
\hline Flag name & \# of bits & $\begin{array}{l}\text { Bit } \\
\text { value }\end{array}$ & Description & Comments \\
\hline \multicolumn{5}{|l|}{ Product quality QA summary flags } \\
\hline $\begin{array}{l}\text { Summary quality flag for aerosol optical } \\
\text { thickness ("QA usefulness") }\end{array}$ & 1 & $\begin{array}{l}0 \\
1\end{array}$ & $\begin{array}{l}\text { Not useful data } \\
\text { Useful }\end{array}$ & $\begin{array}{l}\text { All products are fill values } \\
\text { Valid products }\end{array}$ \\
\hline $\begin{array}{l}\text { Estimated quality flag of aerosol optical } \\
\text { thickness "QA Confidence flag" (QAC) }\end{array}$ & 3 & $\begin{array}{l}0 \\
1 \\
2 \\
3 \\
4-7\end{array}$ & $\begin{array}{l}\text { Poor } \\
\text { Marginal } \\
\text { Good } \\
\text { Very Good } \\
\text { Not Used (TBD) }\end{array}$ & \\
\hline $\begin{array}{l}\text { Summary quality flag for aerosol optical } \\
\text { thickness }\end{array}$ & 1 & $\begin{array}{l}0 \\
1\end{array}$ & $\begin{array}{l}\text { Not useful data } \\
\text { Useful }\end{array}$ & Repeat of bit 0 \\
\hline $\begin{array}{l}\text { Estimated quality flag of aerosol optical } \\
\text { thickness }\end{array}$ & 3 & $\begin{array}{l}0 \\
1 \\
2 \\
3 \\
4-7\end{array}$ & $\begin{array}{l}\text { Poor } \\
\text { Marginal } \\
\text { Good } \\
\text { Very Good } \\
\text { Not Used (TBD) }\end{array}$ & Repeat of bits $1-3$ \\
\hline \multicolumn{5}{|l|}{ Retrieval processing QA flags - Processing path flags } \\
\hline $\begin{array}{l}\text { Part I: retrieving condition flags when inversion } \\
\text { is performed - retrieved value will be output }\end{array}$ & 4 & $\begin{array}{l}0 \\
1 \\
2 \\
3 \\
4 \\
5 \\
6 \\
7 \\
8 \\
9 \\
10 \\
11 \\
12-15\end{array}$ & $\begin{array}{l}\text { Retrieval performed normally (no issues) } \\
\text { Procedure } 2 \text { performed (semi-bright surface, } \rho_{2.11}>0.25 \text { ) } \\
\text { Water pixels in } 10 \times 10 \text { box } \\
\text { Possible Cirrus present } \\
\text { Fitting error } \varepsilon>0.25 \\
-0.1<\text { Retrieved } \tau<0.0 \\
\text { \# pixels between } 12 \& 20 \\
\text { \# pixels between } 21 \& 30 \\
\text { \# pixels between } 31 \& 50 \\
\text { Angström out of bounds } \\
\text { Retrieved } \tau<0.2 \\
\text { No Retrieval } \\
\text { Not used (TBD) }\end{array}$ & $\begin{array}{l}\text { (0) } \mathrm{QAC}=3 \\
\text { (1) } \mathrm{QAC}=0 \\
\text { (2) } \mathrm{QAC}=0 \\
\text { (3) } \mathrm{QAC}=0 \\
\text { (4) } \mathrm{QAC}=0 \\
\text { (5) } \mathrm{QAC}=3 \\
\text { (6) } \mathrm{QAC}=0 \\
\text { (7) } \mathrm{QAC}=1 \\
\text { (8) } \mathrm{QAC}=2 \\
\text { (9) } \mathrm{QAC}=0 \\
\text { (10) } \mathrm{QAC}=3 \\
\text { (11) } \mathrm{QAC}=0 \\
\text { (12-15) }\end{array}$ \\
\hline $\begin{array}{l}\text { Part II: retrieving condition flags when inver- } \\
\text { sion is NOT performed - fill values are output }\end{array}$ & 4 & $\begin{array}{l}0 \\
1 \\
2 \\
3 \\
4 \\
5 \\
6 \\
7-8\end{array}$ & 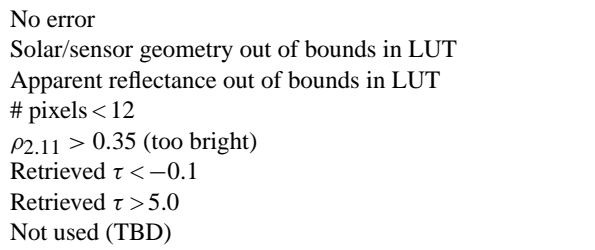 & $\begin{array}{l}\text { QAC }=0 \\
\text { QA Useful flag }=0\end{array}$ \\
\hline Aerosol Type & 2 & $\begin{array}{l}0 \\
1 \\
2 \\
3\end{array}$ & All empty & Not currently filled \\
\hline Thin cirrus or stratospheric aerosol index & 2 & $\begin{array}{l}0 \\
1 \\
2 \\
3\end{array}$ & All empty & Not currently filled \\
\hline \multicolumn{5}{|c|}{ Retrieval processing QA flags - Input data resource flags } \\
\hline Total ozone & 2 & $\begin{array}{l}0 \\
1 \\
2 \\
3\end{array}$ & $\begin{array}{l}\text { TOVS } \\
\text { TOMS } \\
\text { Climatology } \\
\text { DAO }\end{array}$ & \\
\hline Total precipitable water & 2 & $\begin{array}{l}0 \\
1 \\
2 \\
3\end{array}$ & $\begin{array}{l}\text { NCEP/GDAS } \\
\text { MOD05 - NIR } \\
\text { Climatology } \\
\text { DAO }\end{array}$ & \\
\hline Snow cover & 2 & $\begin{array}{l}0 \\
1 \\
2-3\end{array}$ & $\begin{array}{l}\text { MOD35-cloud mask } \\
\text { MOD10-L3 } 8 \text { day product. } \\
\text { TBD }\end{array}$ & \\
\hline Spare & 6 & & TBD & \\
\hline
\end{tabular}


Table C2. Product quality and retrieval processing QA flags over ocean.

\begin{tabular}{|c|c|c|c|c|}
\hline Flag name & \# of bits & $\begin{array}{l}\text { Bit } \\
\text { value }\end{array}$ & Description & Comments \\
\hline \multicolumn{5}{|l|}{ Product quality QA summary flags } \\
\hline $\begin{array}{l}\text { Summary quality flag for "best" solution: "QA } \\
\text { usefulness" flag }\end{array}$ & 1 & $\begin{array}{l}0 \\
1\end{array}$ & $\begin{array}{l}\text { Not useful } \\
\text { Useful }\end{array}$ & $\begin{array}{l}\text { (0) products are fill values } \\
\text { (1) valid products }\end{array}$ \\
\hline $\begin{array}{l}\text { Estimated quality of aerosol parameters of } \\
\text { "best" solution "QA Confidence" or "QAC" }\end{array}$ & 3 & $\begin{array}{l}0 \\
1 \\
2 \\
3 \\
4-7\end{array}$ & $\begin{array}{l}\text { Poor } \\
\text { Marginal } \\
\text { Good } \\
\text { Very Good } \\
\text { Not Used (TBD) }\end{array}$ & \\
\hline $\begin{array}{l}\text { Summary quality flag for "average" solution: } \\
\text { "QA usefulness" flag }\end{array}$ & 1 & $\begin{array}{l}0 \\
1\end{array}$ & $\begin{array}{l}\text { Not useful } \\
\text { Useful }\end{array}$ & $\begin{array}{l}\text { (0) products are fill values } \\
\text { (1) valid products }\end{array}$ \\
\hline $\begin{array}{l}\text { Estimated quality of aerosol parameter of } \\
\text { "average" solution "QA Confidence" or "QAC" }\end{array}$ & 3 & $\begin{array}{l}0 \\
1 \\
2 \\
3 \\
4-7\end{array}$ & $\begin{array}{l}\text { Poor } \\
\text { Marginal } \\
\text { Good } \\
\text { Very Good } \\
\text { Not Used (TBD) }\end{array}$ & $\begin{array}{l}\text { average solution is used for } \\
\text { populating joint product }\end{array}$ \\
\hline \multicolumn{5}{|l|}{ Retrieval processing QA flags - Processing path flags } \\
\hline $\begin{array}{l}\text { Part I: retrieving condition flags when inversion } \\
\text { is NOT performed - fill values are output }\end{array}$ & 4 & $\begin{array}{l}0 \\
1 \\
2 \\
3 \\
4 \\
5 \\
6 \\
7 \\
8 \\
9 \\
10 \\
11-15\end{array}$ & $\begin{array}{l}\text { Retrieval is performed } \\
\text { Glitter present }\left(\mathrm{GA}<40^{\circ}\right) \\
\text { Cloudy (less than } 10 \text { pixels) } \\
* * * \text { Not used*** } \\
\text { Number of valid VIS/SWIR channels }(0.55-1.24 \mu \mathrm{m}) \text { is insufficient } \\
\text { Number of valid channels }<3 \\
\text { Geometry out of bounds } \\
\text { Land pixels in } 10 \times 10 \mathrm{~km} \text { box } \\
\text { Retrieved } \tau<-0.01 \\
\text { Retrieved } \tau>5.0 \\
\text { No valid reflectance for any channel } \\
\text { TBD }\end{array}$ & $\begin{array}{l}\text { (0) QAC defined by Part II } \\
\text { (1) QAC }=0 \text {, no retrieval, } \\
\text { but some arrays filled. } \\
\text { ( }-10) \text { QAC }=0 \text {, and no } \\
\text { arrays filled. }\end{array}$ \\
\hline $\begin{array}{l}\text { Part II: retrieving condition flags when inver- } \\
\text { sion is performed - retrieved value will be } \\
\text { output }\end{array}$ & 4 & $\begin{array}{l}0 \\
1 \\
2 \\
3 \\
4 \\
5 \\
6 \\
7 \\
8 \\
9 \\
10 \\
11 \\
12 \\
13 \\
14 \\
15 \\
16-19 \\
20\end{array}$ & 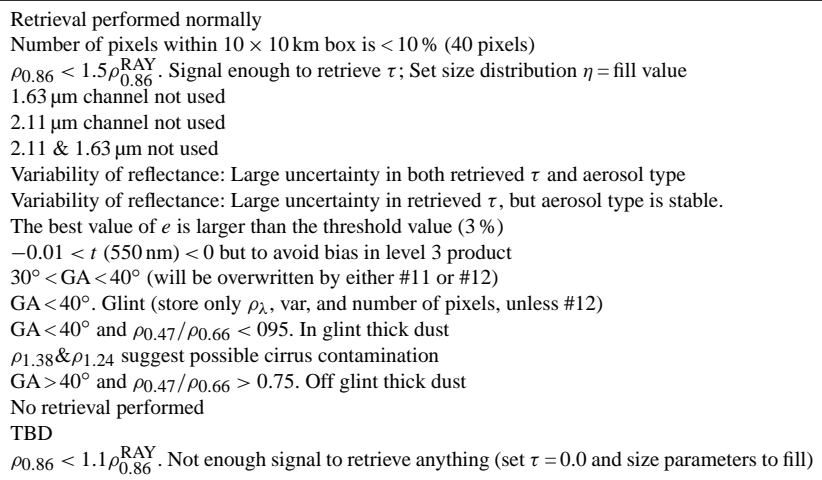 & $\begin{array}{l}\text { (0) } \mathrm{QAC}=3 \\
\text { (1) } \mathrm{QAC}=1 \\
\text { (2) } \mathrm{QAC}=2 \\
\text { (3) } \mathrm{QAC}=1 \\
\text { (4) } \mathrm{QAC}=1 \\
\text { (5) } \mathrm{QAC}=0 \\
\text { (6) } \mathrm{QAC}=1 \\
\text { (7) } \mathrm{QAC}=2 \\
\text { (8) } \mathrm{QAC}=1 \\
\text { (9) } \mathrm{QAC}=0 \\
\text { (10) } \mathrm{QAC}=1 \\
\text { (11) } \mathrm{QAC}=0 \\
\text { (12) } \mathrm{QAC}=0 \\
\text { (13) } \mathrm{QAC}=0 \\
\text { (14) } \mathrm{QAC}=2 \\
\text { (15) } \mathrm{QAC}=0 \\
\text { (16-19) } \\
\text { (20) } \mathrm{QAC}=1\end{array}$ \\
\hline \multicolumn{5}{|c|}{ Retrieval processing QA flags - Input data resource flags } \\
\hline Total ozone & 2 & $\begin{array}{l}0 \\
1 \\
2 \\
3\end{array}$ & $\begin{array}{l}\text { TOVS } \\
\text { TOMS } \\
\text { Climatology } \\
\text { DAO }\end{array}$ & \\
\hline Total precipitable water & 2 & $\begin{array}{l}0 \\
1 \\
2 \\
3\end{array}$ & $\begin{array}{l}\text { NCEP/GDAS } \\
\text { MOD05 - NIR } \\
\text { Climatology } \\
\text { DAO }\end{array}$ & \\
\hline Snow cover & 2 & $\begin{array}{l}0 \\
1 \\
2-3\end{array}$ & $\begin{array}{l}\text { MOD35-cloud mask } \\
\text { MOD10-L3 } 8 \text { day product. } \\
\text { TBD }\end{array}$ & \\
\hline Spare & 2 & & TBD & \\
\hline
\end{tabular}

The following tables describe the byte decoding of the MxD04 "Quality_Assurance_Land", and "Quality_Assurance_Ocean" SDSs. Each flag corresponds to a certain number of bits, and bit values corresponding to results of certain tests. Note that the flags representing the case of valid retrieval but lower confidence is known as "Part I" over land, but "Part II" over ocean. Similarly the flags representing the case of no valid retrieval are known as Part II over land, but Part I over ocean. Under the column "Comments", we describe possible flag cascades. For example, if Part I over land receives value $=8$ (less than optimal clear sky pixels) then the QAC would be set to 2 (good quality). 
Acknowledgements. We thank Bill Ridgway (SSAI/GSFC), Georgios Britzolakis (Sigma Space Corp.) and the MODAPS team for facilitating our extensive iterative testing needs. We are grateful to Zia Ahmad (SDSI/GSFC) for help with over-ocean LUTs and the AER team for helping us with LBL-RTM interpretation. We thank Robert Wolfe (GSFC), Jack Xiong (GSFC) and the MCST teams for discussions about updating land/sea flags, calibration, and all the other details that enable high quality MODIS observations. We could not do this study without the AERONET and MAN teams' continuing support of quality controlled, easy-access data. Finally, we appreciate the extensive feedback from our named (Jeff Reid and Michael Garay) as well as our anonymous reviewers. This work was supported by NASA's NNH09ZDA001N-TERRAQUA: the Science of Terra and Aqua.

Edited by: D. Tanre

\section{References}

Ackerman, S. A., Strabala, K. I., Menzel, W. P., Frey, R. A., Moeller, C. C., and Gumley, L. E.: Discriminating clear sky from clouds with MODIS, J. Geophys. Res., 103, 32.141-32.157, doi:10.1029/1998JD200032, 1998.

Ackerman, S. A., Frey, R., Strabala, K. I., Liu, Y., Gumley, L., Baum, B. A., and Menzel, W. P.: Discriminating clear-sky from cloud with modis: Algorithm Theoretical Basis Document (MOD35), 6th Edn., Cooperative Institute for Meteorological Satellite Studies, University of Wisconsin-Madison, 2010.

Ahmad, Z. and Fraser, R. S.: An Iterative Radiative Transfer Code For Ocean-Atmosphere Systems, J. Atmos. Sci., 39, 656-665, doi:10.1175/15200469(1982)039<3C0656:AIRTCF>3E2.0.CO;2, 1982.

Al-Saadi, J., Szykman, J., Pierce, R. B., Kittaka, C., Neil, D., Chu, D. A., Remer, L., Gumley, L., Prins, E., Weinstock, L., MacDonald, C., Wayland, R., Dimmick, F., and Fishman, J.: Improving national air quality forecasts with satellite aerosol observations, B. Am. Meteorol. Soc., 86, 1249-1261, doi:10.1175/BAMS-869-1249, 2005.

Anderson, T. L., Charlson, R. J., Winker, D. M., Ogren, J. A., and Holmén, K.: Mesoscale Variations of Tropospheric Aerosols, J. Atmos. Sci., 60, 119-136, doi:10.1175/15200469(2003)060<0119:MVOTA>2.0.CO;2, 2003.

Anderson, T. L., Wu, Y., Chu, D. A., Schmid, B., Redemann, J., and Dubovik, O.: Testing the MODIS satellite retrieval of aerosol fine-mode fraction, J. Geophys. Res., 110, 18204, doi:10.1029/2005JD005978, 2005.

Benedetti, A., Morcrette, J. J., Boucher, O., Dethof, A., Engelen, R. J., Fisher, M., Flentje, H., Huneeus, N., Jones, L., Kaiser, J. W., Kinne, S., Mangold, A., Razinger, M., Simmons, A. J., and Suttie, M.: Aerosol analysis and forecast in the European Centre for Medium-Range Weather Forecasts Integrated Forecast System: 2. Data assimilation, J. Geophys. Res., 114, D13205, doi:10.1029/2008JD011115, 2009.

Bodhaine, B., Wood, N., Dutton, E., and Slusser, J.: On Rayleigh optical depth calculations, J. Atmos. Ocean. Tech., 16, 18541861, 1999.
Breon, F.-M., Vermeulen, A., and Descloitres, J.: An evaluation of satellite aerosol products against sunphotometer measurements, Remote Sens. Environ., 115, 3102-3111, doi:10.1016/j.rse.2011.06.017, 2011.

Carmona, I., Kaufman, Y. J., and Alpert, P.: Using numerical weather prediction errors to estimate aerosol heating, Tellus B, 60, 729-741, doi:10.1111/j.1600-0889.2008.00371.x, 2008.

Carroll, M. L., Townshend, J. R., DiMiceli, C. M., Noojipady, P., and Sohlberg, R. A.: A new global raster water mask at $250 \mathrm{~m}$ resolution, International Journal of Digital Earth, 2, 291-308, doi:10.1080/17538940902951401, 2009.

Carroll, M. L., Townshend, J. R. G., DiMiceli, C. M., Loboda, T., and Sohlberg, R. A.: Shrinking lakes of the Arctic: Spatial relationships and trajectory of change, Geophys. Res. Lett., 38, 20406, doi:10.1029/2011GL049427, 2011.

Chander, G., Xiong, X. J., Choi, T. J., and Angal, A.: Monitoring on-orbit calibration stability of the Terra MODIS and Landsat 7 ETM+ sensors using pseudo-invariant test sites, Remote Sens. Environ., 114, 925-939, doi:10.1016/j.rse.2009.12.003, 2010.

Chu, D. A., Kaufman, Y. J., Remer, L. A., and Holben, B. N.: Remote sensing of smoke from MODIS airborne simulator during the SCAR-B experiment, J. Geophys. Res., 103, 31979-31987, doi:10.1029/98JD01148, 1998.

Chu, D. A., Kaufman, Y. J., Ichoku, C., Remer, L. A., Tanre, D., and Holben, B. N.: Validation of MODIS aerosol optical depth retrieval over land, Geophys. Res. Lett., 29, MOD2.1-MOD2.4, doi:10.1029/2001GL013205, 2002.

Chu, D. A., Kaufman, Y. J., Zibordi, G., Chern, J. D., Mao, J., Li, C., and Holben, B. N.: Global monitoring of air pollution over land from the Earth Observing System-Terra Moderate Resolution Imaging Spectroradiometer (MODIS), J. Geophys. Res., 108, 4661, doi:10.1029/2002JD003179, 2003.

Clough, S. A., Iacono, M. J., and Moncet, J.-L.: Line-by-Line Calculations of Atmospheric Fluxes and Cooling Rates: Application to Water Vapor, J. Geophys. Res.-Atmos., 97, 15761, doi:10.1029/92JD01419, 1992.

Clough, S. A., Shephard, M. W., Mlawer, E. J., Delamere, J. S., Iacono, M. J., Cady-Pereira, K., Boukabara, S., and Brown, P. D.: Atmospheric radiative transfer modeling: a summary of the AER codes, J. Quant. Spectrosc. Ra., 91, 233-244, doi:10.1016/j.jqsrt.2004.05.058, 2005.

Cox, C. and Munk, W.: Measurement of the Roughness of the Sea Surface from Photographs of the Sun's Glitter, Journal of the Optical Society of America, 44, 838-850, doi:10.1364/JOSA.44.000838, 1954.

Crusius, J., Schroth, A. W., Gasso, S., Moy, C. M., Levy, R. C., and Gatica, M.: Glacial flour dust storms in the Gulf of Alaska: Hydrologic and meteorological controls and their importance as a source of bioavailable iron, Geophys. Res. Lett., 38, L06602, doi:10.1029/2010GL046573, 2011.

de Meij, A., Pozzer, A., and Lelieveld, J.: Trend analysis in aerosol optical depths and pollutant emission estimates between 2000 and 2009, Atmos. Environ., 51, 75-85, doi:10.1016/j.atmosenv.2012.01.059, 2012. 
Dubovik, O., Sinyuk, A., Lapyonok, T., Holben, B. N., Mishchenko, M., Yang, P., Eck, T. F., Volten, H., Munoz, O., Veihelmann, B., van der Zande, W. J., Leon, J.-F., Sorokin, M., and Slutsker, I.: Application of spheroid models to account for aerosol particle nonsphericity in remote sensing of desert dust, J. Geophys. Res., 111, 11208, doi:10.1029/2005JD006619, 2006.

Engel-Cox, J. A., Holloman, C. H., Coutant, B. W., and Hoff, R. M.: Qualitative and quantitative evaluation of MODIS satellite sensor data for regional and urban scale air quality, Atmos. Environ., 38, 15-15, doi:10.1016/j.atmosenv.2004.01.039, 2004.

Evans, K. F. and Stephens, G. L.: A new polarized atmospheric radiative transfer model, J. Quant. Spectrosc. Ra., 46, 413-423, 1991.

Franz, B. A. B., Bailey, S. W. S., Werdell, P. J. P., and McClain, C. R. C.: Sensor-independent approach to the vicarious calibration of satellite ocean color radiometry, Appl. Optics, 46, 5068-5082, doi:10.1364/AO.46.005068, 2007.

Gao, B., Yang, P., Han, W., Li, R., and Wiscombe, W.: An algorithm using visible and 1.38-mu $\mathrm{m}$ channels to retrieve cirrus cloud reflectances from aircraft and satellite data, IEEE T. Geosci. Remote, 40, 1659-1668, doi:10.1109/TGRS.2002.802454, 2002.

Giles, D. M., Holben, B. N., Eck, T. F., Sinyuk, A., Smirnov, A., Slutsker, I., Dickerson, R. R., Thompson, A. M., and Schafer, J. S.: An analysis of AERONET aerosol absorption properties and classifications representative of aerosol source regions, J. Geophys. Res., 117, 17203, doi:10.1029/2012JD018127, 2012.

Gueymard, C.: SMARTS2: a simple model of the atmospheric radiative transfer of sunshine: algorithms and performance assessment, Florida Solar Energy Center, 1-78, 1995.

Herman, M., Deuzé, J.-L., Marchand, A., Roger, B., and Lallart, P.: Aerosol remote sensing from POLDER/ADEOS over the ocean: Improved retrieval using a nonspherical particle model, J. Geophys. Res., 110, D10S02, doi:10.1029/2004JD004798, 2005.

Hoff, R., Zhang, H., Jordan, N., Prados, A., Engel-Cox, J., Huff, A., Weber, S., Zell, E., Kondragunta, S., Szykman, J., Johns, B., Dimmick, F., Wimmers, A., Al-Saadi, J., and Kittaka, C.: Applications of the Three-Dimensional Air Quality System to Western U.S. Air Quality: IDEA, Smog Blog, Smog Stories, AirQuest, and the Remote Sensing Information Gateway, J. Air Waste Manage., 59, 980-989, doi:10.3155/1047-3289.59.8.980, 2009.

Holben, B. N., Eck, T. F., Slutsker, I., Tanre, D., Buis, J. P., Setzer, A., Vermote, E., Reagan, J. A., Kaufman, Y. J., Nakajima, T., Lavenu, F., Jankowiak, I., and Smirnov, A.: AERONET - A federated instrument network and data archive for aerosol characterization, Remote Sens. Environ., 66, 1-16, doi:10.1016/S00344257(98)00031-5, 1998.

Holben, B. N., Eck, T. F., Slutsker, I., Smirnov, A., Sinyuk, A., Schafer, J., Giles, D., and Dubovik, O.: Aeronet's Version 2.0 quality assurance criteria, edited by: Tsay, S.-C., P. Soc. Photo.Opt. Ins., 16, 6408, doi:10.1117/12.706524, 2006.

Hsu, N. C., Tsay, S. C., King, M. D., and Herman, J. R.: Aerosol Properties Over Bright-Reflecting Source Regions, IEEE T. Geosci. Remote, 42, 557-569, doi:10.1109/TGRS.2004.824067, 2004.

Hsu, N. C., Tsay, S. C., King, M. D., and Herman, J. R.: Deep blue retrievals of Asian aerosol properties during ACE-Asia, IEEE T. Geosci. Remote, 44, 3180-3195, doi:10.1109/TGRS.2006.879540, 2006.
Hsu, N. C., Gautam, R., Sayer, A. M., Bettenhausen, C., Li, C., Jeong, M. J., Tsay, S.-C., and Holben, B. N.: Global and regional trends of aerosol optical depth over land and ocean using SeaWiFS measurements from 1997 to 2010, Atmos. Chem. Phys., 12, 8037-8053, doi:10.5194/acp-12-8037-2012, 2012.

Hubanks, P. A.: MODIS Atmosphere QA Plan for Collection 005, Greenbelt, MD USA, NASA Goddard Space Flight Center, 57, 2012.

Hubanks, P. A., King, M. D., Platnick, S., and Pincus, R.: MODIS atmosphere L3 gridded product algorithm theoretical basis document, ATBD Reference Number: ATBD-MOD-30, 2008.

Huete, A., Didan, K., van Leeuwen, W., Miura, T., and Glenn, E.: MODIS Vegetation Indices, Land Remote Sensing and Global Environmental Change, 1, 579, doi:10.1007/978-1-4419-67497_26, 2011.

Hyer, E. J., Reid, J. S., and Zhang, J.: An over-land aerosol optical depth data set for data assimilation by filtering, correction, and aggregation of MODIS Collection 5 optical depth retrievals, Atmos. Meas. Tech., 4, 379-408, doi:10.5194/amt-4-379-2011, 2011.

Ichoku, C., Chu, D., Mattoo, S., Kaufman, Y., Remer, L., Tanre, D., Slutsker, I., and Holben, B.: A spatio-temporal approach for global validation and analysis of MODIS aerosol products, Geophys. Res. Lett., 29, 1616, doi:10.1029/2001GL013206, 2002.

Ichoku, C., Remer, L., Kaufman, Y., Levy, R., Chu, D., Tanre, D., and Holben, B.: MODIS observation of aerosols and estimation of aerosol radiative forcing over southern Africa during SAFARI 2000, J. Geophys. Res.-Atmos., 108, 8499-8499, doi:10.1029/2002JD002366, 2003.

IPCC, I. P. O. C. C.: Climate Change 2007 - The Physical Science Basis, Cambridge University Press. 2007.

Jeong, M. J., Hsu, N. C., Kwiatkowska, E. J., Franz, B. A., Meister, G., and Salustro, C. E.: Impacts of cross-platform vicarious calibration on the Deep Blue aerosol retrievals for Moderate Resolution Imaging Spectroradiometer aboard Terra, IEEE T. Geosci. Remote., 49, 4877-4888, doi:10.1109/TGRS.2011.2153205, 2011.

Jethva, H., Satheesh, S. K., and Srinivasan, J.: Assessment of second-generation MODIS aerosol retrieval (Collection 005) at Kanpur, India, Geophys. Res. Lett., 34, L19802, doi:10.1029/2007GL029647, 2007.

Jethva, H., Torres, O., Remer, L. A., and Bhartia, P. K.: A Color Ratio Method for Simultaneous Retrieval of Aerosol and Cloud Optical Thickness of Above-Cloud Absorbing Aerosols From Passive Sensors: Application to MODIS Measurements, IEEE T. Geosci. Remote, 51, 3862-3870, doi:10.1109/TGRS.2012.2230008, 2013.

Kahn, R. A.: Reducing the Uncertainties in Direct Aerosol Radiative Forcing, Surv. Geophys., 33, 701-721, doi:10.1007/s10712 011-9153-z, 2011.

Kahn, R. A., Garay, M. J., Nelson, D. L., Yau, K. K., Bull, M. A., Gaitley, B. J., Martonchik, J. V., and Levy, R. C.: Satellitederived aerosol optical depth over dark water from MISR and MODIS: Comparisons with AERONET and implications for climatological studies, J. Geophys. Res.-Atmos., 112, D18205, doi:10.1029/2006JD008175, 2007.

Kasten, F. F. and Young, A. T. A.: Revised optical air mass tables and approximation formula, Appl. Optics, 28, 4735-4738, doi:10.1364/AO.28.004735, 1989. 
Kaufman, Y. J., Tanre, D., Remer, L. A., Vermote, E. F., Chu, A., and Holben, B. N.: Operational remote sensing of tropospheric aerosol over land from EOS moderate resolution imaging spectroradiometer, J. Geophys. Res., 102, 17051-17068, doi:10.1029/96JD03988, 1997a.

Kaufman, Y. J., Wald, A. E., Remer, L. A., Gao, B.-C., Li, R.R., and Flynn, L.: The MODIS $2.1 \mu \mathrm{m}$ channel-correlation with visible reflectance for use in remote sensing of aerosol, IEEE T. Geosci. Remote., 35, 1286-1298, doi:10.1109/36.628795, 1997b.

Kaufman, Y. J., Ichoku, C., Giglio, L., Korontzi, S., Chu, D. A., Hao, W. M., Li, R. R., and Justice, C. O.: Fire and smoke observed from the Earth Observing System MODIS instrumentproducts, validation, and operational use, Int. J. Remote Sens., 24, 1765-1781, doi:10.1080/01431160210144741, 2003.

Kaufman, Y. J., Koren, I., Remer, L. A., Rosenfeld, D., and Rudich, Y.: The effect of smoke, dust, and pollution aerosol on shallow cloud development over the Atlantic Ocean, P. Natl. Acad. Sci. USA, 102, 11207-11212, doi:10.1073/pnas.0505191102, 2005.

King, L. V.: On the Complex Anisotropic Molecule in Relation to the Dispersion and Scattering of Light, P. R. Soc. Lond. AConta., 104, 333-357, 1923.

King, M. D., Menzel, W. P., Kaufman, Y. J., Tanre, D., Gao, B.-C., Platnick, S., Ackerman, S. A., Remer, L. A., Pincus, R., and Hubanks, P. A.: Cloud and aerosol properties, precipitable water, and profiles of temperature and water vapor from MODIS, IEEE T. Geosci. Remote, 41, 442-458, doi:10.1109/TGRS.2002.808226, 2003.

King, M. D., Platnick, S., Menzel, W. P., Ackerman, S. A., and Hubanks, P. A.: Spatial and Temporal Distribution of Clouds Observed by MODIS Onboard the Terra and Aqua Satellites, IEEE T. Geosci. Remote, 51, 3826-3852, doi:10.1109/TGRS.2012.2227333, 2013.

Kishcha, P., Starobinets, B., and Alpert, P.: Latitudinal variations of cloud and aerosol optical thickness trends based on MODIS satellite data, Geophys. Res. Lett., 34, L05810, doi:10.1029/2006GL028796, 2007.

Kleidman, R. G., O’Neill, N. T., Remer, L. A., Kaufman, Y. J., Eck, T. F., Tanré, D., Dubovik, O., and Holben, B. N.: Comparison of moderate resolution Imaging spectroradiometer (MODIS) and aerosol robotic network (AERONET) remote-sensing retrievals of aerosol fine mode fraction over ocean, J. Geophys. Res.-Atmos., 110, D22205, doi:10.1029/2005JD005760, 2005.

Kleidman, R. G., Smirnov, A., Levy, R. C., Mattoo, S., and Tanre, D.: Evaluation and Wind Speed Dependence of MODIS Aerosol Retrievals Over Open Ocean, IEEE T. Geosci. Remote, 50, 429435, doi:10.1109/TGRS.2011.2162073, 2012.

Koepke, P.: Effective reflectance of oceanic whitecaps, Appl. Optics, 23, 1816-1824, 1984.

Koren, I. and Feingold, G.: Aerosol-cloud-precipitation system as a predator-prey problem, P. Natl. Acad. Sci., doi:10.1073/pnas.1101777108, in press, 2011.

Koren, I. and Kaufman, Y. J.: Direct wind measurements of Saharan dust events from Terra and Aqua satellites, Geophys. Res. Lett., 31, L06122, doi:10.1029/2003GL019338, 2004.

Koren, I., Oreopoulos, L., Feingold, G., Remer, L. A., and Altaratz, O.: How small is a small cloud?, Atmos. Chem. Phys., 8, 38553864, doi:10.5194/acp-8-3855-2008, 2008.
Kotchenova, S. Y., Vermote, E. F., Levy, R., and Lyapustin, A.: Radiative transfer codes for atmospheric correction and aerosol retrieval: intercomparison study, Appl. Optics, 47, 2215-2226, doi:10.1364/AO.47.002215, 2008.

Koukouli, M. E., Kazadzis, S., Amiridis, V., Ichoku, C., Balis, D. S., and Bais, A. F.: Signs of a negative trend in the MODIS aerosol optical depth over the Southern Balkans, Atmos. Environ., 44, 1219-1228, doi:10.1016/j.atmosenv.2009.11.024, 2010.

Levy, R. C., Remer, L. A., Tanré, D., Kaufman, Y. J., Ichoku, C., Holben, B. N., Livingston, J. M., Russell, P. B., and Maring, H.: Evaluation of the Moderate-Resolution Imaging Spectroradiometer (MODIS) retrievals of dust aerosol over the ocean during PRIDE, J. Geophys. Res.-Atmos., 108, 8594, doi:10.1029/2002JD002460, 2003.

Levy, R. C., Remer, L. A., Martins, J. V., Kaufman, Y. J., PlanaFattori, A., Redemann, J., and Wenny, B.: Evaluation of the MODIS aerosol retrievals over ocean and land during CLAMS, J. Atmos. Sci., 62, 974-992, doi:10.1175/JAS3391.1, 2005.

Levy, R. C., Remer, L. A., and Dubovik, O.: Global aerosol optical properties and application to Moderate Resolution Imaging Spectroradiometer aerosol retrieval over land, J. Geophys. Res.Atmos., 112, D13210, doi:10.1029/2006JD007815, 2007a.

Levy, R. C., Remer, L. A., Mattoo, S., Vermote, E. F., and Kaufman, Y. J.: Second-generation operational algorithm: Retrieval of aerosol properties over land from inversion of Moderate Resolution Imaging Spectroradiometer spectral reflectance, J. Geophys. Res.-Atmos., 112, D13211, doi:10.1029/2006JD007811, $2007 \mathrm{~b}$.

Levy, R. C., Leptoukh, G. G., Kahn, R., Zubko, V., Gopalan, A., and Remer, L. A.: A Critical Look at Deriving Monthly Aerosol Optical Depth From Satellite Data, IEEE T. Geosci. Remote, 47, 2942-2956, doi:10.1109/TGRS.2009.2013842, 2009a.

Levy, R. C., Remer, L. A., Tanré, D., Mattoo, S., and Kaufman, Y. J.: Algorithm for remote sensing of tropospheric aerosol over dark targets from MODIS: Collections 005 and 051: Revision 2; Feb 2009, MODIS Algorithm Theoretical Basis Document, 2009b.

Levy, R. C., Remer, L. A., Kleidman, R. G., Mattoo, S., Ichoku, C., Kahn, R., and Eck, T. F.: Global evaluation of the Collection 5 MODIS dark-target aerosol products over land, Atmos. Chem. Phys., 10, 10399-10420, doi:10.5194/acp-10-10399-2010, 2010.

Li, C., Lau, A., Mao, J., and Chu, D.: Retrieval, validation, and application of the 1-km aerosol optical depth from MODIS measurements over Hong Kong, IEEE T. Geosci. Remote, 43, 26502658, 2005.

Li, R. R., Kaufman, Y. J., Gao, B. C., and Davis, C. O.: Remote sensing of suspended sediments and shallow coastal waters, IEEE T. Geosci. Remote, 41, 559-566, 2003.

Li, R. R., Remer, L., Kaufman, Y. J., Mattoo, S., Gao, B. C., and Vermote, E.: Snow and ice mask for the MODIS aerosol products, IEEE Geosci. Remote Sens., 2, 306-310, 2005.

Livingston, J. M., Redemann, J., Shinozuka, Y., Johnson, R., Russell, P. B., Zhang, Q., Mattoo, S., Remer, L., Levy, R., Munchak, L., and Ramachandran, S.: Comparison of MODIS $3 \mathrm{~km}$ and $10 \mathrm{~km}$ resolution aerosol optical depth retrievals over land with airborne sunphotometer measurements during ARCTAS summer 2008, Atmos. Chem. Phys. Discuss., 13, 15007-15059, doi:10.5194/acpd-13-15007-2013, 2013. 
Lyapustin, A., Wang, Y., Laszlo, I., Kahn, R., Korkin, S., Remer, L., Levy, R., and Reid, J. S.: Multiangle implementation of atmospheric correction (MAIAC): 2. Aerosol algorithm, J. Geophys. Res.-Atmos., 116, doi:10.1029/2010JD014986, 2011.

Martins, J. V., Tanré, D., Remer, L., Kaufman, Y., Mattoo, S., and Levy, R.: MODIS Cloud screening for remote sensing of aerosols over oceans using spatial variability, Geophys. Res. Lett., 29, 8009, doi:10.1029/2001GL013252, 2002.

McComiskey, A., Schwartz, S. E., Schmid, B., Guan, H., Lewis, E. R., Ricchiazzi, P., and Ogren, J. A.: Direct aerosol forcing: Calculation from observables and sensitivities to inputs, J. Geophys. Res.-Atmos., 113, 9202, doi:10.1029/2007JD009170, 2008.

Meister, G., Franz, B. A., Kwiatkowska, E. J., and McClain, C. R.: Corrections to the Calibration of MODIS Aqua Ocean Color Bands Derived From SeaWiFS Data, IEEE T. Geosci. Remote, 50, 310-319, doi:10.1109/TGRS.2011.2160552, 2012.

Mielonen, T., Levy, R. C., Aaltonen, V., Komppula, M., de Leeuw, G., Huttunen, J., Lihavainen, H., Kolmonen, P., Lehtinen, K. E. J., and Arola, A.: Evaluating the assumptions of surface reflectance and aerosol type selection within the MODIS aerosol retrieval over land: the problem of dust type selection, Atmos. Meas. Tech., 4, 201-214, doi:10.5194/amt-4-201-2011, 2011.

Mishchenko, M. I., Geogdzhayev, I. V., Rossow, W. B., Cairns, B., Carlson, B. E., Lacis, A. A., Liu, L., and Travis, L. D.: LongTerm Satellite Record Reveals Likely Recent Aerosol Trend, Science, 315, 1543-1543, doi:10.1126/science.1136709, 2007.

Monahan, E. C. and Muircheartaigh, I.: Optimal Power-Law Description of Oceanic Whitecap Coverage Dependence on Wind Speed, J. Phys. Oceanogr., 10, 2094-2099, doi:10.1175/15200485(1980)010<2094:OPLDOO>2.0.CO;2, 1980.

Moody, E. G., King, M. D., Platnick, S., Schaaf, C. B., and Feng Gao: Spatially complete global spectral surface albedos: value-added datasets derived from Terra MODIS land products, IEEE T. Geosci. Remote, 43, 144-158, doi:10.1109/TGRS.2004.838359, 2005.

Moody, E. G., King, M. D., Schaaf, C. B., and Platnick, S.: MODIS-Derived Spatially Complete Surface Albedo Products: Spatial and Temporal Pixel Distribution and Zonal Averages, J. Appl. Meteorol. Clim., 47, 2879-2894, doi:10.1175/2008JAMC1795.1, 2008.

Munchak, L. A., Levy, R. C., Mattoo, S., Remer, L. A., Holben, B. N., Schafer, J. S., Hostetler, C. A., and Ferrare, R. A.: MODIS $3 \mathrm{~km}$ aerosol product: applications over land in an urban/suburban region, Atmos. Meas. Tech., 6, 1747-1759, doi:10.5194/amt-6-1747-2013, 2013.

National Research Council (US): Committee on Climate Data Records from NOAA Operational Satellites: Climate Data Records from Environmental Satellites, National Academy Press, 2004.

Oo, M. M., Jerg, M., Hernandez, E., Picón, A., Gross, B. M., Moshary, F., and Ahmed, S. A.: Improved MODIS Aerosol Retrieval Using Modified VIS/SWIR Surface Albedo Ratio Over Urban Scenes, IEEE T. Geosci. Remote, 48, 983-1000, doi:10.1109/TGRS.2009.2028333, 2010.

Petrenko, M., Ichoku, C., and Leptoukh, G.: Multi-sensor Aerosol Products Sampling System (MAPSS), Atmos. Meas. Tech., 5, 913-926, doi:10.5194/amt-5-913-2012, 2012.
Pope III, C. A., Burnett, R. T., Thun, M. J., Calle, E. E., Krewski, D., Ito, K., and Thurston, G. D.: Lung Cancer, Cardiopulmonary Mortality, and Long-term Exposure to Fine Particulate Air Pollution, JAMA, 287, 1132-1141, doi:10-1001/pubs.JAMA-ISSN0098-7484-287-9-joc11435, 2002.

Redemann, J., Zhang, Q., Livingston, J., Russell, P., Shinozuka, Y., Clarke, A., Johnson, R., and Levy, R.: Testing aerosol properties in MODIS Collection 4 and 5 using airborne sunphotometer observations in INTEX-B/MILAGRO, Atmos. Chem. Phys., 9, 8159-8172, doi:10.5194/acp-9-8159-2009, 2009.

Reid, J. S., Benedetti, A., Colarco, P. R., and Hansen, J. A.: International Operational Aerosol Observability Workshop, B. Am. Meteorol. Soc., 92, ES21-ES24, doi:10.1175/2010BAMS3183.1, 2011.

Remer, L. A. and Kaufman, Y. J.: Dynamic aerosol model: Urban/industrial aerosol, J. Geophys. Res., 103, 13859-13871, doi:10.1029/98JD00994, 1998.

Remer, L. A., Kaufman, Y. J., Holben, B. N., Thompson, A. M., and McNamara, D.: Biomass burning aerosol size distribution and modeled optical properties, J. Geophys. Res., 103, 3187931891, doi:10.1029/98JD00271, 1998.

Remer, L. A., Tanre, D., Kaufman, Y. J., Ichoku, C., Mattoo, S., Levy, R., Chu, D. A., Holben, B., Dubovik, O., Smirnov, A., Martins, J. V., Li, R. R., and Ahmad, Z.: Validation of MODIS aerosol retrieval over ocean, Geophys. Res. Lett., 29, MOD3.1MOD3.4, doi:10.1029/2001GL013204, 2002.

Remer, L. A., Kaufman, Y. J., Tanre, D., Mattoo, S., Chu, D. A., Martins, J. V., Li, R. R., Ichoku, C., Levy, R. C., Kleidman, R. G., Eck, T. F., Vermote, E., and Holben, B. N.: The MODIS aerosol algorithm, products, and validation, J. Atmos. Sci., 62, 947-973, doi:10.1175/JAS3385.1, 2005.

Remer, L. A., Kleidman, R. G., Levy, R. C., Kaufman, Y. J., Tanré, D., Mattoo, S., Martins, J. V., Ichoku, C., Koren, I., Yu, H. and Holben, B. N.: Global aerosol climatology from the MODIS satellite sensors, J. Geophys. Res.-Atmos., 113, D14S07, doi:10.1029/2007JD009661, 2008.

Remer, L. A., Mattoo, S., Levy, R. C., Heidinger, A., Pierce, R. B., and Chin, M.: Retrieving aerosol in a cloudy environment: aerosol product availability as a function of spatial resolution, Atmos. Meas. Tech., 5, 1823-1840, doi:10.5194/amt-5-1823-2012, 2012.

Remer, L. A., Mattoo, S., Levy, R. C., and Munchak, L. A.: MODIS $3 \mathrm{~km}$ aerosol product: algorithm and global perspective, Atmos. Meas. Tech., 6, 1829-1844, doi:10.5194/amt-6-1829-2013, 2013.

Salomonson, V. V., Barnes, W. L., Maymon, P. W., Montgomery, H. E., and Ostrow, H.: MODIS: Advanced facility instrument for studies of the Earth as a system, IEEE T. Geosci. Remote, 27, 145-153, 1989.

Sayer, A. M., Hsu, N. C., Bettenhausen, C., Ahmad, Z., Holben, B. N., Smirnov, A., Thomas, G. E., and Zhang, J.: SeaWiFS Ocean Aerosol Retrieval (SOAR): Algorithm, validation, and comparison with other data sets, J. Geophys. Res., 117, D03206, doi:10.1029/2011JD016599, 2012a.

Sayer, A. M., Smirnov, A., Hsu, N. C., Munchak, L. A., and Holben, B. N.: Estimating marine aerosol particle volume and number from Maritime Aerosol Network data, Atmos. Chem. Phys., 12, 8889-8909, doi:10.5194/acp-12-8889-2012, 2012 b. 
Sayer, A. M., Hsu, N. C., Bettenhausen, C., and Jeong, M.-J.: Validation and uncertainty estimates for MODIS Collection 6 "Deep Blue" aerosol data, J. Geophys. Res.-Atmos., 118, 7864-7872, doi:10.1002/jgrd.50600, 2013.

Schaaf, C. B., Liu, J., Gao, F., and Strahler, A. H.: Aqua and Terra MODIS Albedo and Reflectance Anisotropy Products, Land Remote Sensing and Global Environmental Change, 1, 549-561 , doi:10.1007/978-1-4419-6749-7_24, 2011.

Schafer, J. S., Eck, T. F., Holben, B. N., Artaxo, P., and Duarte, A. F.: Characterization of the optical properties of atmospheric aerosols in Amazonia from long-term AERONET monitoring (1993-1995 and 1999-2006), J. Geophys. Res.-Atmos., 113, D04204, doi:10.1029/2007JD009319, 2008.

Shi, Y., Zhang, J., Reid, J. S., Holben, B., Hyer, E. J., and Curtis, C.: An analysis of the collection 5 MODIS over-ocean aerosol optical depth product for its implication in aerosol assimilation, Atmos. Chem. Phys., 11, 557-565, doi:10.5194/acp-11-557-2011, 2011.

Smirnov, A., Holben, B. N., Slutsker, I., Giles, D. M., McClain, C. R., Eck, T. F., Sakerin, S. M., Macke, A., Croot, P., Zibordi, G., Quinn, P. K., Sciare, J., Kinne, S., Harvey, M., Smyth, T. J., Piketh, S., Zielinski, T., Proshutinsky, A., Goes, J. I., Nelson, N. B., Larouche, P., Radionov, V. F., Goloub, P., Krishna Moorthy, K., Matarrese, R., Robertson, E. J., and Jourdin, F.: Maritime Aerosol Network as a component of Aerosol Robotic Network, J. Geophys. Res., 114, D06204, doi:10.1029/2008JD011257, 2009.

Stier, P., Feichter, J., Kinne, S., Kloster, S., Vignati, E., Wilson, J., Ganzeveld, L., Tegen, I., Werner, M., Balkanski, Y., Schulz, M., Boucher, O., Minikin, A., and Petzold, A.: The aerosol-climate model ECHAM5-HAM, Atmos. Chem. Phys., 5, 1125-1156, doi:10.5194/acp-5-1125-2005, 2005.

Sun, J., Xiong, X., Angal, A., Chen, H., Geng, X., and Wu, A.: On-orbit performance of the MODIS reflective solar bands timedependent response versus scan angle algorithm, edited by: Butler, J. J., Xiong, X. J., and Gu, X., Proc. SPIE, 8510, 85100J, doi:10.1117/12.930021, 2012.

Tanre, D., Herman, M., and Kaufman, Y.: Information on aerosol size distribution contained in solar reflected spectral radiances, J. Geophys. Res.-Atmos., 101, 19043-19060, 1996.

Tanre, D., Kaufman, Y. J., Herman, M., and Mattoo, S.: Remote sensing of aerosol properties over oceans using the MODIS/EOS spectral radiances, J. Geophys. Res., 102, 16971-16988, 1997.

Tanre, D., Remer, L. A., Kaufman, Y. J., Mattoo, S., Hobbs, P. V., Livingston, J. M., Russell, P. B., and Smirnov, A.: Retrieval of aerosol optical thickness and size distribution over ocean from the MODIS airborne simulator during TARFOX, J. Geophys. Res., 104, 2261-2278, doi:10.1029/1998JD200077, 1999.

van Donkelaar, A., Martin, R. V., Levy, R. C., da Silva, A. M., Krzyzanowski, M., Chubarova, N. E., Semutnikova, E., and Cohen, A. J.: Satellite-based estimates of ground-level fine particulate matter during extreme events: A case study of the Moscow fires in 2010, Atmos. Environ., 45, 6225-6232, doi:10.1016/j.atmosenv.2011.07.068, 2011.
Vermote, E. F. and Kotchenova, S.: Atmospheric correction for the monitoring of land surfaces, J. Geophys. Res., 113, D23S90, doi:10.1029/2007JD009662, 2008.

Wang, D., Morton, D., Masek, J., Wu, A., Nagol, J., Xiong, X., Levy, R., Vermote, E., and Wolfe, R.: Impact of sensor degradation on the MODIS NDVI time series, Remote Sens. Environ., 119, 55-61, 2012.

Wang, J. and Christopher, S. A.: Intercomparison between satellitederived aerosol optical thickness and $\mathrm{PM}_{2.5}$ mass: Implications for air quality studies, Geophys. Res. Lett., 30, 2095, doi:10.1029/2003GL018174, 2003.

Wen, G., Marshak, A., Levy, R. C., Remer, L. A., Loeb, N. G., Várnai, T., and Cahalan, R. F.: Improvement of MODIS aerosol retrievals near clouds, J. Geophys. Res.-Atmos., 118, 9168-9181, doi:10.1002/jgrd.50617, 2013.

Witte, J. C., Douglass, A. R., da Silva, A., Torres, O., Levy, R., and Duncan, B. N.: NASA A-Train and Terra observations of the 2010 Russian wildfires, Atmos. Chem. Phys., 11, 9287-9301, doi:10.5194/acp-11-9287-2011, 2011.

Wolfe, R. E., Nishihama, M., Fleig, A. J., Kuyper, J. A., Roy, D. P., Storey, J. C., and Patt, F. S.: Achieving sub-pixel geolocation accuracy in support of MODIS land science, Remote Sens. Environ., 83, 31-49, doi:10.1016/S0034-4257(02)00085-8, 2002.

Xiong, X., Sun, J., Wu, A., Chiang, K.-F., Esposito, J., and Barnes, W.: Terra and Aqua MODIS calibration algorithms and uncertainty analysis, Sensors, 5978, 255-264, doi:10.1117/12.627631, 2005.

Xiong, X., Sun, J., Barnes, W., Salomonson, V., Esposito, J., Erives, H., and Guenther, B.: Multiyear on-orbit calibration and performance of Terra MODIS reflective solar bands, IEEE T. Geosci. Remote, 45, 879-889, doi:10.1109/TGRS.2006.890567, 2007.

Young, A. T.: Revised depolarization corrections for atmospheric extinction, Appl. Optics, 19, 3427-3428, doi:10.1364/AO.19.003427, 1980.

Yu, H., Kaufman, Y. J., Chin, M., Feingold, G., Remer, L. A., Anderson, T. L., Balkanski, Y., Bellouin, N., Boucher, O., Christopher, S., DeCola, P., Kahn, R., Koch, D., Loeb, N., Reddy, M. S., Schulz, M., Takemura, T., and Zhou, M.: A review of measurement-based assessments of the aerosol direct radiative effect and forcing, Atmos. Chem. Phys., 6, 613-666, doi:10.5194/acp-6-613-2006, 2006.

Zhang, J. and Reid, J. S.: A decadal regional and global trend analysis of the aerosol optical depth using a data-assimilation grade over-water MODIS and Level 2 MISR aerosol products, Atmos. Chem. Phys., 10, 10949-10963, doi:10.5194/acp-1010949-2010, 2010.

Zhang, J., Reid, J. S., Westphal, D. L., Baker, N. L., and Hyer, E. J.: A system for operational aerosol optical depth data assimilation over global oceans, J. Geophys. Res.-Atmos., 113, D10208, doi:10.1029/2007JD009065, 2008. 